Portland State University

PDXScholar

5-1-1973

\title{
Spatial variations in the intra-urban response to a noise source
}

Wilbur David Conder

Portland State University

Follow this and additional works at: https://pdxscholar.library.pdx.edu/open_access_etds

Part of the Environmental Monitoring Commons, Physical and Environmental Geography Commons, and the Urban Studies and Planning Commons

Let us know how access to this document benefits you.

\section{Recommended Citation}

Conder, Wilbur David, "Spatial variations in the intra-urban response to a noise source" (1973).

Dissertations and Theses. Paper 1755.

https://doi.org/10.15760/etd.1754

This Thesis is brought to you for free and open access. It has been accepted for inclusion in Dissertations and Theses by an authorized administrator of PDXScholar. Please contact us if we can make this document more accessible: pdxscholar@pdx.edu. 
AN ABSTRACT OF THE THESIS OF Wilbur David Conder for Master of Science In Geography presented May 1, 1973.

Title: Spatial Varlations in the Intra-Urban Response to a Noise Source.

APPROVED BY MEMBERS OF THE THESIS COMMITTEE:

D. Richard Lycan, Chai rman

Thomas M. Poulsen

Clarke H. Brooke

Most research on the urban sonic environment has been recent. One finding has been that physical noise exposure indices calibrate poorly with human noise response. The vagaries of human response to noise have given impetus to research to isolate the factors that differentiate human response to noise. The present thesis continues this research. The thesis specifies human noise response to occur on three levels: awareness, annoyance, and complaint. The factors that structure each level of noise response are identifled in the published literature. 
Noise awareness is a function of noise exposure. Noise annoyance is a function of noise exposure to a lesser degree. In addition annoyance is structured by attitudes toward the noise source, special interests in its economic benefits and personal susceptibility to noise irritation. Complaint concerning noise involves the previous factors plus an affluence or sociomeconomic component. The trend as ons moves upward in the noise response hierarchy is for the structuring factors to become specific to individuals rather than location. Hence, noise awareness with respect to a stationary noise source will vary spatially, while complaint will be random in space.

In testing these premises the author has made use of noise exposure indices for Portland International Airport and a social survey of response in the area surrounding the airport. The noise exposure indices were supplied by the consulting firm of Bolt, Beranek, and Newman Inc. and the social survey was conducted and tabulated by the Center for Population Research and Census at Portland State University. Multivariate methods were used for testing the premises concerning the hierarchical relationships between awareness, annoyance, and conplaint. The variables representing awareness, annoyance, and complaint are guantified from the survey data through principle component and factor scores computer programs.

The noise awareness measure is selected for greatest emphasis since it underlies to annoyance and complaint. The noise awareness measure is investigated and eprors in its measurement are estimated through psychometric methods.

Trend surface techniques are used to test the spatiai regularity 
of awareness, annoyance, and complaint. As hypothesized, awareness is regular in space, annoyence less so, and complaint is random.

Through multiple regression analysis noise awareness is tested against socio-economic measures, noise exposure measures, attitudes, and special interest. Noise exposure variables account for the largest part of the variation in noise awareness.

A trend surface analysis is conducted on the values of awareness predicted by a large number of exposure, attitude, and other variables. The process is repeated for the residual values from the multiple regression. Predicted values are systematic in space but the residual values are largely random. The predicted values are mapped and compared with the actual smoothed awareness response surface. The two maps correspond weli. It is concluded that noise exposure corrected for ambient noise levels adequately approximates the noise awareness response surface. 


\title{
SPATIAL VARIATIONS IN THE INTRA-URBAN \\ RESPONSE TO A NOISE SOURCE
}

by

WILBUR DAVID CONDER

A thesis submitted in partial fulfillment of the requirements for the degree of

\author{
MASTER OF SCIENCE \\ in \\ GEOGRAPHY
}

\author{
Portland State University \\ 1973
}


TO THE OFFICE OF GRADUATE STUDIES AND RESEARCH:

The nembers of the Commitice approve the thesis of

Wibur David Conder presented May 1, 1973.

D. Richard Lycan, Chairman

Thomas M. Poulsen

Clarke H. Brooke

APPROVED:

Dale E. Courtney, Head, Department/ of Geography

David Clark, Dean of Graduate Studies and Research 
TAELE OF CONTENTS

PAGE

LIST OF TABLES ...................... . . iv

LIST OF FIGURES ......................... vi

\section{CHAPTER}

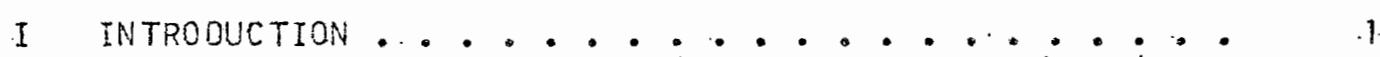

The Scope and Approach of the Study ....... 4

it NOISE MEASUREMENT AND HUMAN PESPONSE . . . . . . . ' 8

Physical Characteristics and Heasurement...... 8

Human Measures of Noise............ 9

Aircraft Specific Moise Measures....... 12

Noise Response is Multi-level.......... 16

The effects of Socio-economic Status, Attitudes, etc.................. 17

II THE STUDY AREA AND THE PIA SURVEY. . . . . . . . . 22

The Area..................... 22

Topography.................. 24

Land Use.................... 24

Socio-economic Texture of the Survey Area. . . . 28

Noise Exposure of the Area.......... 28

Survey Procedures. . . . . . . . . . . 34

Survey Content......................... 34

Survey Results................ 35 
IV MEASURING THE RESPONSE tO NOISE .......... 40

Previous Noise Response Measurement...... 40

Construction of the Noise 4wareness Measure... 45

Errors within the Awareness Measure...... 50

Summary of Chapter ............ 55

$\checkmark$ ANALYSIS OF THE FACTORS THAT STRUCTURE AWARENESS OF

A NOISE SOURCE................. 56

Testing the Response Hierarchy. . . . . . . 56

The Factors that Structure Noise Awareness. . . 57

Summary of Chapter. . . . . . . . . 75

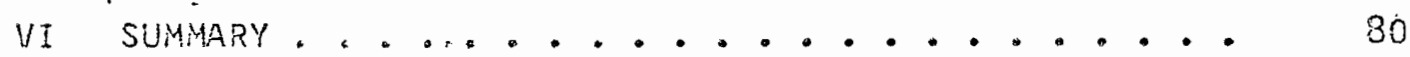

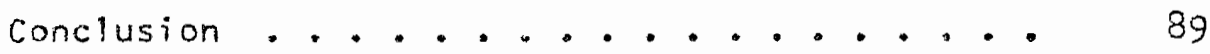

SELECTED BIBLIOGRAPHY . . . . . . . . . . . . . . . . 91

APPENDIX A: The Survey Questionnaire............ 96

APPENDIX 8: Measurement of Error in the Noise Awareness

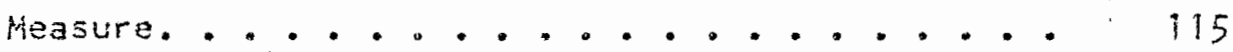

APPENDIX C: Calculation of Traffic Noise Measure....... 120

APPENDIX 0: Maps of Human and Mechanical Noise Response . . 123 


\section{LIST OF TABLES}

TABLE

PAGE

I Comparison of Three Principle Exposure Indices'

Ability to Measure Noise Annoyance. . . . . . . 16

II Population Exposed to Aircraft Noise by Nef

Contour Interval ...................... 32

II Number and Percent of People Reporting Aircraft

Sounds More Noticeable by Various Characteristics.

IV Percent Pesponding which Type of Sound is Most Notice-

able by Geographic sector .............

$\checkmark$ Percent Responding Number of Activities Interrupted by

Aircraft by NeF Value...............

VI Knowledge of Airport Expansion Plans and Interruption of Activities by Aircraft............ 37

VII Quastions Selected for Principle Components Analysis.. 45

VII Rotated Factor Matrix .................. 48

IX Matrix of Paired Comparisons by Susceptibility to

Interruption by Aircraft Noise ........ 54

$x$ Estimating Equation for Trend Surface of Noise

Awareness (Factor I). ................. 59

XI Estimating Equation for Trend Surface of lloise

Complaint (Factor III)................ 
XII Estimating Equation for Trend Surface of Noise Annoyance (Factor IV). . . . . . . . . . .

XII Estimating Equation for Regression of NOise Awareness

Measure with Environmental Attitude Variables

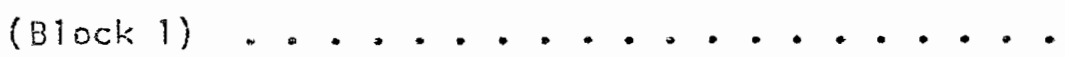

XIV Estimating Equation for Regression of Noise Aware-

ness Measure with Airport Attitude, Special

Interest and Information Source Variables

(Block 2) ..................

KV Estimating Equation for Regression of Moise Awareness

Measure with socio-economic Variables (Block 3). .

XVI Estimating Equation for Regression of Noise Awareness

Measure with Noise Exposure Variables (Block 4). .

XVII Estimating Equation for Regression of Noise Awareness

Maasure Noise Exposure, Attitudinal and Socio-

economic Variables................

XVIII Estimating Equation for Trend Surface of Predicted

Vaives from Multiple Regression of Moise Aware-

ness with Noise Exposure, Attitudinal and Socio-

economic Variables . . . . . . . . . . 76

XIX Estimating Equation for Trend Surface of Residual

Values from Multiple Regression of Noise Awareness

with Noise Exposure, Attitudinal and Socio-econonic

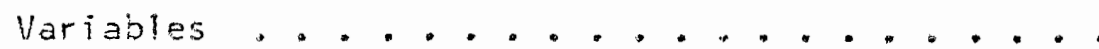




\section{LIST OF FIGURES}

FIGURE

PAGE

I Physical Characteristics of Sound. . . . . . . . 8

2 The Survey Area. . . . . . . . . . . . . . 23

3 Land Use. . . . . . . . . . . . . . 25

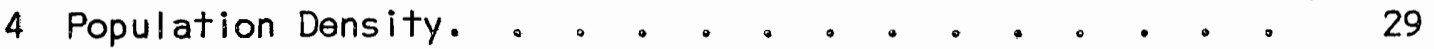

5 Population Change 1960-1970. . . . . . . . . . 30

61970 NEF Contours. • . . . . . . . . . . . . 33

7 Response Curve of Susceptibility of Various Activities to Interruption by Aircraft Noise at Heathrow Airport. . . 43

8 Response Curve of Susceptibility of Various Activities to Interruption by Aircraft Noise at Portland International Airport. • . . . • . . • . • . • • . . 44

9. Aircraft Noise Awareness. . . . . . . . . . . . 58

10 Aircraft Noise Annoyance. . . . . . . . . . . 60

Il Flow Diagram of Variable Analysis. . . . . . . . 64

12 Predicted Values of Noise Awareness. . . . . . . . 78

I3 Salient Features of the Hierarchy of Noise Response. . . 90 
CHAPTER I

INTRODUCTION

The role of noise as a stress factor in an urban system is poorly understood. 1 Research has only begun on the physiological and behavioral effects of exposure to the urban sonic environment.2 This research has concentrated on exposure of individuals to extreme noise environments associated with military, manufacturing and construction activities. Community response to noise, most important from a planning standpoint, has oniy recently been recognized as an important research area. 3 Henning von Gierke has outlined the scope of this research:

The responsibility of science and technology can be summarized as follows: We have to characterize and measure community noise; we have to give scientific data to relate community noise to community reaction; we have to agree on

Here noise is defined as unwanted sound, see: T. Berland, The Fight for Quiet (Englewood Cliffs, New Jersey: Prentice Hali, $1 9 7 0 \longdiv { , 0 . } 3 5 1$. Also this definition is implied in the U. S. Federa) Council for Science and Technology: Committee on Environmental Quality, Noise: Sound without Value (Hashington, D.C.: U.S. Governnent Printing office, 1968$)$, pp. 1-5.

2. M. Stewar?, "Keynote Address," in D. W. Ward and J. E. Friche, eds., Conference on Noise as a Public Health Hazard Washington 0. C.: The American Speech and Hearing Association, 1969), p. 8.

3A. Mckennel, and J. Hunt, Noise Annoyance in Central London (London: Her Majesty's Stationery Office, 1966), $\overline{p p}$. T-129. Also U. S. Panel on Moise Abatement, The Noise Around Us: Findings and Recommendations (Washington, D. E.: U.S. Dept. of Commerce, 1970), p. 1-24. 
uniform measurement and assessment procedures...

Finally we have to evaluate the control possibilities and give alternate plans--desired environments versus costs and goals. 4

Research on communicy response to noise has centered around

three areas. These are:

(1) the measurement and forecasting of noise magnitude

(2) analysis of how a community interprets and judges noise

(3) analysis of behavior induced by continued noise exposure. As is typical for a new field, the research efforts have not been evenly distributed among the three areas.

To the present most research has been directed to the physical measurement of noise, coupled with a continuing series of attompts to calibrate instruments to match humen perceptions of noise as measured in laboratory experiments. 5 Further research has tailored these instruments and indices to specific noise sources. 6 It is unlikely that refinement of this approach will yield results commensurate with effort expended. Leaders in the field have noted that the largest gap in knowledge about noise and man is between laboratory experiments on individuals and actual community response. 7

4. von Gierke, "Opening Remarks," in Ward and Friche, eds., Public Health Hazard, p. 166.

5. Rudimose, "Primer on Methods and Scales of Noise Measurement," in Ward and Friche, eds., Public Health Hazard, pp. 24-26.

6rRACOR Inc., Community Reaction to Airoort Noise, Washington, 0. C.: National Aeronautics and Space Administration, 19/1), pp 5.3-6.3. Also, A. Wilson, Noise: Final Report (London: Her Majesty's stationery office, 1963$)$, p. $1-217$.

7 Uon Gierke, "Opening Remarks," in Ward and Friche, eds., Publis Heal th Hazard, p. 153. 
Attempts to fill this gap have focused research on isolating those variables which cause annoyance and complaint. ${ }^{8}$ While some results show pronise, the work overall is uneven and conclusions are sometimes contradictory. 9 A major drawback in this type of research has been the inability to specify community noise response in terms suitable for formal statistical analysis.

Between measurement of the physical sound and community annoyance lies a major area in community noise research. Always implied but often overlooked is research on the scope of community awareness of noise as distinct from annoyance and complaint. Throughout the paper these three components of community noise response are definad as:

(1) Awareness - Awareness of noise is defined as the ability of an individual to remember the magnitude and frequency of a particular noise and to identify its source.

(2) Annoyance - Noise annoyance is defined as the individual's passive negative reaction to noise in general or to a particular noise.

(3) Complaint - Complaint about noise is defined as the individual's active negative reaction to noise in general or to a particular noise.

Given that physical measurements of noise exposure are accurate, it would seem necessary to determine the factors which structure invidual and community awareness of noise before attempting to determine the causes of annoyance and complaint. Making the relationship

8 Wison, Noise: Final Report, pp. 196-210.

$9_{A}$ good example can be found in regard to the significance of sociomeconomic status in MkKennel and Hunt, Hoise Awareness, p. II., compared with P. Dorsky, "fffects of Noise on Communty Behavior," in biard and Friche, eds., Public Heal th Hazar, p. 191. 
between awareness, annoyance and complaint explicit will greatly facilitate the specification of community noise response. While it is generally true that people actually annoyed by noise are aware of noise, the converse is not true. Many persons are aware but not annoyed. Rather, awareness of noise and subsequent annoyance and complaint depend upon the factors which structure noise ayareness. The question becomes: What are the factors that structure noise awareness? Is noise awareness mainly a function of locational variables such as.exposure and ambient noise leve?? Is it mainly specific to individuals? or is it the result of a complex mix of locational and individual factors? If noise awareness is essentially location specific, then attempts to reduce noise by eliminating or muffling noise sources would result in reduction of noise awareness and subsequent annoyance and complaint. If, on the other hand, noise awareness is specific to individuals, one might question the efficacy of noise level reduction in specific locations.

From the preceding discussion two questions have been raised with respect to noise awareness. Thesa are: (1) What relationship does it bear to annoyance and complaint and (2) what are the factors that structure noise awareness? This paper is directed toward answering the second question, but necessary to answering the second question is some insight regarding the first.

The Scope and Approach of the Study

Selected literature is reviewed in Chapter II with emphasis 
upon noise measurements and human noise response. Particular attention is paid to the formulation of noise exposure indices and their relation to human response. In addition, variables praviously. found to be associated wi th noise awareness, annoyance and complaint are specified. From this information a hierarchical system of noise response is established with noise awareness being the most general and last complicated response.

In order to answer the second question some prelininary. hypotheses are made below concerning. the factors that structure noise awareness:

(1) Noise awareness iș specific to location rather than individuals. Individuals, regardless of atitudes and sociomeconomic status, will be equally aware of the noise present at a given location.

(2) Attributes specific to location such as elevation or climate are regular in space. Attributes peculiar to individuals such as size or clothing preferences are generally less regular in space.

(3) If (1) and (2) hold, then a response pattern structured by location specific factors will be regulariy distributed in space forming a pattern similar to elevation contours. Response patterns structured mainly by individual preferences will tend more to be random with high and low values in close proximity.

A two-fold strategy is adopted for tesking these assumptions. The strategy makes use of a survey of community response to aircraft noise conducted in conjunction with the Port of Portland's environmental impact statement on the proposed expansion of portland International Airport (hereafter abbreviated as PIA). The first part of the strategy involves neasuring the spatial regularity of the of the noise avareness measure. This is accomplished by the use of 
"trend surface analysis."10 The measures of annoyance and complaint are aiso tested in this manner. These procedures are covered in the first section of Chapter $V$.

The second fhase of the strategy involves the determination of the factors that structure noise ariareness. These factors are taken from questions asked in the survey and published transportation and census data. They are then divided into blocks and correlated with noise awareness through the use of multiple regression. 11 The importance of the individual ractors is compared with previous findings of other researchers. They are also considered in terms of thether they are individual or location specific. Significant factors are included in a final analysis. The results of this final analysis are related to the hypotheses and their implications are discussed. These items are covered in the second section of chapter V.

Provided as background to the two questions is an extended analysis of the survey area, the efficacy of noise response measurements in general, and the method selected for measuring noise response in this study in particular.

$10_{A}$ comprehensive review of the utility of trend surface techniques in geographic research can be found in $R$. $J$. Chorley and $P$. Haggett, "Trend Surface Mapping in Geographica! Research," Transactions and Papers of the institute of British Geographers, No. 37 , $7(1965), 9 p \cdot 47.67$.

1 The specific forms of multivariate analysis used are principle components and multiple regression analysis. Applications of these techniques to geographic problems are discussed in I. J. King, Statistical Analysis in Geography (Englewood Cliff, New Jersey: Prentice-riali, 1969), pp. 152-153 and pp. 166-184. 
The methods of delimiting the survey area are discussed as are sampling and survey procedures. Land use trends and broad patterns of socio-economic variation are examined in the survey area and their implications to noise response stated. Moreover, the results of the PIA survey are presented in a series of tables. These results preview to some degree the findings of later analysis. These data are contained in the various sections of Chapter III.

The accuracy of relating noise response to an ordinal scale is discussed with examples from several previous.studies. Dissenting. opinions are offered as well and these are demonstrated to be reconchlable to an ordinal scale approach.

Extraction of noise awareness from annoyance and complaint as a spatial response trend is analyzed in detail and the method of extraction is presented.12 Errors within the awareness measure are defined as inconsistencies in the resulting ordinal scale. The magnitude of these errors is estimated and the effect on the study results is evaluated. All questions concerning noise response measures are detailed in Chapter IV.

Finaliy, in Chapter $Y I$ the results of each chapter are reviewed. Also presented, is the relationship between noise awareness, noise annoyance and noise complaint suggested by the analysis.

12Ibid, pp. 166-184. 
Physical Characteristics and Measurement

Sound has measureable physical characteristics. It is transmitted as a compressional wave, thus requiring a physical medium for transmission. The two characteristics of sound pertinent to the paper are amplitude and frequency. Figure 1 shows their features.

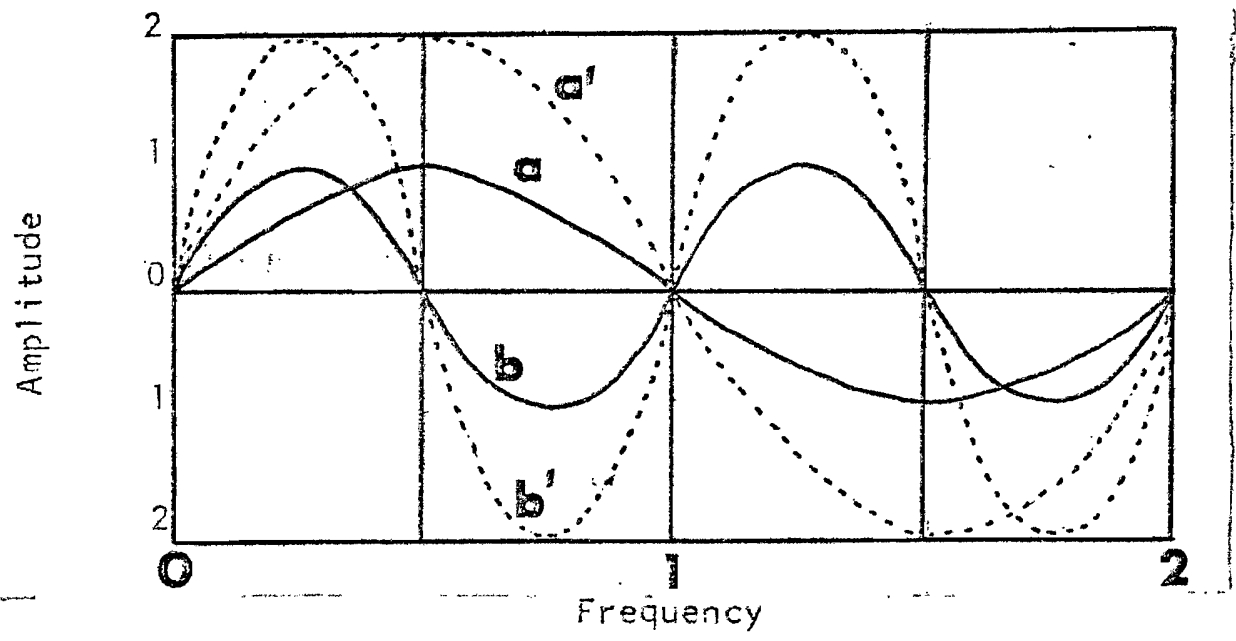

Figure 1. Physical characterics of sound.

Lines $a$ and $b$ in the diagram represent two sound waves having a frequency of 1 and 2 respectively. It can be observed that line $b$ makes two cycles every time line a makes one. Lines $a^{\prime}$ and $b^{\prime}$ represent the same frequencies but in this instance the amplitude has been doubled. Frequency is relativa to the length of the line while amplitude refers to the height.

From Figure 1 it can be observed that amplitude and frequency are independent of one another. 
Based on the range of human hearing the frequency spectrum is broken into three bands. These are infrasonic lless than 20 cycles per second), sonic $(20-30,000$ cycles per second), and ultrasonic (greater than 30,000 cycles per second). 1 The sonic band is the one within the human hearing range. The sonic band is further broken down into octaves and fractions of octaves. An octave is defined as a division of the sound frequency spectrum wherein higher divisions are multiples of 10 wer divisions. For instance, 600.1200 c.p.s., 1200-2400 c.p.s., and $2400-4800$ c.p.s. are octave bands.

Amplitude is measured on the basis of Sound Pressure Levels. In other words amplitude will be a function of the amount of energy contained in a sound wave as measured by the amount of comprassion and rarefaction imparted to the transmitting medium. The common unit for measuring sound pressure levels is the decibel. The base for the decibel is .00002 dynes per square centimeter. This value equals one decibel. ${ }^{2}$ The amplitude range for sound is from .00001 to 100,000 dynes per square centimeter. This large range necessitates the use of a logarithmic scale. This scale is called the decibel scale with each increment of ten units being ten times greater than the preceding increment. A sound measured atfifty decibels would have ten times greater amplitude than if measured at for ty decibels.

Human Measures of Hoise

Rudimose, "Primer on Methods and Scales of Noise Measurement," in ward and Friche, eds., Public Health Hazard, p. 22.

2 Ibid. 
Roughly equivalent to the physical measurements of sound are the attributes humans ascribe to sound; namely pitch and loudness. Pitch is analogous to frequency with sounds of low frequency being regarded as "low" and sounds of high frequency being called "high". The relationship is not direct. Sounds which are doubled in frequency are not judged as having twice the pitch. Loudness is equivalent to amplitude in much the same manner that pitch is like frequency with low amplitude sounds regarded as quiet and high ampli"tude sounds regarded as "loud," "noise," etc. Again the relationship is not direct and herein lies the crux of most noise research in the past: Are there systematic differences between frequency and pitch and amplitude and loudness? Are pitch and loudness independent like frequency and amplitude? If these quastions can be answered, is it possible to design instruments to account for the difference between physical measurement and human perception?

Laboratory experiments between judgments of loudness have revealed that sounds between $125-5000$ c.p.s. are judged louder than at lower or higher frequencies. Consequently, pitch and loudness are not totally independent. In addition human judgments of loudness and actual amplitude have been calibrated under laboratory conditions. 3 The results have been a number of measures and instruments wich attempt to account for the differences between human perceptions and physical measurement. Among the first was the dBA scale,

$301 t$, Beranek, and Newman, Inc., The Logan Airport Envitonmental Impact Study (Boscon: Bolt, Beranek and Newnan, 1971), P. 
a modification of the decibel scale. 4 This scale is calibrated on a meter so that it discriminates and weights sounds falling between 400 and 10,000 c.p.s. in frequency. Later modifications have produced the $d B C$ scale which is sensitive to sound from 125-10,000 c.p.s. Another development along the same lines has been octave analyzers which focus on a specific segment of the frequency spectrum. These have been refined to the point where measurement on a one-third octave basis is comon. Rudimose notes that a basic short. coming of this approach is that as the frequency measurement becomes more selective, the output decreases and less of the total sound energy is measured. Also despite increasing sophistication of the neasuring instruments, the effectiveness of the devices in neasuring sounds of short duration (less than .2 sec.) is poor. 5

Another : outcome of the attempts to equate human response to sound levels has been the development of scales other than the commonly used "D" scales. Two of these are "sones scale" and the "Speech Interference Level." In the sones scale wint measures loudness, one sone is equal to $1000 \mathrm{cop} . \mathrm{s}$. at $40 \mathrm{~dB}$. The result is that the scale of amplitude is weighted for human judgments of loudness. The Speech interference Level is developed by weighting the dB levels in the 600-1200, 1200-2400, and $2400-4800$ c.p.s. Dctave bands. 6 Both correlate well with subjective rating of loudness in laboratory

4Rudimose, "Mriner on Hethods and Scales of Noise Measurement," in Ward and Friche, eds., Public Health Hazard, P. 24.

S.Ibid., p. 26.

6 ibid. 
experiments. 7 Further sophistication along the same lines has resulted in the PNdB and EPNdB scales. The Perceived Noise Level (PNdB) is similar to the sone scale but designed primarily for aircraft noise. The Effective Perceived Noise Level (EPNdB) is a modiFication of the PNdB to allow for subjective variations in human judgment of noise induced by pure tone components of sound and duration of exposure. Generally noisiness increases with amount of pure tone and duration.

\section{Aircraft Specific Noise iheasures}

Pecently the evolution of noise measurement instrumentation has seen the development of a class of noise exposure indices. While indices have also been developed for noise sources other than aircraft, the discussion will consider only aircraft noise indices consistent with the focus of the study. These noise indices attempt to compensate for duration, frequency and time of day of occurence as well as the factors covered by measures such as sones and PNL. The first of these is the Composite Noise Rating (CNR). The CNR method uses the highest values of the Perceived Noise Level at the point of observation or measurement. Computation is done through the following formula: 9

$$
\text { (1) } C N R_{i p}=P N L_{i p}+\log _{10}\left(\mathrm{~L}_{d i p}+20 N_{n i p}\right)-12
$$

7. Cohn, "effects of Nojse on Psychological State," in Ward and Friche, eds., Public Health Hazard, p. 76.

Bolt, Beranek, and Newman, Inc., Logan Airport Study, p. II -B and $P$. III $-3 i$.

$$
9 \text { Did, P. III-34. }
$$


Where PNL ip is the Perceived Noise Level at point p for time i. Mdip is the number of day occurences at point por time $i$, and $\mathrm{N}_{\mathrm{Nip}}$ is the number of night occurences at point $p$ for time $i$. The total CNR for a one day period is arrived at by:

$$
\text { (2) } C N R_{t p}=10 \log _{10} \sum_{i=1}^{N} \operatorname{Anti} \log \left(C N R_{i p} / 10\right)
$$

Where CNRtp is the total Composite Noise Rating at point $p$, and $N$ is the number of time periods in the day.

An alternate method is the Noise and Number Index (NMI). It is conceptualiy identical to CNR. It has an advantage in that computationally it is simpler. NMI is defined as follows: 10

$$
\text { (3) } \text { NNI }=\text { PNL }+15 \log _{10} N-80
$$

Where PNL is the average Parceived Noise Level for maximum flyover noise levels for period $i$, and $N$ is the number of flyovers in period i. An adjustment for night operations yields:

$$
\text { (4) NNI }=10 \log _{10}\left(\text { Antilog } N N I_{d}\right) / 10 \mp(\text { AntilogNNIn }+17) / 10
$$

Where NNI $n$ is the NNI for night operations and NNI $I_{j}$ is the NNI for day operations. Values of NNI need only be calculated for day operations, night operations and total operations theraby avoiding lengthy summations.

Noise Exposure Forecasts (NEF) are the latest, most elegant and most computabionally dirficult. They represent an attempt to include al the elements of previous noise measures with the aridition of tone, 10 rbid. 
duration, aircraft type and trajectory. NEF values are computed thusly: 11

$$
\text { (5) } N E F_{i j p}=E P N L_{i j p}+\operatorname{lolog}_{10} \mathrm{~N}_{d i p}+\left(50 / 3 \mathrm{~N}_{n i j p}\right)-88
$$

Where NEF $i j p$ is the NEF value at point p for aircraft type $i$ on trajectory $j$. EPNL $i j p$ is the Effective Perceived Noise Level for aircraft $i$ on trajectory $j$ at point $p$. Nd is the number of day occurences and $M_{n}$ is the number of night occurences.

Total NEF at point $\rho$ is computed by:

$$
\text { (b) } N E F_{p}=10 \log _{10} \sum_{k=1}^{N} \text { Antilog(NEFijp/10) }
$$

Where $M$ is the product of the types of aircraft times the different trajectories $(M=i \times j)$.

NEF's are calculated for a large number of points and a contour map is produced therefrom. An example of this process can be seen in Figure 6. For planning purposes this method has the advantage of being able to consider the effects of aircraft and trajectory alterations. Predicted NEF values for Future airport operations can be computed as well. The F.A.A. considers the NEF contours suitabie "solely for plaming purposes with respect to future land uses." 12 The Logan Airport Study concludes that NEF contours "could be helpful in planning new airports but that they would not be concise enough to plan for an already existing community located close to a major

$$
\begin{aligned}
& 11 \text { Ibid., p. III-37. } \\
& 12 \text { rbid., P. III-37 }
\end{aligned}
$$


existing airport." 13 The study noted that NEF values in spite of their sophistication fail to measure such important physical factors as different turning radii and climb rates for various aircraft, diverging flight paths beyond three miles, atmospheric conditions, terrain and elevation. 14

Closer examination of the three exposure measures, CNR, NNI and NEF reveals them to be essentially comparable. Each represents an attempt to measure factors not previously considered but the essentials remain unchanged. These essentials are a core of perceived noise which is weighted in an "ad hoc" fashion for day and night occurences. Each succeeding method moves further away from data based on human perceptions until the NEF contours with aircraft and trajectory ratings lean towards an infatuation with numerical elegance. A TRACOR Inc. study based on a survey of 3,590 people in seven cities (Boston, Chicago, Dalles, Denver, Los Angeles, Miami, and New York) has found the three measures to be interchangeable. The TRACORInc. report states:

Simple weighted sound pressure level values ( $A B A$ and $d B N$ ) provide adequate approximation to more complex measures for the purpose of determining community noise exposure. 15

As measures of aircraft noise exposure in communities, the Composite Noise Rating (CNR), Noise and Number Index (NNI), and Noise Exposure Forecast (NEF) are practically interchangeable although CNR is slightly superior for predicting annoyance. 16

$$
\begin{aligned}
& 13 \text { Ibid., P. III-38. } \\
& 14 \text { Ibid., P. III-41. } \\
& 15 \text { TRACOR Inc., Reaction to Airport Noise, Is P. } 5.1 . \\
& 16_{\text {Ibid., }} \text {. } 5.3 .5 \text { and p. } 6.2 \text {. }
\end{aligned}
$$


Important to the entire concept of noise exposure measurement is the TRACOR Inc. finding that all three indices correlated poorly with noise annoyance scores calculated from the survey data. 17 The following table is taken from that study.

\section{TABLE I}

COMPARISON OF THREE PRINCIPLE EXPOSURE INDICES' ABILITY TO MEASURE NOISE ANNOYANCE

\begin{tabular}{|c|c|c|c|}
\hline $\begin{array}{c}\text { Annoyance } \\
\text { Measure }\end{array}$ & \multicolumn{3}{|c|}{ Exposure Measure Correlation } \\
\hline G & CNR & NNI & NEF \\
\hline V & 0.37 & 0.34 & 0.32 \\
& 0.33 & 0.31 & 0.30 \\
\hline
\end{tabular}

Notes: G: Measure based on interference with nine different activities.

V: Measure based on annoyance factors "G" plus three others.

Sources: Bolt, Beranek and Newman Inc., Logan Airport Environmental Impact Study (Boston: Bolt, Beranek and Newman,

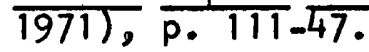

The elegance of the exposure measures notwi thstanding, the fact that the indices correlate poorly with annoyance demonstrates that factors other than simple exposure to noise are operating. These factors are considered in the next section.

Noise Response Is Multi-ievel.

The degree of human response to noise can occur on three levels:

17 Bolt, Beranek and Newman Inc., Logan Airport Study, P. I I I-46. 
awareness, annoyance, and complaint. Here noise awareness, annoyance, and complaint are defined as in Chapter $I$. On an intuitive basis it might be assumed the levels are hierarchical. Awareness is the foundation for annoyance, and awareness and annoyance are the foundations for complaint. The three levels and their inter-relationships are seldom stated explicitly. Generally response to noise is equated with annoyance though oftentimes it is difficult to determine if awareness and complaint are also being measured. 18 The following discussion focuses on the results of research that has been conducted on these three response levels.

The Effects of Socio-Economic Status, Attitudes, etc.

The TRACOR Inc. study incorporated socio-economic and attitudinal variables along with a noise exposure indicator into an explanation of response to aircraft noise. Correlations improved to . 79 in predicting annoyance with CNR plus two geographical and five psychological variables. 19 The correlation between CNR and complaint was improved to .52 with the inclusion of sixteen other variables. 20 TRACOR notes that the predictors of annoyance are primarily physical/ attitudinal while the predictors of complaint are primarily physical/ sociological. 21 These results suggest that factors other than exposure are important in structuring annoyance and complaint. However,

${ }^{18}$ An example of this can be found in wilson, Noise: Final. Report, pp. 74-75.

19 TRACOR Inc., Reaction to Airport Noise, I, pp. 6.4-6.6. 20 Ibid.

21 TRACOR Inc., Reaction to Airport Noise, I, p. 6.8. 
it is unclear whether the variables included were causes or symptoms. Ambiguity as to causality often leads to situations where the explanation is misleading such as observing that a cause of a cold is coughing and sniffling.

McKennel and Hunt in studying noise response in central London divide the noise response into the three levels of awareness, annoyance and complaint. Correlations were taken between noise exposure, social class, occupation, noise awareness, noise annoyance and noise complaint. Noise exposure, ubiquitous and stenning from muttiple sources, was found not to correlate significantly with any of the remaining variables. 22 The correlation of noise awareness was also insigificant with respect to social class and occupetion. 23 however, social class and occupation were found to be weakly correlated with annoyance and complaint. Mckennel and Hunt conclude that the people at the "top end of the social scale are more likely to be bothered by the noises they hear than are people at the lower end." 24

The Mckennel and Hunt study explains the bulk of noise annoyance and complaint through a device called a noise susceptibility rating. This was constructed by obtaining people's attitudes toward noises such as chaik screeching on a black board. They found the susceptibility rating agreed well with annoyance and complaint scores, poorly with physical noise environtent, age and social class. Surprisingly susceptibility was poorly correlated with noise awareness. 25

22Mckennel and Hunt, Moise Annoyance, P. II.

23 ibid.

24 Ibid.

25 rbid. 


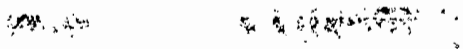

These results strongly suggest that variables specific to individuals influence annoyance but not awareness of naise.

In addition to the results of the central London study Paul Borsky presents a list of factors derived from research in the U.S. which structure individual noise annoyance. These factors are:

(1) Feelings about the necessity and preventability of noise. (If noise source is identified as benign and attempting to al leviate noise, reaction is not strong to high noise levels.)

(2) Economic benefits connected to noise source.

(3) Types of 1 iving activities effected. (Interference with sleep, rest and relaxation produces greater annoyance.)

(4) The extent to which the neighborhood is generally disliked.

(5) Ideas of effect on general health

(6) General noise sensitivity--more noise sensitive people are less tolerant.

(7) The extent to which fear is associated with noise. (Here annoyance increases instead of decreases with time. $)^{26}$

Borsky notes that such factors as age, sex, family composition, length of residence, etc. have little effect on aircraft noise annoyance. 27 This is somewhat at odds with McKennel and Hunt's findings but cultural differences make comparison difficult.

The Wilson Report and the TRACOR study make explicit statements about complainants as distinct from those people who are only

26 Borsky, "Community Behavior," in Ward and Friche, eds., Public Health Hazard, p. 190.

27 Ibid., P. 191. 
annoyed. They view complainants somewhat differently. The Wilson Report based on a survey within a ten mile radius of Heathrow Airport, London, England concludes that:

Complainants are fairly well representative of the people who are highly annoyed with aircraft noises, who, like the complainants, are found in all the levels of aircraft noise exposure. The main difference between the complainants and those who are equally annoyed but have not complained is that the complainants tend to come from those sections of the communjty who are likely to be more articulate than the average. 28

The TRACTOR Inc. report reaches conclusions partially at variance wi th those of the Wilson Report. It states:

On the average, complainants, in comparison to members of the random samples, tend to live nearer the airport, have higher noise exposure, and to be older, more highly educated, and more affluent...29

Both reports agree on the importance of socio-economic factors such as affluence in structuring noise complaint but disagree on the role of noise exposure.

In summary of the section it can be observed that research is fragmentary, uneven and sometimes conflicting on the three levels of human noise response. Noise awareness is only dealt with specifically in the central London study. Noise annoyance is given good coverage. Here attitudes, special interest and exposure seem to be the major factors that structure the noise response. Socio-economic variables appear to be either weak or insignificant. The factors that structure 28 Wilson, Noise: Final Report, p. 74.
29 TRACOR Inc., Reaction to Airport Noise, I, P. 4. 
complaint appear to be those which structure annoyance plus affluence or socio-economic status."

From the discussion it is possible to specify noise response in more meaningful terms. A tentativa ordaring of the levels of noise response and the factors which structure each is:

(1) Noise awareness exposure

(2) Noise annoyance exposure attitudes and susceptibility special interest

(3) Noise complaint exposure attitudes and susceptibility special interest affluence, sociomeconomic status

A hierarchical response structure based on a set of additive factors is intuitively appealing. However, it is based on uneven and sometimes contradictory research. Necessary to more definitive research is the development of methods to measure and evaluate the levels of noise response independent of one another. 


\section{CHAPTEP III}

THE STUDY AREA AND THE PIA SURVEY

In February 1972 a survey was conducted by the Portiand state University Urban Studies Center in connection with the Port of Portland's proposed airport expansion environmental impact statement. This survey contained questions on individual response to noise, neighbor hood attitudes, age, income, etc. Results of this survey were used by the Port of portland in conjunction with a set of NEF contours developed by Bolt, Beranek and Newman Inc. The survey along with the NEF contours provides the data base for this papar.

The Area

The survey area (cielimited in Figure 2) was chosen from the criteria of including all people who would have a likel ihood of being exposed to aircraft noise. Operationally, this consisted of includ. ing ail the area within the 1970 thirty NEF contour. In addition this area wias extended one mile beyond the thirty Nef contour and three miles beyond the center of the airfort. The population enconpassed by this boundary was $134,0000^{2}$

10. Bishop and $M$. Simpson, Noise Exposure Forecast Contours for 1967,1970 , and 1975 Operations at Selected Airoorts (Van $14 y$, Caifm forni: Bolt, 3eranek and Newman, Inc, ig70), pp. 200-207.

${ }^{2} j_{*}$ E. Haiss, et 31 . "Sociology Section," in Socio-Economic

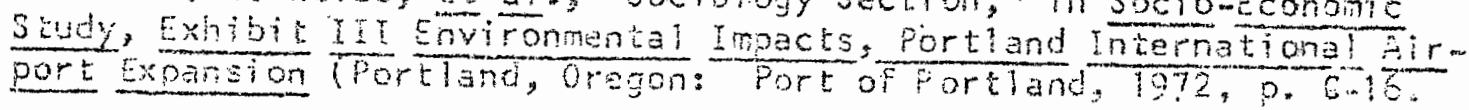




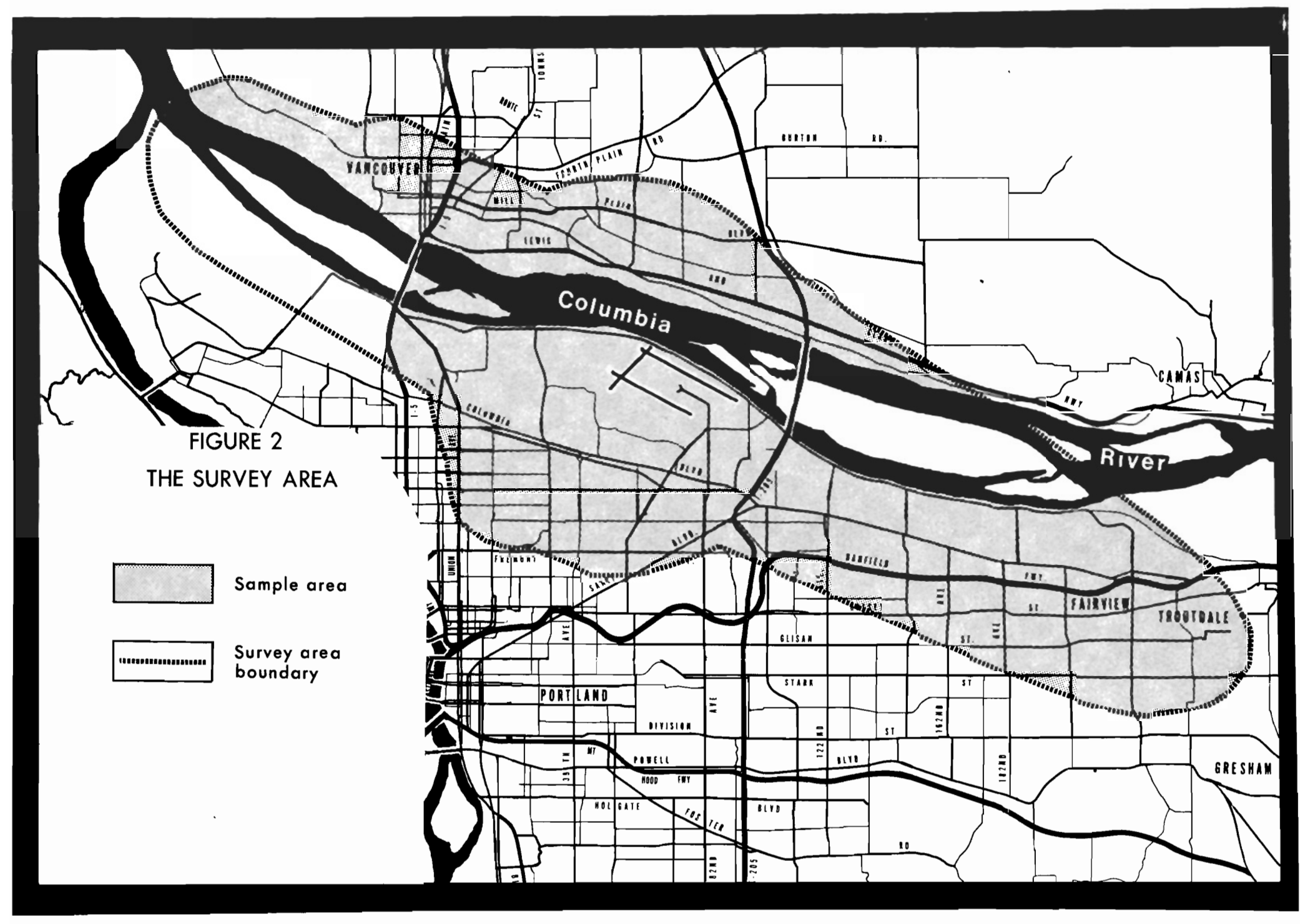


Topograpiy

The salient landscape feature of the survey area is the Columbia River and its accompanying floodplain. This feature dissects the area from east to west. The Columbia River forms a state boundary with Washington lying to the north and oregon to the south. The floodplain is located on the oregon side. It is from one to two miles in width and is protected from spring floods by a system of levees maintained by the Corps of Engineers. The Washington side of the river comprising Vancouver, Wastington and its environs rises steeply from the Columbia to a rolling plain ranging in elevation from one hundred to two hundred feet. Only the western sector of the Washington side of the survey area has a floodplain and here it is but one-half mile wide. On the oregon side the rise in elevation beyond the floodplain is slight to moderate. Only in the far eastern sections beyond Fairview are there steep slopes comparable to those on the Washington side.

Land Use

Land uses within the survey area (as depicted in figure 3) are gererally keyed by (1) the presence of the Columbia River and its fioodplain, (2) distance from the city center and (3) accessibility. The first factor ralates to the general trand in land use. The second to the age of the land use and the third to the rate of change in land LS:

Due to frequent Flooding and poor drainage the Columbia River floodplain has been regarded in the past as suited chiefly to agricul turat uses. Exceptions occur in the form of scattered dwellings and 


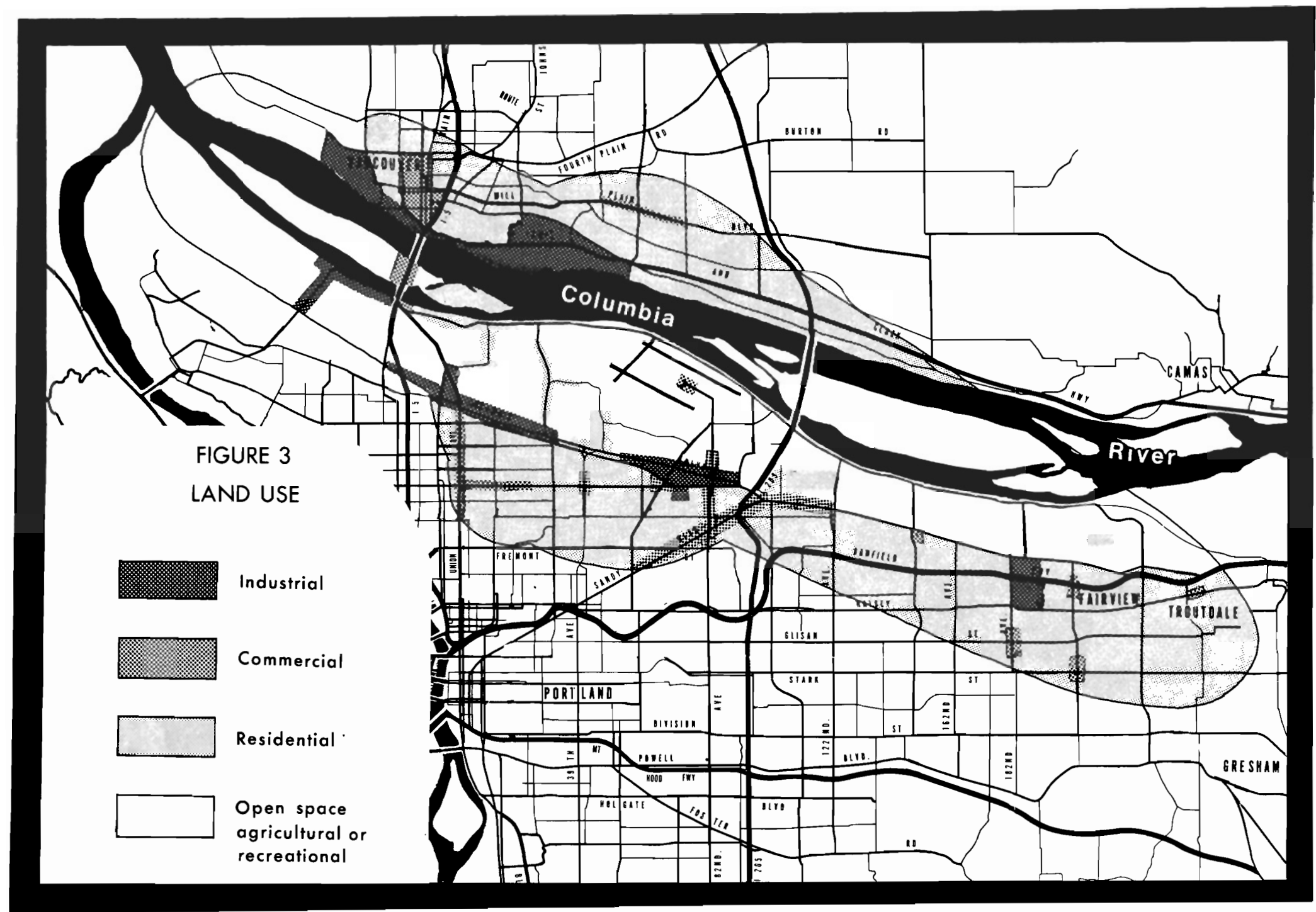


industries. In the past thirty years large amounts of open land with propinquity to the urban area have served as attractions to an increasing number of industries, chief of which has been the Portland International Airport. Nevertheless, the area lying within the floodplain is predominantly agricultural and open land.

On the margins of the floodplain, fronting Columbia Blvd. on both sides there has developed a ribbon of industrial sites which extend from 8 2nd Ave, on the east to beyond U.S. I-5 on the west. This industrial ribbon is characterized by light, land consuming industries such as engineering and construction equipment sales, and warehousing. In its western extent the ribbon grades into meat packing and canning. industries. The eastern sections of the floodplain have seen the development of industrial parks where a variety of activities from electronics to warehousing are pursued. The floodplain on the Washington side is occupied primarily by the dock and storage facilities of the fort of Vancouver as well as a small airport. Beyond the industrial ribbon the use effacts induced by the Columbia River floodplain vanish and development conforms to the genera: urban trend. Land use is primarily residential with commercial ribbons developed along arterial streets that radiate out from the Portland and Vancouver central business districts. The predominant aspect of land use in this area is age. These areas have developed in accordance with overall urban grouth trends and display the characteristics of residential and commercial areas of similar age throughout the urban area.

The older sections occur in the western and central protions 
of the survey area. The section in portland between I-5 and 42 nd Ave. was annexed to the city previous to 1900.3 . In this area only ten platted subdivisions were recorded after 1950. Total housing units constructed between 1950 and 1963 numbered between 1200-1500.4 All tracts in this area were considered at least 85 percent developed by 1964. A comparable area exists around the Vancouver C 30 but is quite small due to the limited development in Clark County umiti recent times.

In the areas east of 42 nd Ave. in Portland and east of I-5 in Vancouver accessibility and change become the salient land use processes. Land use in these areas is quite young and still in the stage of development. The process becomes more pronouncad as one procaeds eastward. The key to this low density residential development has besen gains in accessibility fostered by the building of freeweys and growth of job opportunities on the urban periphery. In the survey area on the oregon side from 42 nd Ave, to Wood Village between 8500 10,000 housing units were built between 1950-1963.5 Beyond 102nd Ave. most of these occurred in platted subdivisions. 6 Growth east of I-5 in Clark County was comparable in nature to that in East. Hultnomah County thougin the eastivard extent was less due to the accessibjlity limits imposed by the location of the Interstate Bridge across the columbia River.

Portland 6ity Planing Comission, Historic Annexation Map: Poretand oregon, (Portiand, Ore.: Cily planning Comaision, logt).

4 Gureau of hinicipal Research and Service, puMTs interin peport

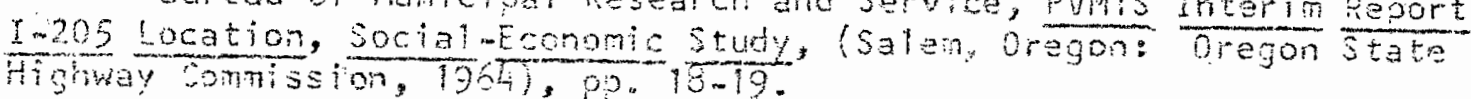
$\frac{5 i d}{6+b i d}$ 
Socio-Economic Texture of the Survey Area.

The effects of the three factors influencing "land use in the survey area can be seen reflected on the population density and population change maps (Figures 4 and 5). The Columbia pivar floodplain has a sparse, stable population. The older areas of Portland and Vancouver have high densities and sightly declining numbers. The fast growing areas in the eastern sectors of the study area have low density and rapid increases in population. 7 A set of socio-economic correlates is also associated with this west to east decline in tha age of the housing stock. ${ }^{8}$ These are from west to east: (1) decreasing age, (2) more children, (3) increasing income and (4) decreasing ethinic differentiation. If a socio-economic dimension is a factor in structuring human response to noise, then the response should vary in space as a reflection of the socio-economic variaEion within the study area.

Noise Exposure of the Area

Topograpiny of the study area as explained earlier is dominated by a river and associated floodplain with a gradual slope upward to tigher elevations. The exception is the abrupt rise from the columia

7Data for the Portland-Vancouver SiSA were obtained from Metropolitan Planning Commission, Population and Housing (Portlant, Ore.: Metro. Planning Commission, 1965) and Columoia Region Association of Governments, 1970 Census: Population and Housing (Portland,

BThis aspect of urban research is discussed at length in $8.4 . L$. Berry, and F. E. Horton. Geographic perspectives on Urban systens, (Englewood Cliffs, New Jersey; Prentice Hall inc., 1970 ) Ch. 10, p.
$306-394$. 


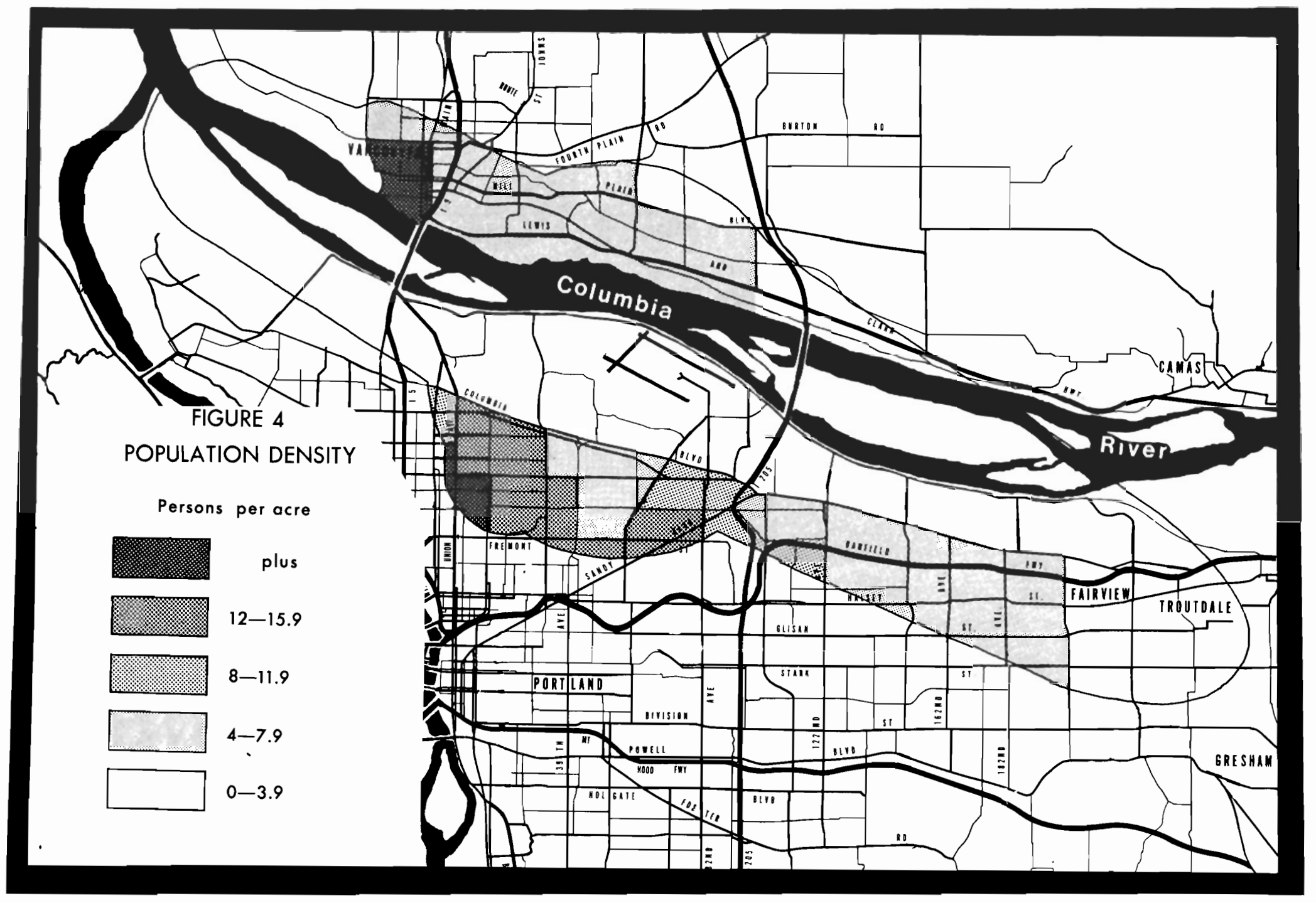




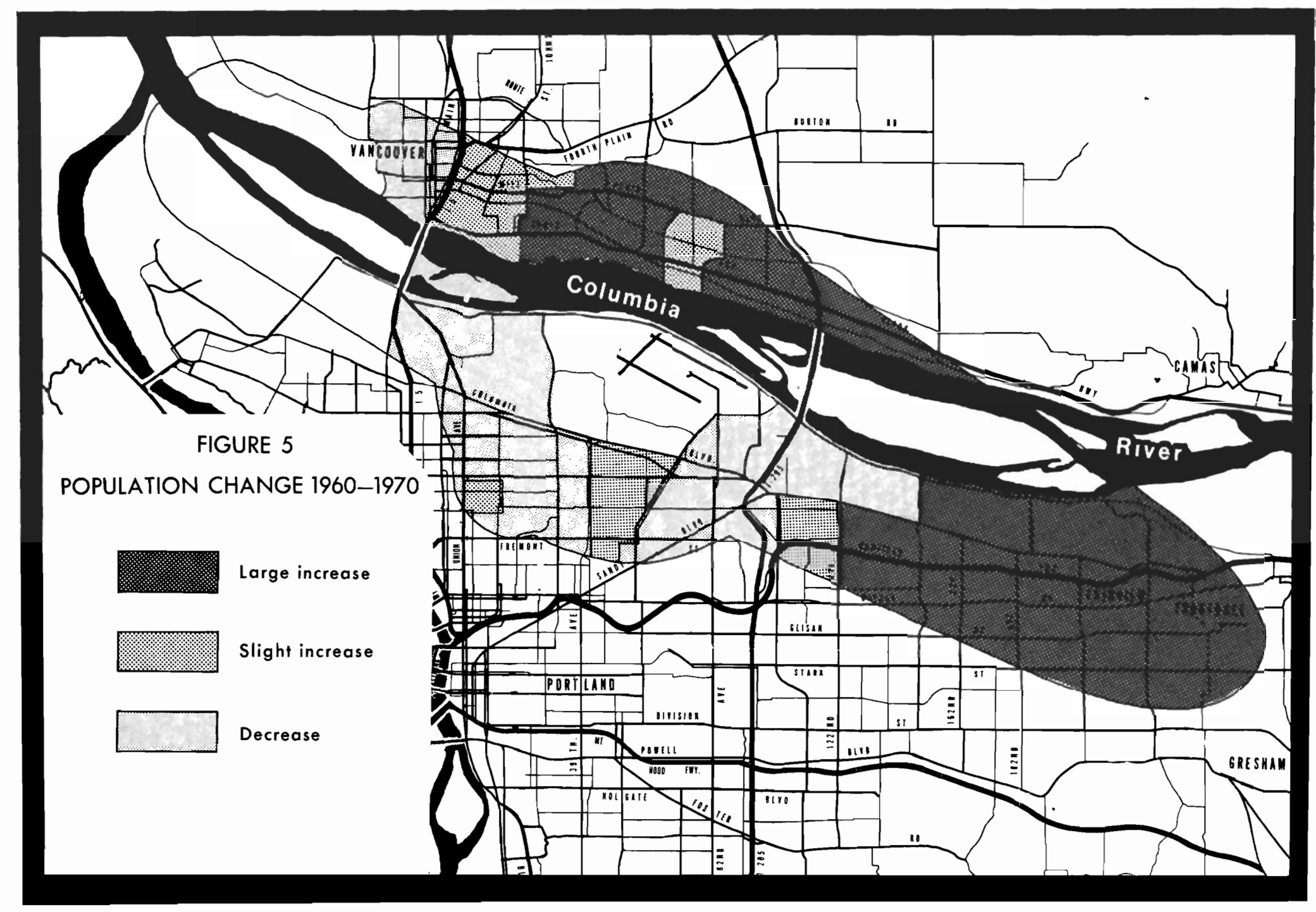


on the Washington side. For saveral miles along this rise an excellent panorama is offered and the airport on the oregon side is visible. Other things equal there is some question as to whether this area is more exposed to noise than is indicated by the NEF contours. As noted previously NEF methodology does not allow for terrain and elevation variations. This omission is justified by the argument that aircraft associated noise is propagated inearly downward and is not susceptible to attenuation by terrain variations, unlike surface noise sources such as automobiles. 9 However, the rise area unlike other exposed areas has direct line-of-sight to the airport; therby exposing it to ground associated noises as well as aircraft associated noises. This unique situation could result in greater than anticipated noise exposure.

Competing noise from automobiles and human habitation 3 lso is a component in the sonjc environment of the survey area. A general assumption is that the more predominant other noise scurces become the less one is able to distinguish a particular noise source. 10 Oue to the distribution of population density and the layout of the Eransportation system, ambient noise levels are peculiar to places. Hence, it follows that the effects of this factor will be spatial. The distribution of housing types by age and style roughly follows the pattern of building cycles. One might expect that the

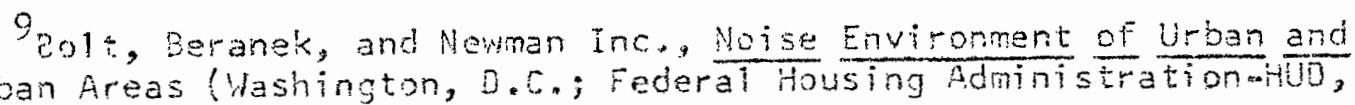
Suburban Areas (Washington, D.C.; Federal Housing Adninis tration ardo,
Gb) Appendix III,

ioj. Begman, The Hechaniss of Forecasking the Commutty Woise Imnect of a Transportation System, (Santa honica, Calif.: Rand Corp., 1971, p. 
ability of a dwelling to attenutate noise would be distributed accordingly. However, noise exposure as a function of building constructfon can be debated. Both the Wilson and TRACOR reports indicate that noises tend to be heard according to their outdoor magnitude, regardless of their measured indoor magnitude. 11 This would negate the effects of housing type as a factor modifying noise exposure. Finally and presumably most important is the place of residence with respect to noise source. Figure 6 shows the study area with the 1970 NEF contours imposed upon it. Table II lists the amount of population exposed in each contour interval.

TABLE II

POPULATION EXPOSED TO AIRCRAFT NOISE BY NEF COUNTOUR INTERVAL

\begin{tabular}{lrr}
\hline Contour Interval & Population Exposed & Percent of Total \\
\hline Greater than 35 & 800 & 0.6 \\
$35-30$ & 3,600 & 2.7 \\
Less than 30 & 129,600 & 96.7 \\
\hline
\end{tabular}

Source: R. Lycan, et al., "Land Use Section," Socio-Economic Study, Exhibit III, Environmental Impacts, Portland International Airport Expansion (Portland, Oregon: Port of Portland, 1972), P. F-31. Particularly noticeable is the small proportion of population that is exposed to high levels of aircraft noise. This reflects the retarding effect on residential development of the Columbia River Floodplain. This feature makes the Portland survey somewhat different from previous areas surveyed where greater numbers of population were exposed

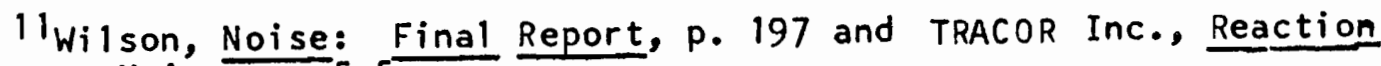
to Airport Noise, P. 5.5 


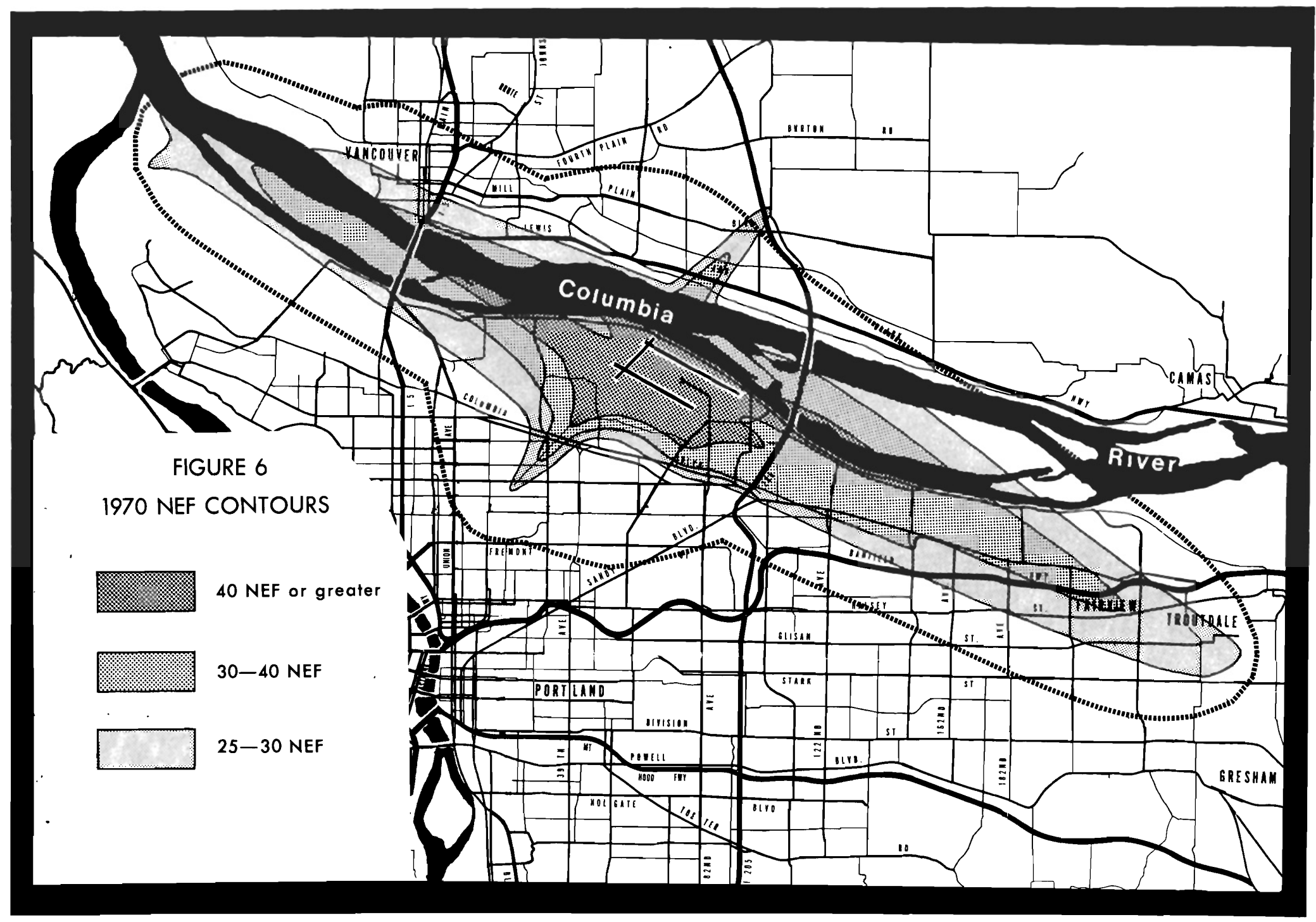


to high aircraft noise levels. 12 Taking the survey area as a whoie it appears that the variations in exposure to aircraft noise where the bulk of the population resides outside of assumed critical limits.

\section{Survay procedures}

The sample representative of the population contained in the survey area was obtained by a survey of 523 households. It was a random, population stratified sample. The number of intervizis in a given area within the study boundaries was proportional to the population residing in that area. The survey was conducted under the auspices of the Population Research and Census Center at Portland State University. The interviewers were instructed and trained before field work began. Two sources of bias were recognized in the sampling procedure. (1) Call backs were not possible for respondents who were not at home and (2) people who refused to be interviewed are not represented. 13

\section{Survey Content}

The survey (copy in Appendix A) contained a range of questions designed to obtain a wide variety of responses. There were sixtynine questions some of which were multiple response, in effect generating approximately eighty questions. The questions could roughiy be grouped into blocks of noise interference, neighborhood/city atti-

12 In the Logan Airport. survey for instance 145,000 people were residing within the NEF 30 contour. 24,000 people were within the ilef 40 contour.

13j. E. Weiss, et 31. "Sociology Section," Environmental Inm pacts, PIA Expansion, P. $\mathrm{C}-18$. 
tudes, environmental atiitudes, socio-economic, and special interest. In addition there were specific questions regarding attitudes toward alternative plans for airport expansion.

The noise interference questions were asked in a manner similar to the methods employed in the Heathrow and TRACOR siudies. ${ }^{14}$ Respondents were asked to related a noise source to interferene with a number of activities such as sleeping, T.V. watching, conversations, etc. A major difference between the Portland study and the Heathrow and TRACOR studies mentioned annoyance or bother specifically. The Portland study only referred to interruption or disturbance. Hence, the Portland study directly measures the degree of awareness rather than annoyance, though it can be argued that annoyance is still present as a dimension of the response. The difficuities engendered by this pärticularly tricky problen, universal in social surveys of this type, will be discussed in Chapter IV.

\section{Survey Rasuits}

In the PIA environmental impact statement responses to aircraft noise were cross tabulated with a number of socio-aconomic, noise exposure, and information variables. These are presented in Tables III and IV. Conspicuous was the failure of income or education to relate to notice of aircraft sounds. Sex, owner-renter, and political party were weak indicators of notice of aircraft noise with males,

14 . Jennings, "Psychology Section," Environmental Impacts, PIA Expansion, $p .0-44$. 


\section{TABLE III}

NUMBER AND PERCENT OF PEOPLE REPORTING

AIRCRAFT SOUNDS MORE NOTICEABLE

BY VARIOUS CHARACTERISTICS

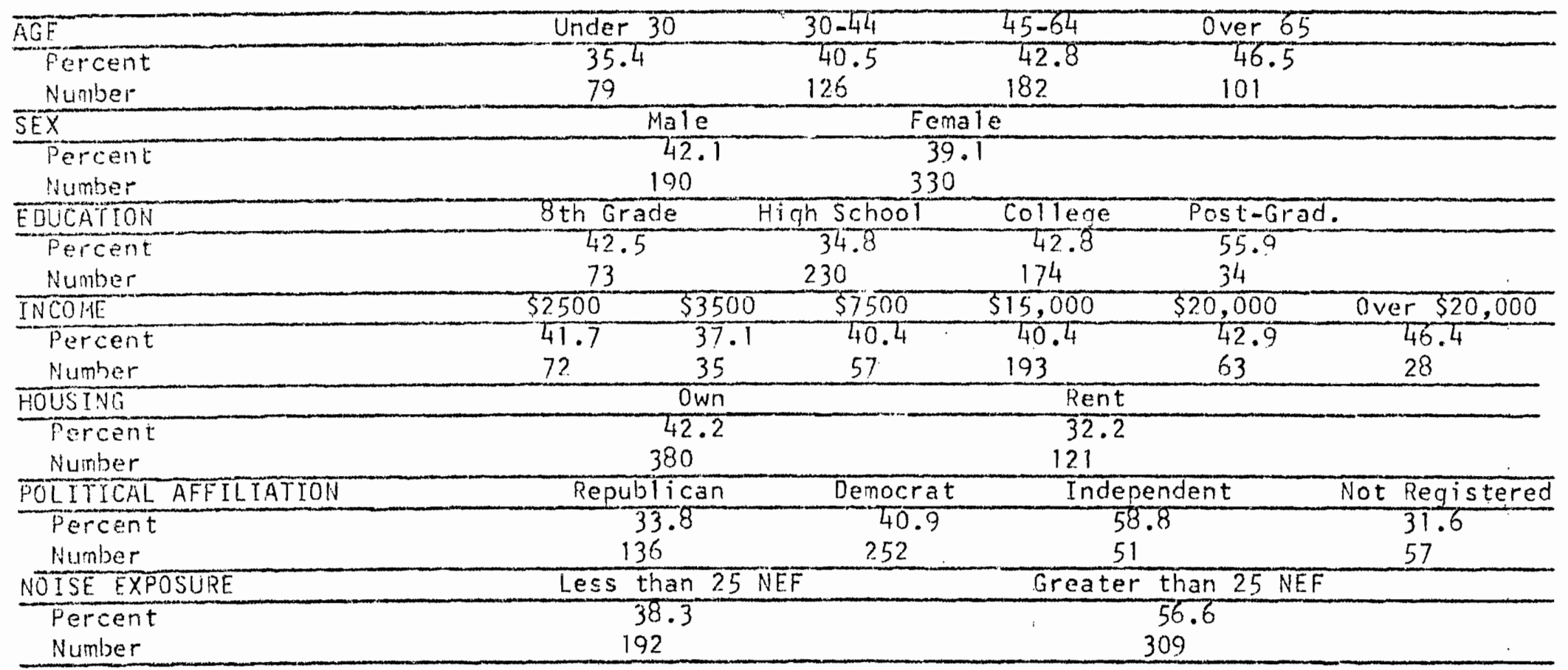

Source: J. Weiss, et al. "Sociology Section," Socio-Economic Study, Exhibit III, Environmental Impacts Portland International Airport Expansion (Portland, Ore: Port of Portland, 1972) 
TABLE IV

PERCENT RESPONDING WHICH TYPE OF

SOUNO IS MOST NOTICEABLE BY

GEOGRAPHIC SECTOR

\begin{tabular}{lcccc}
\hline $\begin{array}{c}\text { Type of } \\
\text { Sound }\end{array}$ & $\begin{array}{c}\text { Southivest } \\
\text { of PIA }\end{array}$ & $\begin{array}{l}\text { South } \\
\text { of PIA }\end{array}$ & $\begin{array}{c}\text { Southeast } \\
\text { of PIA }\end{array}$ & $\begin{array}{c}\text { Vancouver } \\
\text { Clark Cty. }\end{array}$ \\
\hline Aircraft & 37.6 & 31.1 & 40.4 & 52.9 \\
Mechanical & 38.5 & 59.8 & 50.3 & 40.4 \\
Human & 23.9 & 8.9 & 9.3 & 6.6 \\
\hline
\end{tabular}

Source: Same as Table III

TABLE V

PERCENT RESPONDING NUMBER OF ACTIVITIES

INTERRUPTED BY AIRCRAFT

BY NEF VALUE

\begin{tabular}{ccc}
$\begin{array}{c}\text { Number of Activities } \\
\text { Interrupted }\end{array}$ & $\begin{array}{c}\text { Less than } \\
\text { NEF }\end{array}$ & $\begin{array}{c}\text { Greater than } \\
25 \text { NEF }\end{array}$ \\
\hline 0 & 50.9 & 20.8 \\
1 & 24.3 & 20.8 \\
$2-3$ & 18.9 & 47.5 \\
$4-5$ & 5.9 & 17.0
\end{tabular}

Source: Same as Table III.

TABLE VI

KNOWLEDGE OF AIRPORT EXPANSION

PLANS AND INTERRUPTION OF

ACTIVITIES BY AIRCRAFT

\begin{tabular}{lcc}
\hline Typa of Information & One or More Interruptions & None \\
\hline Vague & 36.6 & 43.5 \\
Environmental & 48.5 & 36.0 \\
No Knowledge & 10.2 & 24.8
\end{tabular}

Source: Sane as Table III. 
owners, and independents being the most conscious of aircraft sound. Location inside the NEF 25 contour was positively correlated with notice of aircraft sounds as was distance from the PIA. In the latter case, however, the correlation was weak. Of interest was the propensity of respondents to cite mechanical noise (auto) as most noticeable south and southeast of the airport while in Clark County aircraft noise was most often noticed. Southwest of the airport in the densely populated older sections human noises were cited as most noticeable more often than in the other sections.

Location within the 25 NEF contour agreed positively with the number of activities reported interrupted by aircraft. Seemingly contradictory, distance was positively related to the number of activities interrupted. As distance from the airport increased, the number of activities interrupted increased. The level of information concerning the airport as measured by awareness and degree of knowledge about expansion plans was positively related to the number of activities interrupted by aircraft noise.

From cross tabulation techniques which generally allow only two or three variables to be compared at a time, it can be concluded that socio-economic data have little to do with noise response as measured in the survey. Exposure to aircraft noise, ambiant noise level as measured by population density, and information levels of respondents do predict a moderate degree of response to a noise source. Unanswered unfortunately, are questions concerning the inter-correlations and interactions of these predictors in structuring noise response. Also unanswered is the important question of the causal anoiguity of the noise 
response measurements.

Clearly, some points that have been pursued throughout the paper should be investigated. These are:

(1) What really is being measured, awareness, annoyance, complaint, or a degree of all three?

(2) Given that the three levels of noise response are intertwined and induce considerable measurement error in the noise variables, how might they be separated?

(3) Are the factors that structure noise awareness, annoyance and complaint additive and hierarchical as specified in Chapter II?

(4) Is awareness of noise location specific as hypothesized?

Questioris one and two are examined in Chapter IV. Chapter V deals with the latter two questions. 
MEASURING THE RESPOHSE TO NOISE

\section{Previous Hoise Response Measurement}

Social surveys of noise response from the Heathrow study to the present PIA study have made the assumption that "annoyance" can be measured as a function of the number of interrupted activities a particular noise creates. 1 . The Heathrow study arrived at this conelusion after cross tabulating a number of questions wherein the respondents stated how annoyed they were by aircraft noise and how many activities were interrupted or bothered by aircraft noise. The degree of annoyance was then compared to the number of activities disturbed by means of a Guttman scale criterion. ${ }^{2}$ The Heathrow study concluded that annoyance measured in this manner was a continuous scale with the magnitude of annoyance agreeing with the number of activities bothered or disturbed. They note that the "scale points 0, 2, 3, and 4 correspond approximately to the verbal categories of 'not at all', 'a.little', 'moderately', and 'very much' annoyed." ${ }^{3}$. Of particular importance was that the interference questions were couched in terms of bother, annoyance and disturbance. This would suggest that respondents were keyed to

$$
\begin{aligned}
& \text { Wilson, Noise: Final Report, p. } 205 . \\
& \text { 2ibid., p. } 206 . \\
& \text { 3ibid. }
\end{aligned}
$$


answer in terms of annoyance rather than ayaraness. It does not imply that respondent's ansuers to a series of interference questions would produce an annoyance scale wh thout prompting to think in terms of annoyance.

A surprising finding of the fieathrow study was that the degree of amoyance agreed with the number of activities disturbed. Previous rasearch has suggested that annoyance bears only a partial relation to the magnitude of interference. Cohn notes that unpleasant feelings or attitudes about certain sounds based on their infornation content can lead to annoyance wich might be altogether out of proportion to the phyical characteristics of the sound. Congruent with the Heathrow results other research has shown that annoyance grows with increasing ragnitude of noise. Horever, annoyance also is greater for sounds of higher frequency and for sounds wich are random in time and duration. 5 Borsky writes that much greater annoynce results from interruption of sleep or rest than talking or listening.

These results suggast two conflicting views of noise annoyance. The Heathron study considers it a continuous scalable ordinal entity while others clain to to be an autonomous response to a specific

"Cohn, "effects of Noise on Esychological State," in Ward and Friche, eds., Heal th Hazard, P. 80.

5 Ibid., p. 33 .

6. Borsiy, nsone of the Hunen Factors underlying Commuity Racetions to Air Force loise," in "lationa Research Council Committee of Hearing Acoustics, Gth Annez seazin of the drod Forces Washington,

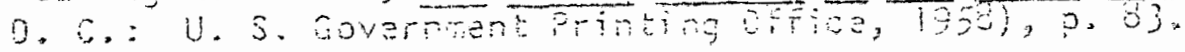


disturbance not necessarily related to the number of activities interrupted. ${ }^{7}$ These views can be reconciled by considering the observation that different activities have different thresholds of disturbance. It is probable that interruption of annoyance-sensitive activities requires noise magnitudes sufficient to interfere with less annoyance-sensitive activities. Hence, people who are highly annoyed becausa their sleep is interrupted will tend to also report house vibrations and T.V. interruption, though the bulk of the annoyance is connected to sleep loss. In Figures 7 and 8 the percent of people reporting disturbance of various activities in the Heathrow and PIA studies is compared to aircraft noise magnitude.

While the activity categories are not entirely comparable, it can be seen that activities connected with high annoyance such as sleep and entertainment have low flat response curves. Activities that produce less annoyance when interrupted such as T.V. watching and conversation have higher steeper response curves. This indicates that a person highly annoyed over sleep disturbance would very likely mention his conversations and T.V. watching were disturbed as well. This result: supports both the contentions of the Hilson Report and those of Borsky and Cohn.

Aside from the question of whether annoyance is scaleable, there reinains the question of what is being measured: awareness, annoyance or complaint? This question is likely to remain troublesome in survey work where one does not have access to polygraph-like devices for measuring individual reactions. This is particularly true of the PIA

7 Mckennel and Hunt, Noise Annoyance, p. 1. 


\section{FIGURE 7}
RESPONSE CURVE OF SUSCEPTIBILITY OF VARIOUS ACTIVITIES TO INTERRUPTION BY AIRCRAFT NOISE AT HEATHROH AIRPORT

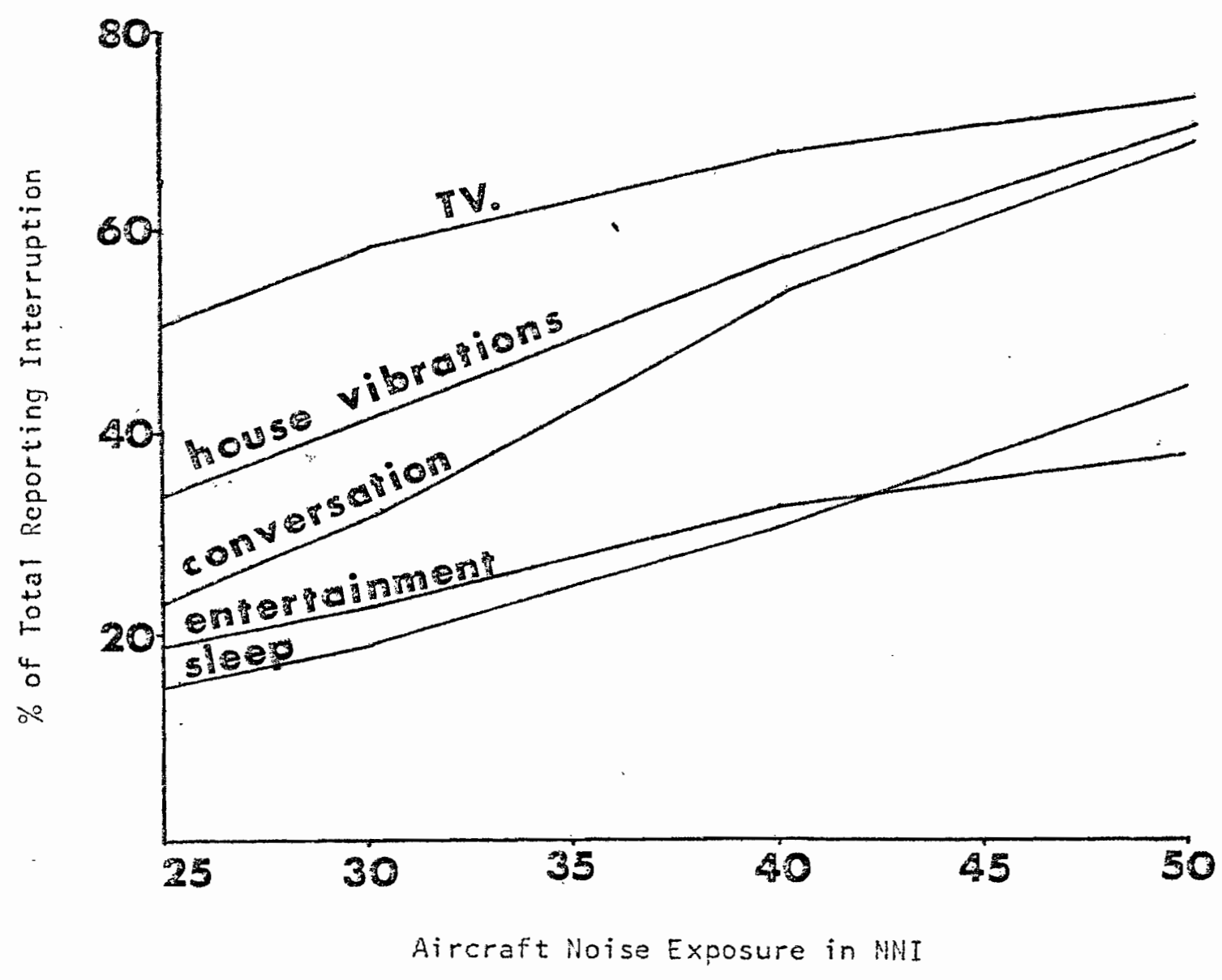

Source: A. Hilson, Noise: Final Report (London: Her Majesty's Stationery office, 1963), p. 210 . 
FIGURE 8

\section{RESPONSE CURVE OF SUSCEPTIBILITY OF VARIOUS ACTIVITIES}

TO INTERRUPTION BY AIRCPAFT NOISE AT PORTLAND

INTERNATIONAL AIRPORT

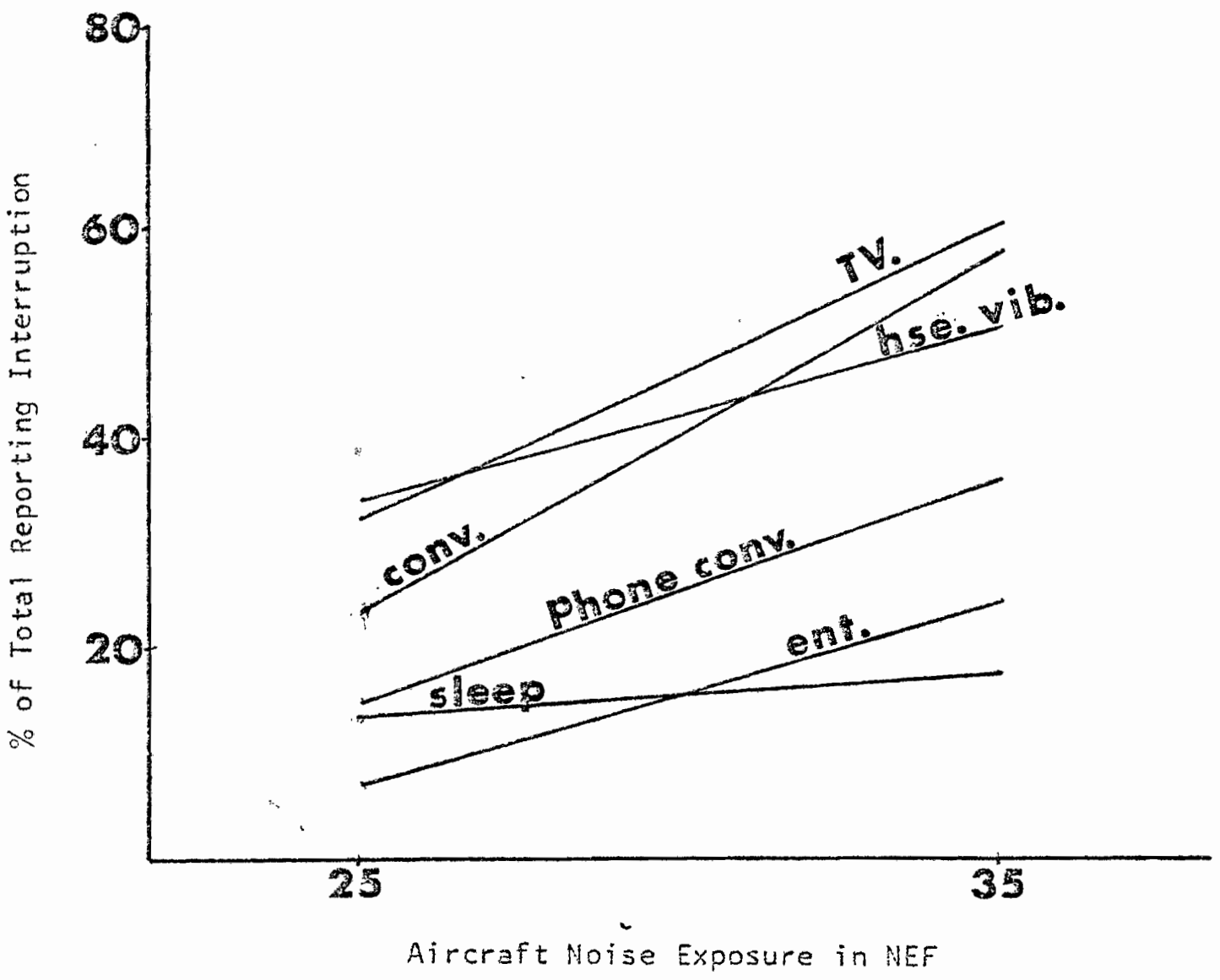

Source: Data calculated from survey taken as part of Environmental Impacts, PIA Expansion. 
survey where the questions on interruption or disturbance of activities were asked wi thout reference to annoyance or bother. For the purposes of this paper which investigates noise awareness, the extraction of awareness from amnoyance and complaint is mandatory.

Construction of the Noise Awareness Measure

In constructing the noise awareness masure seventeen questions" were selected from the survey data. (Table VII) Nine of these questions concerned aircraft interruption of activities such as conversation and sleeping. The remaining eight reported explicit information about the respondent's attitudes toward aircraft. In the latier group were questions which asked about previous complaints over aircraft activities and if aircraft activities were a disliked feature of the neighborhood.

The major difference between the two groups of questions was that attitude, either positive or negative, could not be inferred from the first set of questions. In contrast attitude toward aircraft operations was fairly explicit in the second set of questions. of interest is the degree of correlation between questions in the first set and questions in the second. Do the questions in the first set correlate with questions in the second set?

If they do, then we can relate them to definite attitudes toward aircraft operations such as annoyance and complaint. If they fail to correlate, then we can conclude the first set of questions indicates a neutral attitude toward aircraft operations. As such they would be indicators of noise awareness. 
TABLE VII

QUESTIONS SELECTED FOR PRINCIPLE

COMPONENTS ANALYSIS

QUESTIONS

PERCENT YES

1. Aircraft noise is most noticeabie.

$38 \%$

2. Aircraft interruptconversation.

$28 \%$

3. Aircraft interrupt telephone.

$16 \%$

4. Aircraft interrupt sleep.

$14 \%$

5. Aircraft interrupt television.

$35 \%$

6. Aircraft interrupt work. $3 \%$

7. Aircraft interrupt intertainnent. $9 \%$

8. Aircraft interrupt hobbies.

$1 \%$

9. Aircraft interrupt walks. $3 \%$

10. Aircraft interrupt other activities. $2 \%$

11. The airport is a disliked feature of the neighborhood.

12. Aircraft deposit oil fils.

13. Kerosene is smelled

i4. The home has been damaged

15. Aircraft crashes wory. $24 \%$

15. Have compiained about aircrart. $4 \%$

17. Aircraft induced home vibrations are disturbing.

Source: Data were complled from a survey taken as part of Environmental Impacss, PIA Expansion. 
The method of principle components analys is was chosen for analyzing the correlations between the seventeen survey questions on noise response. 8 This method has the advantage of reducing a large number of questions into several classes called factors. The factors are based on the intercorrelations of the questions. Thereby, one need not interpret the correlations of each question separately. Rather the factors can be interpreted.

These factors have the property of being unrelated to one another within the limits of the data analyzed. "Thus, each factor based on the seventeen questions analyzed will be measuring a different trend in the response to aircraft noise.

Table VII presents the results of the orinciple comoonents analysis. Four interpretable factors were obtained. Most noticeable was that the nine activity interuption questions did not regroup into factors with the eight attutude questions. Instead the first set of nine broke into an indoor activity interruption factor and an outdoorlaway-from-home interruption factor. Both of these factors were judged to be indicators of noise awareness.

The questions which stated explicit attitudes toward aircraft operations also broke into two factors. One factor contained a direct reference to complaint and was related to non-auditory notice of aircraft such as smelling kerosene and seeing oil film. The fact that aircraft-caused home damage was connected with this factor

${ }^{3}$ The techniques usad are discussed in $W$. W cooiey and $P . R$. Lohnes, Multivariate Data Analysis (New York: John wiley and Sons, ${ }^{9}$ L. J King, Statistical Analysis in Reography, pp. 173-179. 
TABLE VIII

ROTATED FACTOR MATRIX

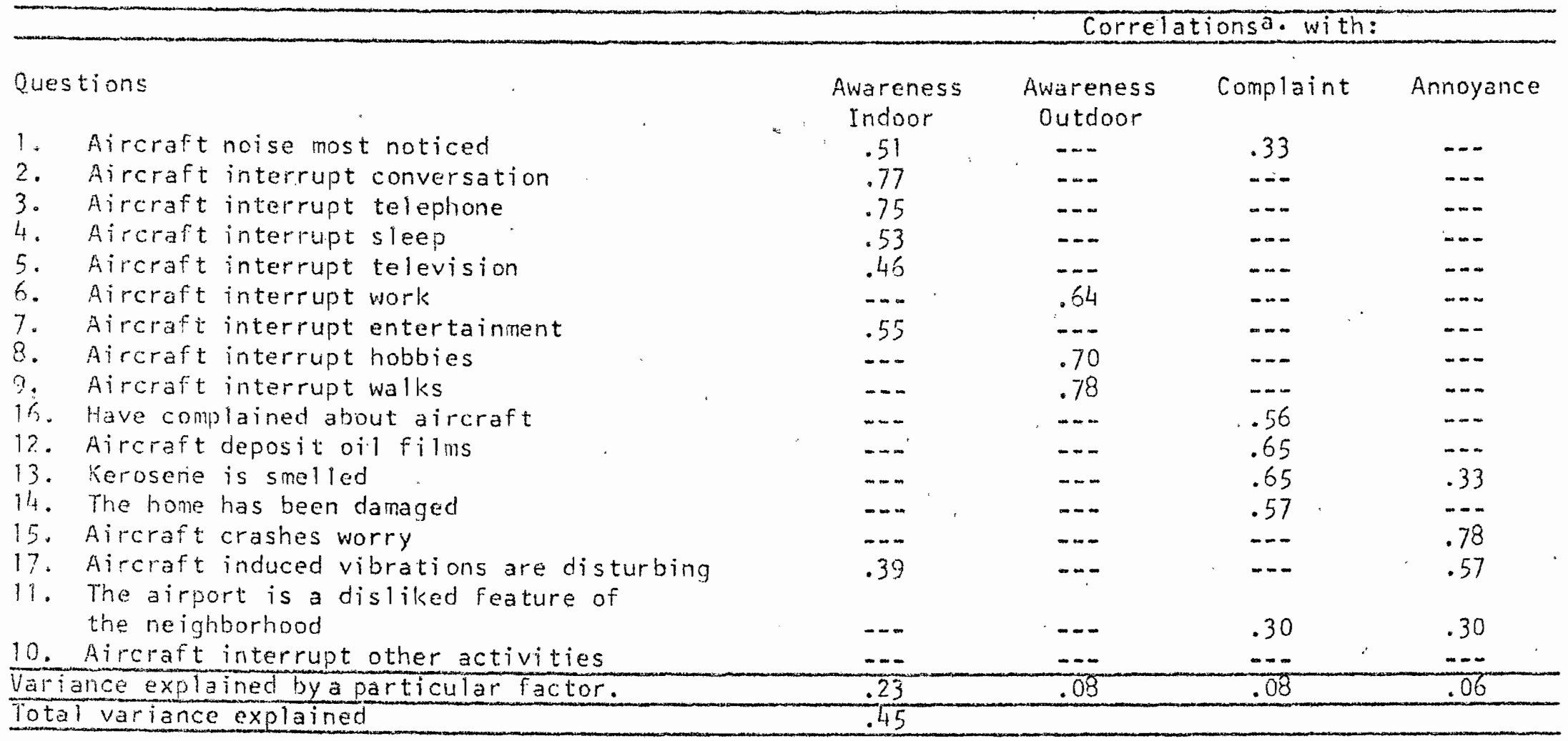

Notes: a. Correlations under .30 are omitted.

Source: Same as Table VII. 
further emphasized its strong negative attitude toward aircraft operations. For these reasons this factor was held to measure complaint.

The fourth factor showed concern over aircraft crasining and disturbance over aircraft-caused hame vibrations. Different from factor three was the emphasis on passive concern rather than active hostility. This agrees with previous research on the difference between those annoyed and those complaining over aircraft operations. 10 Though the factor does not refer to annoyance explicitly, it appears to indicate it.

The second factor, outdoor/avay-from-home noise awareness, was excluded from further analysis. This was done because there was a good chance that in this factor exposure to aircraft noise occurred away from home. Consequently, response to this factor would have little to do with place of residence. Since all noise exposure data were compared to place of residence, resoonses formed away from home would be meaningless in the context of this study. Accordingly, noise awareness as measured in factor one was chosen as the noise awareness measure.

Each respondent was scored on the noise awareness, annoyance and complaint measures. This was done through the use of a factor scores program. 11 In this program a person scores on a factor in direct proportion to the number of questions he has answered positively

103. Borsky, "Human Factors Underlying Community Reactions to Air Force Noise," in NRC Comittee of Hearing Acoustics, 6th Meeting, p. 80 .

11. J. King, Statistical Analys is in Ceography, pp. 173-179. 
which are highly correlated with that factor. For instance, on the indoor noise awareness factor a person mentioning a large number of activities interrupted would score high. Use of this program allowed each respondent to be scored on the three measures, thus producing measures of awareness, annoyance and complaint to be used in further analysis.

Errors within the Noise Awareness Measure

Two sources of error are present within the noise awareness measure. The first error relates to the difficulty of establishing an unambiguous definition of awareness as the first factor. The second error has to do with the problem of scaling the noise awareness measure through the use of a factor scores program.

From the specification of the hierarchy of noise response outlined in Chapter II arises a condition which the noise awareness measure should satisfy. From Chapter II we know that awareness is the most frequent noise response; annoyance the next nost frequent, and complaint the least. Consequently, the factors purporting to measure noise awareness, annoyance and complaint should exhibit the same ordering.

The data in Table VII indicate that the questions in the indoor awareness response are among the most frequently mentioned. Questions within the complaint factor are mentioned, as expected, relatively seldom. However, questions in the annoyance factor are mentioned almost as frequently as are the questions in the awareness factor. This disagrees with the prior specification of noise annoyance and noise awareness.

Aiso from the specification contained in Chapter II, noise 
annoyance should explain a larger amount of variation in the noise response than does the complaint factor. Table VIII shows. this is not so. The complaint factor explains more variation than does the annoyance factor.

Lastly, from other research it is known that interruption of such activities as sleep is connected with high annoyance. ${ }^{12}$ In this instance sleep interruption is correlated with awareness rather than annoyance.

This evidence leads to the conciusion that noise annoyance is partly confused with the noise awareness ineasure. Since awareness and annoyance measures are based on unrelated factors, this conclusion seens contradictory. However, the factors are only unrelated within the range of the data included in the analysis. Questions not included in the analysis could change the interpretation of the factors. A change in interpretation seems likely in view of the fact that the factors used in the awareness, annoyance and complaint measurements explain but forty-five percent of the overall variation in response to aircraft activity. Consequently, the awareness measure probably is not pure in that it contains a component of noise annoyance.

The use of a factor scores program resulted in a scale of noise awareness upon which each respondent was measured. From the discussion in the first part of Chapter IV there is evidence that noise

12Borsky, "Community Behavior," in Ward and Friche, eds., Public Health Hazard, p. 190. 
response is scaleable. However, incorporation into a multiple regression analysis requires more accuracy than necessarily exists in the noise awareness scale. Blalock cautions that of tentimes statistical techniques, particularly multivariate analysis, do not meet the stringent measurement requirements necessary for meaningful application. 13 Tintner points out that if one assumes there are errors in the equations as is typical in regression analysis, then no errors can be assumed for the variables. ${ }^{14}$ since much of the analysis critical to the hypotheses and substantive results of this paper uses multiple regression techniques, it follows that some insight must be gained as to how much measurenent error is contained in the dependent variable. The larger the amount of error the larger the disparity between the theoretical correlation limit of 1.00 and the actual correlation limit.

The degree of error within the awareness measure was evaluated by noting the number of times an activity less susceptible to noise interruption was disturbed before a more susceptible activity was. Five activities were selected from the PIA survey data. These were by order of susceptibility to noise interruption: T.V., conversation, phone, sleep and entertainment. These activities are contained within the noise awareness measure. One item contained in the awareness

13H. H. Blalock, Socjal Statistics (New York: HcGraw Hill Book Co., Inc., 1960); p. 19 . p. 154.

14. Tintner, Economezrics (New York: John Wiley and Sons, 1952), 
measure, notice of aircraft noise, was not included in the amalysis due to difficulties in retrieving it from computer card files.

Table Ix contains a matrix with the five activities contained in the noise awareness measure listed by order of susceptibility from high to low. The numbers in the upper diagonal list the times the activity contained in the column was correctly conpared to the activity represented in the row. The lower diagonal contains the number of times the activity listed in the row was incorrectly compared to the column activity. For instance, the matrix shows that television was correctly mentioned ahead of conversation 125 times while conversation was incorrectly mentioned ahead of television sixty times. Using this matrix the degree of error in the measure was calculated three different ways. These methods are outined by Torgerson. 15 All three methods produced conparable results. Due to their complexity two methods are discussed in Appendix B. The other, Guttman's coefficient of reproducibility (Rep.), is simply the ratio of total responses to incorrect responses subtracted from one. It can be quickly computed from the information contained in Table Ix. The numbers below the diagonal were counted as errors as they represented instances when an activity with low susceptibility to aircraft interruption was disturbed before an activity with high susceptibility. In this instance the ratio of total responses to errors subtracted fron one was .808 . Guttman originally selected .85 as the dividing line between scales and nonscales. This has since been revised to

15. S. Torgerson, Theory and Methods of Scaling (New York:

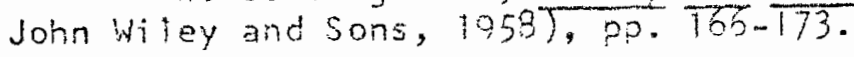


TABLE IX

MATRIX OF PATREO COMPARISONS BY SUSCEPTIBILITY

TO INTERRUPTION BY AIRCRAFT NOISE

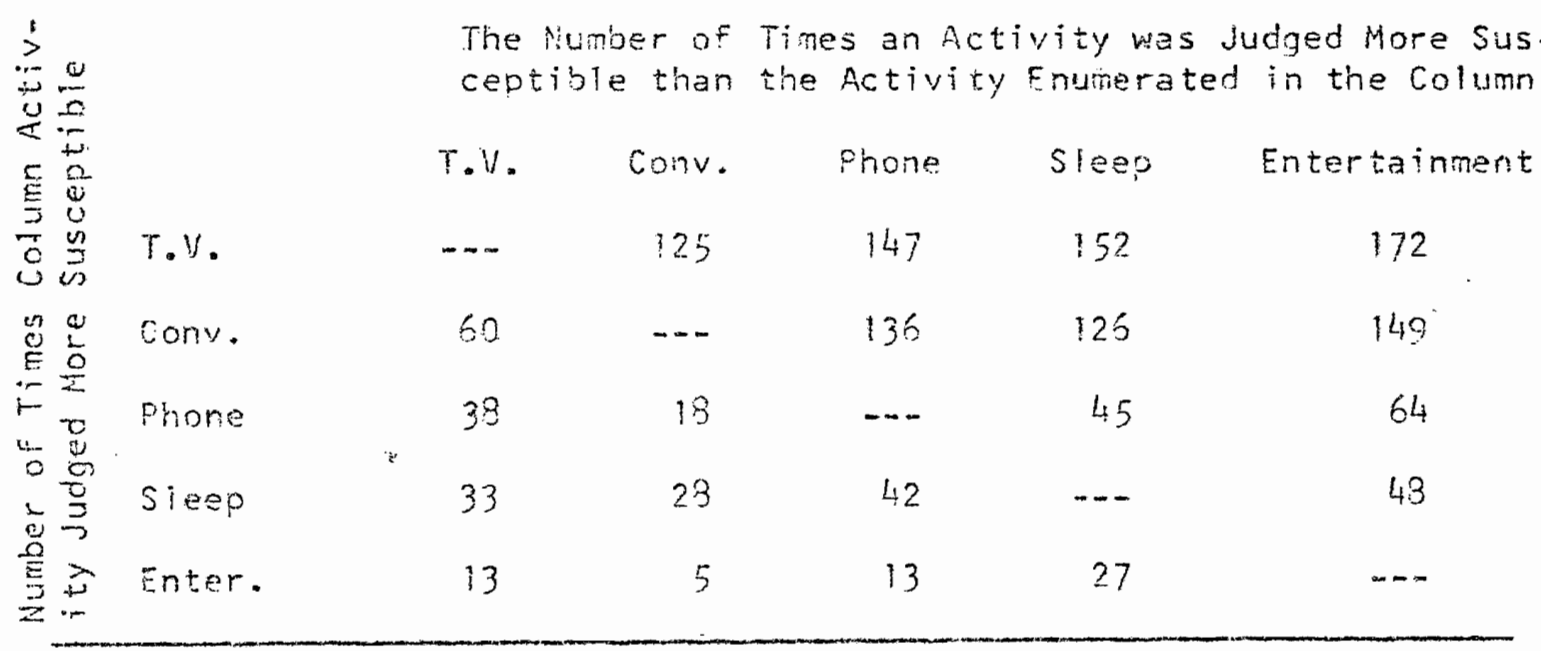

Source: Same as:Table VII. 
90.16 For the PIA survey the awareness measurement would on strict grounds be regarded as a nonscale, though the .808 coefficient of reproducibility indicates well developed trends in the data.

From the information derived by the other two methods it was found that much of the error came from inversions between conversation and television and phone calls and sleep. Combining these four categories into two resulted in a Rep. of .85 , significant by Guttman's earlier standard.

In general the three methods indicate serious errors exist in the noise awareness scale. Ho further attempt was made to evaluate the accuracy of the scale resulting from the factor scores program.

\section{Summary of Chapter}

From the preceding discussion two sources of error are considered present in the noise awareness measure. First is error stemming from the inability to totally distinguish awareness from annoyance and complaint. Second is the inability of number of activities interrupted to actually measure the extent of noise awareness. For instance, mention of four activities interrupted as compared to mention of two interruptions does not necessarily indicate more: noise awareness. While measuring noise awareness in terms of factor scores tempers this problem, it is still present. In combination these two sources of error are expected to detract from any ragression analysis which is based on error-free measurement of variables. Consequently, results obtained in Chapter $/ /$ will be "understatements" of the reiationships isolated.

15 isid., p. 323. 


\title{
CHAPTER V
}

\author{
ANALYSIS OF THE FACTORS THAT STRUCTURE \\ AWARENESS OF A NOISE SOURCE
}

Testing the Response Hierarchy

From the listing in Chapter II of the hierarchy of noise response and the factors that structure it, the following statement can be made:

As the level of the hierarchy increases from awareness through annoyance to complaint, the pattern of noise response becomes less dependent on location and more dependent on individuals. Hence, predictions of noise response with a set of variables measuring location will decline in accuracy with the increasing level of the noise response hierarchy.

With the data at hand this is a tostabie premise. The method adopted was "trend surface analysis." 1 This method measures the degree of spatial association inherent in a given variable. In other words, value patterns wich are non-random and systematic in space such as topographic contours can be accurately predicted from their spatial coordinates. Two points, close in space, will be expected

'Chorley and Haggett, "Trend Surface Mapping," Transactions and Papers: Institute of British Geographers, pp. 47-67. The method of fitting a set of irregularly spaced points to a two dimensional surface is by the least squares procedure of regression analysis. In this instance: $Z=B_{03}+B_{1} U+B_{2} i+B_{3} U^{2}+B_{4} V U+B_{5} V^{2}+B_{6} U^{3}+$ $B_{7} U^{2} V+B_{3} U V^{2}+B_{9} V^{3}$; where $Z$ is a value for any point and $U$ and $V$ are its coordinates. The subsequent terms are polynomial expansions of the coordinates. For this analysis the expansion was limited to a cubic trend. Further expansion generally yields no significant improvement. 
to have similar values. Value patterns caused by non-spatial variables such as color preferences of individuals would not have the property of spatial association; hence trend surface analysis would not predict them accurately.

The variables tested in this instance are those measured by the factor scores of factors one (noise awareness), three (noise complaint) and four (noise annoyance). The predictive power of the trend surface technique should decline from awareness to annoyance to complaint. Contained in Figures 9 and 10 and Tables X-XII are the results of the analysis. Corralation coefficients for awareness, annoyance, and complaint are $.59, .28$, and .15 respectively. Awareness and annoyance are shown to be significant spatial trends while complaint is largely random in space. The dec? ine in explanation occurs as predicted. These results support the premise and substantiate the measurement techniques.

In figures 9 and 10 the spatial trends for noise awareness and annoyance are presented asimaps. Most noticeable is that the contours for noise awareness approximate the pattern of the NEF contours shown in Figure 6. The small spatial pattern of noise annoyance, on the other hand, appears to be almost the reverse of the NEF contours with the high annoyance values falling outside 30 NEF and perpendicular to it.

The Factors that Structure Noise Awareness

since the noise awareness response surface can be adequately defined as a contiguous spatial association, it follobs that the same 


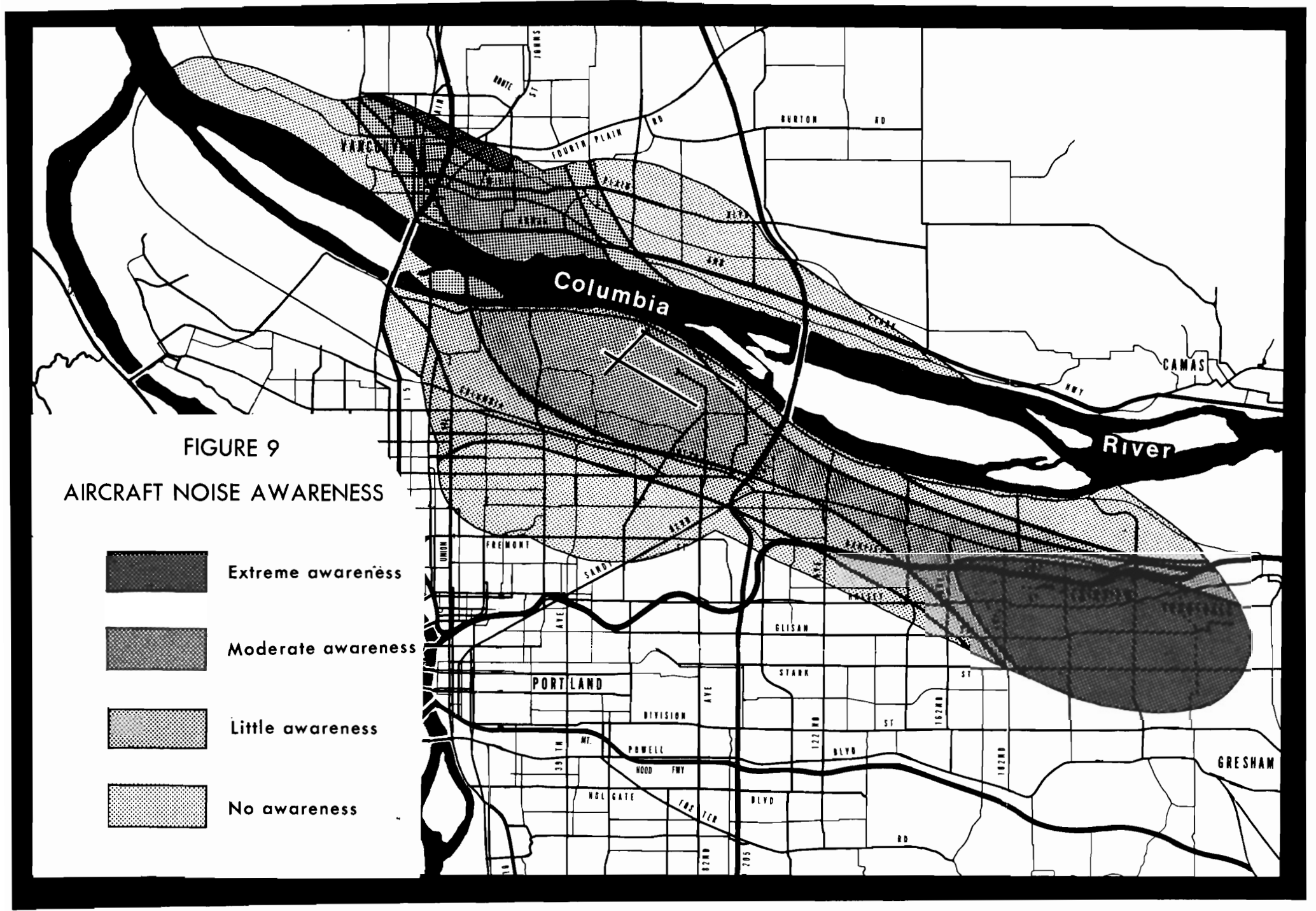


TABLE X

ESTIMATING EOUATION FOR TRENB SUPFACE OF NOISE AHARENESS (FACTOR I)

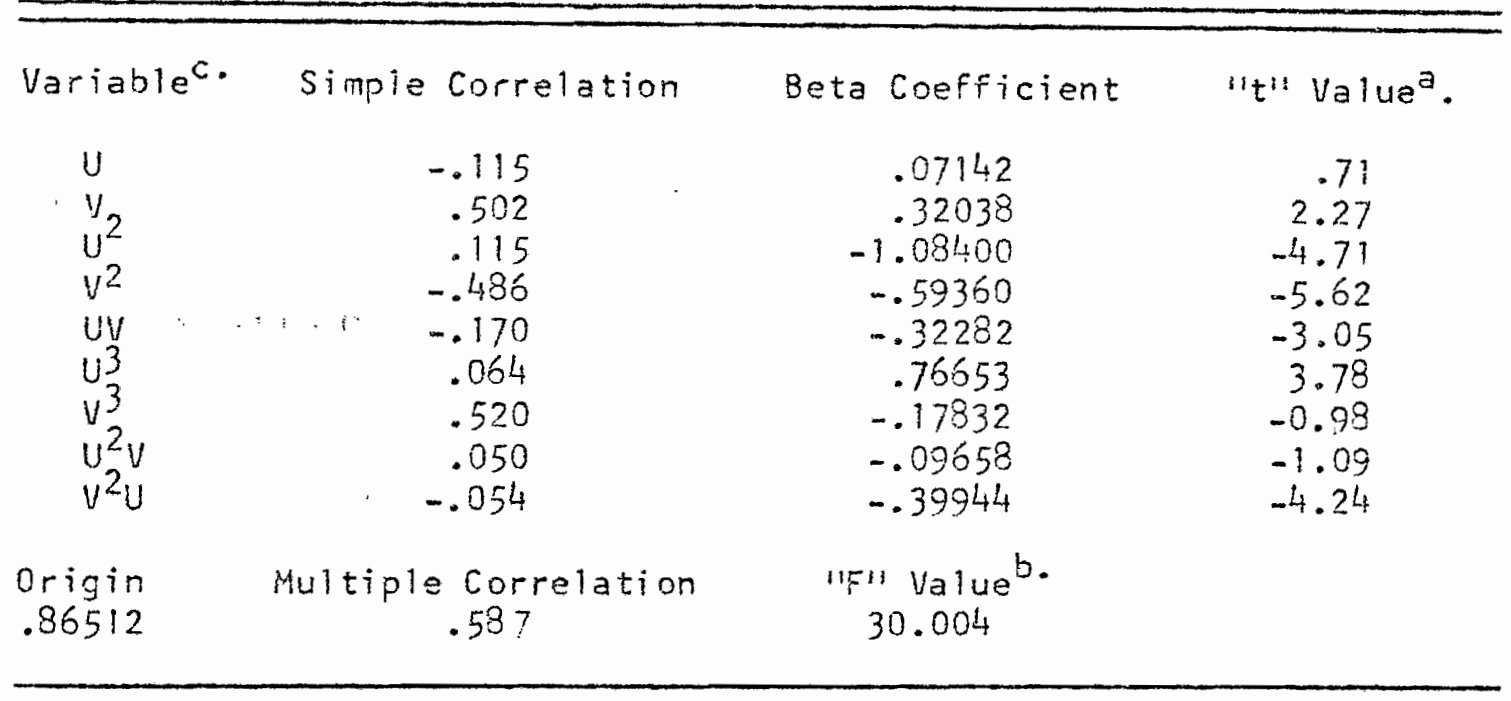

Notes: a. Critical value of "t": with over 500 degrees of freedom is 1.96 , at the $95 \%$ confidence level.

b. Critical value of "F" with over 500 degrees of freedom and 9 variables is approximately 1.90 at the $95 \%$ confidence level.

c. "U" and "y" are the rectangular coordinate locations of the residences of the survey respondents. 


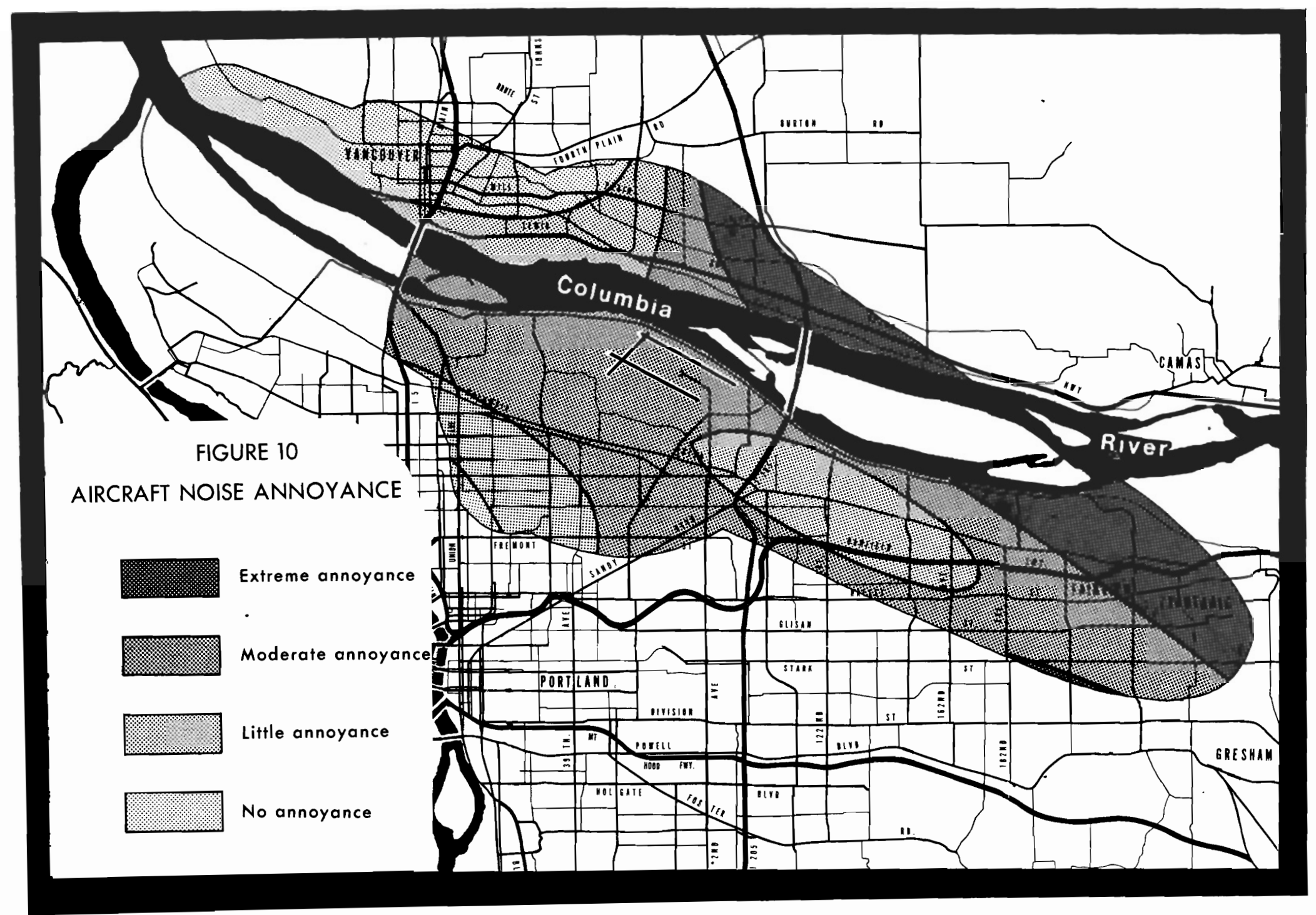


TABLE YI

ESTIMATING EQUATION FOR TREND SURFACE OF NOISE COMPLAINT (FACTOR III)

\begin{tabular}{|c|c|c|c|}
\hline Variable & Simple Correlation & Beta Coefficient & "t" Value \\
\hline $\mathrm{U}$ & .025 & -.10068 & -0.68 \\
\hline$V_{0}$ & -.090 & -.10936 & -0.73 \\
\hline$u^{2}$ & -.033 & -.03262 & -0.12 \\
\hline$v^{2}$ & .047 & -.02598 & -0.24 \\
\hline UY & .080 & .18306 & 1.59 \\
\hline$u^{3}$ & .001 & .07590 & 0.39 \\
\hline$v^{3}$ & -.068 & .05732 & 0.32 \\
\hline$u^{2} v$ & -.004 & -.00000 & -0.00 \\
\hline$v^{2} u$ & .030 & .15706 & 1.36 \\
\hline $\begin{array}{l}\text { origin } \\
.55390\end{array}$ & $\begin{array}{c}\text { Muftiple Correlation } \\
.150\end{array}$ & $\begin{array}{c}\text { "P" Value } \\
1.31875\end{array}$ & \\
\hline
\end{tabular}

Note: The critical values for "tt" and $F$ " are the same as in Table $X$. 
TABLE XII

ESTIMATING EQUATION FOR TREND SURFACE OF NOISE ANNOYANCE (FACTOR IV)

\begin{tabular}{|c|c|c|c|}
\hline Variable & Simple Correlation & Beta Coefficient & $"$ "t" Va1ue \\
\hline $\begin{array}{l}u \\
v \\
u^{2} \\
v^{2} \\
u \frac{y}{u} \\
u^{3} \\
v^{3} \\
u^{2} v \\
v^{2} u\end{array}$ & $\begin{array}{r}-.056 \\
.149 \\
-.005 \\
.010 \\
.128 \\
-.016 \\
.068 \\
.120 \\
-.112\end{array}$ & $\begin{array}{r}.10741 \\
.32935 \\
.85310 \\
.17168 \\
.43519 \\
-.68867 \\
-.06704 \\
-.01757 \\
.17566\end{array}$ & $\begin{array}{r}0.75 \\
2.28 \\
3.34 \\
1.62 \\
3.91 \\
-2.88 \\
-0.39 \\
-0.17 \\
1.58\end{array}$ \\
\hline $\begin{array}{l}\text { Origin } \\
.22252\end{array}$ & $\begin{array}{c}\text { Multiple Correlation } \\
.283\end{array}$ & $\begin{array}{l}\text { "F" VaTue } \\
4.97467\end{array}$ & \\
\hline
\end{tabular}

Note: The critical values for "t" and "ffl are the same as in Table $X$. 
surface can be approximated by the variables which create this surface. Measurement of those variables constitutes a considerable problem. one variable already discussed is noise exposure. The uncertainties that apply to the NEF values are probably representative of all variables which purport to explein noise response.

Errors of measurement and uncertainty in the specification of the noise awareness variable combined with measurement errors in causa! variables probably limit correlations to a level below those developed through trend surface analysis. Thus it is expected that the .59 correlation coefficient obtained between awareness and the spatial trend will form the upper limit of correlation between noise awareness and variables other than location. It would follow that groups of variables other than location would approximate the corralation but not surpass it.

Figure 11 presents a flow chart which iliustrates the procedure for evaluating the variables suspected of structuring aircraft noise awareness. Due to restrictions placed on the size of regression matrices by the limited core storage capacity of the 1130 computer, the independent variables were broken into blocks. These blocks were dem fined as:

(1) Environmental city neighborhood attitude

(2) Airport attitude special interest information sources

(3) Socio-economic

(4) Noise exposure

Using the dependent variable, noise awareness, as measured by the factor scores from factor one of the principle components analysis, 
FIGURE 11

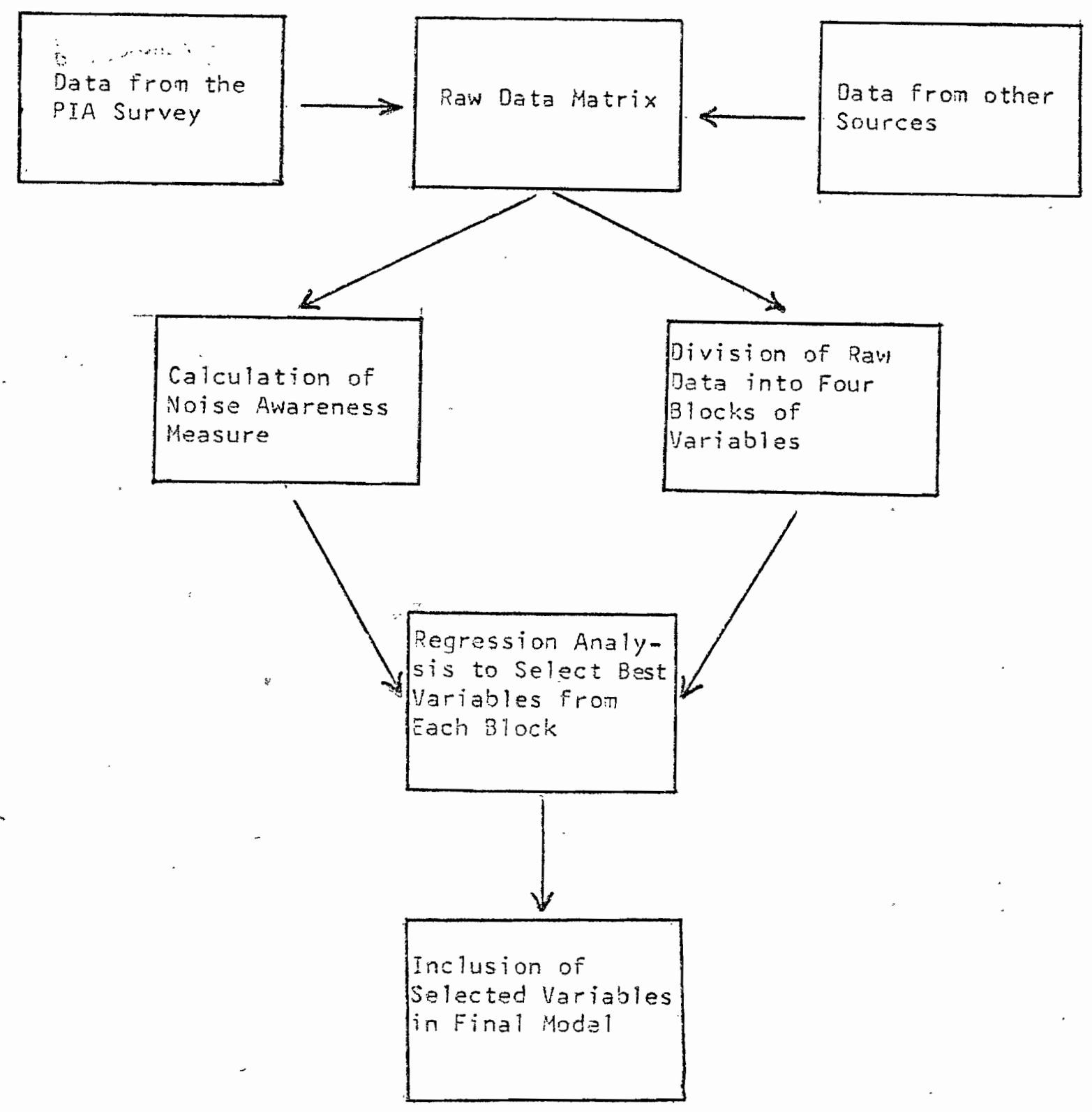

Figure 11: Flow diagram of Variable Analysis for determining the variables that effect noise anareness. 
each block was evaluated by means of a multiple regression analysis. A "final model" was constructed by selecting from each block variables which showed some promise of explaining noise awareness and for which some argument, however tenuous, could be made for their causality.

Tables XIII-XVI present the results of the multiple regression analysis. Correlation coefficients between noise awareness and environmental/city/neighborhood attitudes, airport atti tude/special interest/information sources, socio-economic, and noise exposure blocks were $.30, .29, .12$ and .29 respectively. With the exception of the socio-economic block all blocks were equal in predicting noise awareness.

Significant variables in blocks one and three are essentially measures of exposure. Block one is taken from information contained in the survey. Block three is a mixture of survey data combinad with exposure data calculated independently. (Methods and procedures of calcuation are given in Appendix (C). In block one neighborhood noise level and frequency of noise best predicted noise awareness. Neighborhood "noisiness" was not directly related to annoyance as there was a tendency for people who rated neighborhoods as good also to rate them as noisy. This is also contrary to Borsky's results on the characteristics of people annoyed by noise. 2 on the other hand the quality of the city as a whole declined with incraase in noisiness.

${ }^{2}$ Borsky, "Community Behavior," in ward and Friche, eds., Pubic Health Hazard, p. 190. 
ESTIMATING EQUATION FOR REGRESSION OF NOISE AWARENFSS MEASURE WITH ENVIRONMENTAL ATTITUDE VARIABLES (Block 1)

\begin{tabular}{|c|c|c|c|c|c|}
\hline Variable & Coding: Mean & $\begin{array}{l}\text { Standard } \\
\text { Deviation }\end{array}$ & $\begin{array}{l}\text { Simple } \\
\text { Corr. }\end{array}$ & $\begin{array}{l}\text { Beta Co- } \\
\text { efficient }\end{array}$ & "t" Value \\
\hline Attitude toward city & Ordinal ${ }^{\mathrm{a}} \cdot 1.72$ & .75 & .07 & .08693 & 1.92 \\
\hline Atricude toward neighborhood & Ordinal ${ }^{2} \cdot 1.96$ & .88 & .00 & -.06471 & -1.35 \\
\hline Changes in neighborhood & Ordinat $1^{a} \cdot 2.07$ & .61 & -.04 & -.03299 & -0.75 \\
\hline Noise level in neighborhood & ardina $1^{b} \cdot 3.29$ & 1.40 & -.20 & -.16710 & -3.80 \\
\hline Noise more bothersome at home or work & Nominal ${ }^{c} \cdot .20$ & .40 & .04 & -.00723 & -0.17 \\
\hline Are neighborhood dislikes environmental? & Nominald. .52 & .50 & .08 & .03821 & 0.83 \\
\hline Frequency of noise & Ordinale. 2.56 & .99 & -.23 & -.20543 & -4.76 \\
\hline $\begin{array}{l}\text { Origin } \\
.84374\end{array}$ & $\begin{array}{c}\text { tiple Correlation } \\
.300\end{array}$ & \multicolumn{4}{|c|}{$\begin{array}{l}\text { "F" Valuef. } \\
7.28\end{array}$} \\
\hline
\end{tabular}

Notes: a. Coded one through four, from positive to negative attitudes.

b. Coded one through four, from very noisy to not noisy.

c. Coded positively on more bothersome at work.

d. Coded positively on environmental dislikes.

e. Coded one through four from highly frequent to infrequent.

$f$. Critical values of "t" and "F" are 1.96 and 2.03 , respectively at $95 \%$ confidence 1 evel. 
TABLE XIV

ESTIMATING EQUATION FOR REGRESSION OF NOISE AWARENESS MEASURE WITH AIRPORT ATTITUDE, SPECIAL INTEREST AND INFORMATION

SOURCE VARIABLES (B lock 2)

\begin{tabular}{|c|c|c|c|c|c|c|}
\hline Variable & Coding & Mean & $\begin{array}{l}\text { Standard } \\
\text { Deviation }\end{array}$ & $\begin{array}{l}\text { Simple } \\
\text { Corr. }\end{array}$ & $\begin{array}{l}\text { Beta Co- } \\
\text { efficient }\end{array}$ & "t'val. b \\
\hline Heard about expansion? & Nomina! ${ }^{a}$ & .85 & .35 & .12 & .13762 & 2.72 \\
\hline Precise information on Expansion? & Nominala. & .54 & .50 & .09 & .14345 & 3.13 \\
\hline Approve or disapprove of expansion? & Nominal ${ }^{a}$. & .47 & .50 & -.15 & -.09356 & -2.01 \\
\hline Number of times to airport? & Interval & 3.41 & 1.81 & -.09 & -.10995 & -2.54 \\
\hline Use Columbia River for recreation? & Nominal ${ }^{a} \cdot$ & .33 & .47 & -.02 & -.06882 & -1.59 \\
\hline Discussed aircraft noise problems? & Nominala. & .24 & .43 & .17 & .16919 & 3.90 \\
\hline $\begin{array}{l}\text { origin } \\
-0.32912\end{array}$ & \multicolumn{3}{|c|}{$\begin{array}{c}\text { Multiple Correlation } \\
.291\end{array}$} & \multicolumn{2}{|c|}{$\begin{array}{c}\text { "F" Value } \\
7.97\end{array}$} & \\
\hline
\end{tabular}

Notes: a. Coded positively on affirmative response.

b. Critical values of "t" and 11 wl and 1.96 and 2.12 respectively, at $95 \%$ confidence 1 evel. 
TABLE XV

ESTIMATING EQUATION FOR REGRESSION OF NOISE AWARENESS MEASURE WITH SOCIO-ECONOMIC VARIABLES (Block 3)

\begin{tabular}{|c|c|c|c|c|c|c|}
\hline Variable & Coding & Mean & $\begin{array}{l}\text { Standard } \\
\text { Deviation }\end{array}$ & $\begin{array}{l}\text { Simple } \\
\text { Corr. }\end{array}$ & $\begin{array}{l}\text { Beta Co- } \\
\text { efficient }\end{array}$ & "t" valued. \\
\hline Age & Interval & 43.27 & 16.72 & .03 & .04903 & 0.69 \\
\hline Number of people in household? & $\begin{array}{l}\text { Interval/ } \\
\text { Class }\end{array}$ & 3.11 & 1.49 & .04 & .07226 & 1.43 \\
\hline Own home? & Nominal ${ }^{a}$. & .75 & .43 & .06 & .05474 & 1.19 \\
\hline Length of residence in area? & $\begin{array}{l}\text { Interva!/ } \\
\text { Class }\end{array}$ & 2.74 & 1.14 & .03 & -.01371 & -0.23 \\
\hline place of last residence in study area? & Nominal & .25 & .43 & -.01 & -.00345 & -0.08 \\
\hline Education of head of household? & $\begin{array}{l}\text { Interval/ } \\
\text { Class }\end{array}$ & 4.10 & 1.49 & .02 & .05064 & 0.99 \\
\hline Political and social attitudes & Ordinal ${ }^{b}$ & 1.87 & .71 & -.04 & -.03918 & -0.88 \\
\hline Income & $\begin{array}{l}\text { Interva1/ } \\
\text { class }\end{array}$ & 4.21 & 1.58 & -.02 & -.07238 & $-1 \cdot 31$ \\
\hline Sex male? & Nominala. & .35 & .48 & .05 & .05865 & 1.32 \\
\hline Occupation & Ordinal ${ }^{c}$ & 3.11 & 2.31 & .00 & .03464 & 0.64 \\
\hline $\begin{array}{l}\text { Origin } \\
-0.39161\end{array}$ & \multicolumn{3}{|c|}{$\begin{array}{c}\text { Multiple Correlation } \\
.122\end{array}$} & \multicolumn{3}{|c|}{$\begin{array}{c}\text { "F" Valued. } \\
0.77\end{array}$} \\
\hline
\end{tabular}

Notes: a. Coded positively on affirmative response.

b. Coded one through three from conservative to liberal.

c. Coded one through seven from high executives to unskilled employees.

d. Critical values of "t" and "ff" are 1.96 and 1.85 respectively, at $95 \%$ confidence level. 
TABLE XVI

ESTIMATING EQUATION FOR REGRESSION OF NOISE AWARENESS MEASURE WITH NOISE EXPOSURE VARIABLES (Block 4)

\begin{tabular}{|c|c|c|c|c|c|c|}
\hline Variables & Coding & Mean & $\begin{array}{l}\text { Standard } \\
\text { Deviation }\end{array}$ & $\begin{array}{l}\text { Simple } \\
\text { Corr. }\end{array}$ & $\begin{array}{l}\text { Beta Co- } \\
\text { efficient }\end{array}$ & "tt" Valueb. \\
\hline Distance from PIA & Interval & 4.37 & 2.08 & .03 & -.08888 & -1.88 \\
\hline Live in house? & Nominala. & .82 & .33 & -.09 & -.04560 & -1.05 \\
\hline Density of population & Interval & 8.71 & 4.69 & -.13 & -.19355 & -4.14 \\
\hline Distance from $30 \mathrm{NEF}$ & Interval & 32.96 & 25.12 & -.22 & -.20458 & -4.65 \\
\hline Home at night only? & Nominala. & .24 & .43 & .02 & .05014 & 0.79 \\
\hline Home day and night & Nominala. & .64 & .48 & .01 & .05143 & 0.80 \\
\hline Auto noise in dBA & Interval & 47.60 & 6.15 & -.02 & -.03460 & -0.82 \\
\hline \multicolumn{2}{|c|}{$\begin{array}{l}\text { Origin } \\
0.98888\end{array}$} & \multicolumn{3}{|c|}{$\begin{array}{c}\text { Nultiple Correlation } \\
.289\end{array}$} & \multicolumn{2}{|c|}{$\begin{array}{c}\text { "F" Valueb. } \\
6.73\end{array}$} \\
\hline
\end{tabular}

Notes: a. Coded positively on affirmative responses.

b. Critical values of "t" and "ff" are 1.96 and 2.03 respectively, at the $95 \%$ confidence level. 
In block three density of population per acre and distance from the $30 \mathrm{NEF}$ contour in meters were the only significant variables. Distance from the PIA in miles was marginally significant. A noteable aspect of the distance variable was its change from positive to minus after the effects of the NEF contours had been held constant. The simple correlation was yeakly positive, indicating an increase in noise awareness with distance. However, when the effects of aircraft noise exposure measured by NEF contours are extracted, then the relationship becomes negative, thus indicating as one would expect, that noise awareness declines with distance from the PIA. The narginal. significance of distance, at best a crude exposure variable, demonstrates that not all the variance in aircraft noise awareness associated with exposure has been accounted for. Attempts to neasure competing noise levels were only partially successful with population density seeming to account for screening by human noises. Heasurement of automobile noise was insignificant in predicting noise awareness as were type of dwelling and time spent at home.

Maps $A$ and $B$ in Appendix D show trend surfaces drived from respondents who mentioned in the survey that human noises were most noticeable or mechanical noises other than aircraft were most noticeable. The multiple correlation coefficient for human moises was .47 and for auto noises the multiple correlation coefficient was . 36 . Both have significant spatial trends suggesting a systematic variation, the cause of which can be isolated and measured. Density of population appears to be a suitable measure in explaining human noises but the explanation of automobile noise was unsuccessful. 
Block two includes variables designed to measure attitudes toward the airport, information concerning the airport and special interest. This block is comparable to factors one and two on Borsky's 1ist. ${ }^{3}$ As such they are measures primarily of annoyance and serve to predict awareness only in the sense that noise awareness is a component of noise annoyance. Since the noise annoyance component was not entirely screened out of the awareness measure, these variables were expected to be significant. All variables included in this block were significant with the exception of use of the river for recreation. Information, especially precise information about expansion plans, increased the response score. This was aiso true of having previously discussed aircraft noise problems. Approval of airport expansion plans was connected with a decrease in noise awareness. Special interest or voluntary exposure to noise as measured by the number of visits to the airport or the river adjoining the airport, deflated the awareness measure. Greater knowledge of airport operations and a negative attitude toward them is characteristic of highly annoyed respondents. This agrees with similar findings reported by TRACOR. 4 A high use of airport and surrounding facilities reflects a perception of the airport as a benign, necessary entity. This agrees with Borsky on the effect of institutional attitudes on noise annoyance. 5

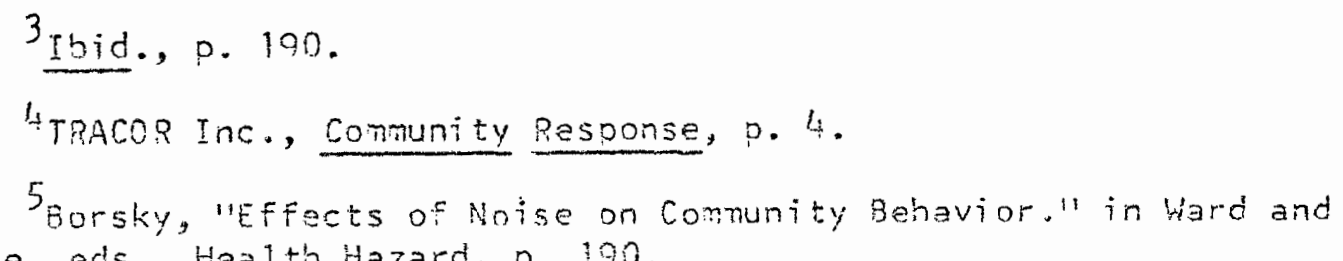
Friche, eds., Health Hazard, P. 190. 
Failure of the socio-economic variables to be of consequence reflects the hierarchical structure of noise response, where socioeconomic variables are only reflected in complaint. It also supports the results of the cross tabulations reported in Chapter III. Since variables of this sort are oftentines clustered in space, as indicated in Chapter III, several of them were continuad into the final model. Rationale for this was to determine if groups with higher socio-economic status might have selected areas of low noise exposure, thus biasing their responses toward low noise awareness. Inclusion with noise exposure variables would hold these effects constant. The three socioeconomic indicators: age, educztion and ownership of home remain insignificant after the noise exposure effects have been screened out. This is consistent with Mckennel and Hunt's study of central London. 6 Preliminary results revealed that frequency of noise and generai information on airport expansion became insignificant when combined With exposure variables so they were deleted. No argument could be made for the causality of discussing airport related problems so it was deleted. Density of population was found to be more effactive when used as an interaction term with automobile noise so the two measures were combined.

Among the significant variables were: three measure exposure, and three measure attitudes, and special interest. As expected, exposure variables have the largest "t values" and highest simple correlation:. Those variables neasuring the annoyance component within

GMckennel and Hunt, ioise Ainnoyance, P. II. 
TABLE XVII

ESTIMATING EQUATION FOR REGRESSION OF NOISE AWARENESS MEASURE NOISE EXPOSURE, ATTITUOINAL AND SOCIO-ECONOMIC VARIABLES

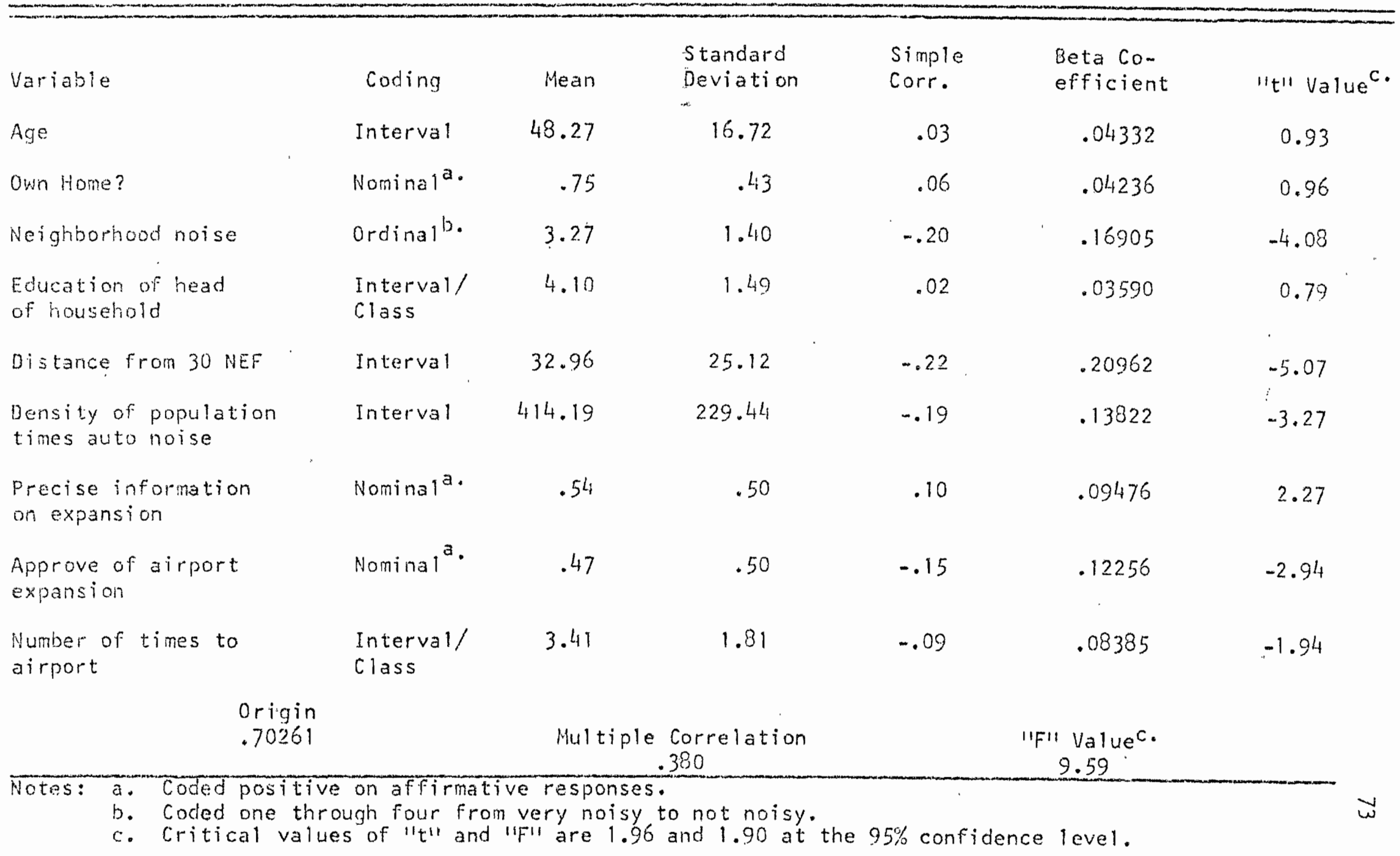


the dependent variable are lower than exposure variables. This is congruent with the specification of the factors that structure awareness of a noise source.

The variables in the final analysis behave as expected. However, the multiple correlation coefficient. is low, merely .38 . Only $14 \%$ of of the variance of the dependent variable is explained. The coefficient of determination resulting from the trend surface analysis was .34 . Under the assumption that this represents the real upper 1 imit due to specification and measurement errors in the dependent and independent variables, $20 \%$ still remains unexplained. This difference is suspected to occur in measurenent of exposure variables. Population densities were measured by Census Tract rather than on a smaller scale. Auto noises though the most commonly mentioned noi se source, viere not measured correctly. Elevation and terrain were unaccounted as was exposure to airport ground noise.

As is true of noise exposure neasures in general, the effort exerted in measuring further noise exposure variables would be beyond the threshold of diminishing returns. The planning criteria in considering the efficacy of the current exposure measures is not the increase in explanation that will be generated by nore detailed measurement. Rather it is: "Can the "true" response surface be approximated by the current set of variables?

The trend surface amalysis of the response to noise awareness has demonstrated that the response can be expressed as a measure of spatial association. Consequently, we can expect that as the variables which account for this surface increase in explanation, they will 
approximate this surface. Conversely, the residual values representing measurement errors and uninciuded variables should become random in space. A trend surface fit on the predicted values from the final regression analysis should reveal a spatial trend while a trend surface fit on the deviations from the predicted values should be low or insignificant.

Tables XVIII and XIX show the results of the trend surface analysis of the predicted and residual values. The correlation coefficient for the predicted values is .55; for the residual vaiues it is .22 . Both trends are significant. The trend of the predicted values is stronger. The very minor trend exhibited by the residuals comes in the area of clark county and at the edges of the NEF 30 contour. This represents the influence of variables not accounted for in the regression analysis. Figure 12 illustrates the trend surface of the pradicted values. It agrees well with the trend surface map of the actual values with the exception of Clark County. (See Figure 9).

\section{Summary of Chapter}

The results of Chapter $V$ were qualified in part by the data measurement problen isolated and discussed in Chapter IV. Despite these difficulties the specification of noise awareness with respect to noise annoyance and noise complaint seems to be substantiated. Woise awareness is as hypothesized specific to location. The degree of noise awareness varies regularly in space. Noise annoyance and noise complaint, specific to individuals vary randonly in space. The inability to accurately measure the three levels of noise 
TABLE XVIII

ESTIMATING EQUATION FOP TPEND SURFACE OF PREDICTED VALUES

FROM MULTIPLE REGRESSION OF NOISE AWARENESS

WITH NOISE EXPOSURE, ATTITUDINAL

AND SOCIO-ECONOMIC VARIABLES

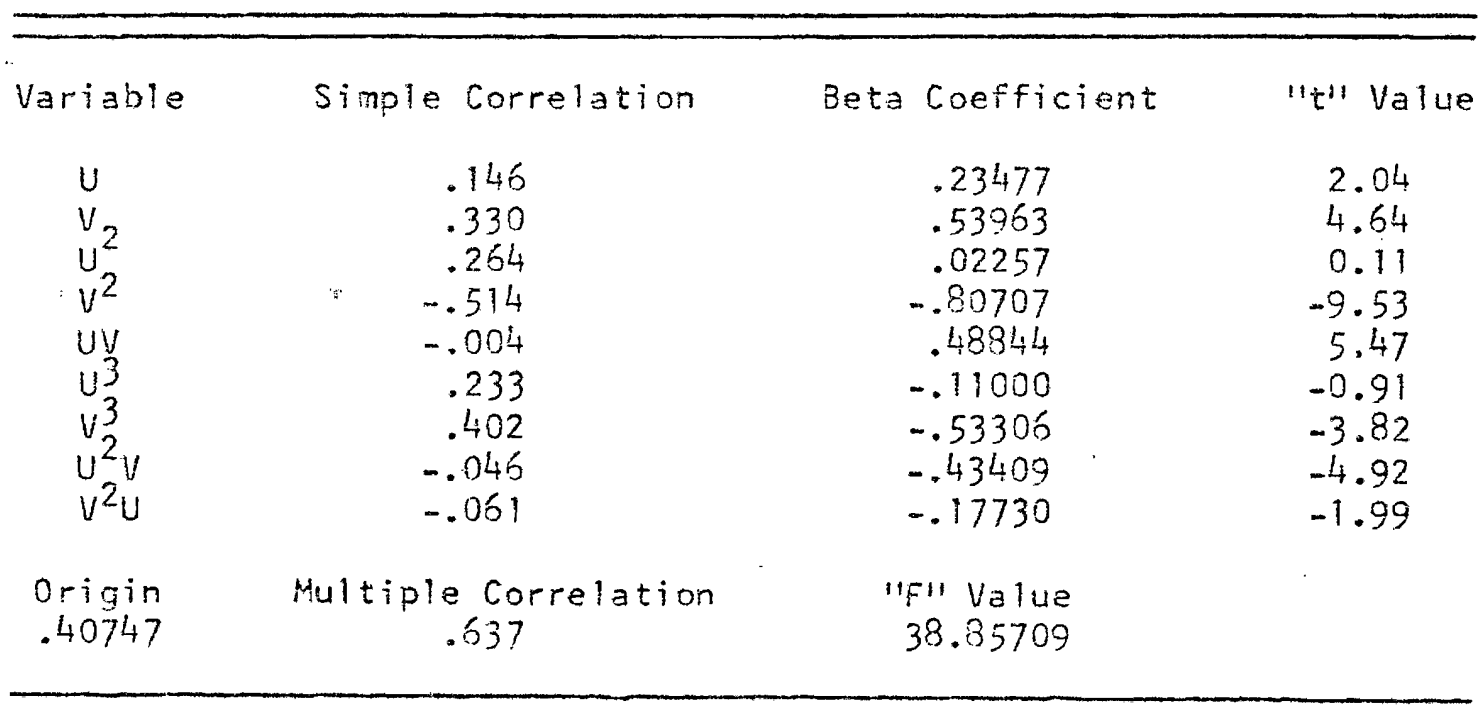

Note: The critical values for "t" and "F"l are the same as in Table $X$. 
TABLE XIX

ESTIMATING EQUATION FOR TREND SURFACE OF RESIDUAL VALUES

FROM MULTIPLE REGRESSION OF NOISE AWARENESS

WITH NOISE EXPOSURE, ATTITUDINAL

AND SOCIO-ECOHDMIC VARIABLES

\begin{tabular}{|c|c|c|c|}
\hline Variable & Simple Corralation & Beta Coefficient & "t" Value \\
\hline $\mathrm{U}$ & -.107 & .01371 & 0.09 \\
\hline$v_{0}$ & .147 & .24383 & 1.66 \\
\hline $\mathrm{U}_{n}^{2}$ & -.101 & -.20738 & -0.80 \\
\hline$v^{2}$ & -.080 &. .16230 & -1.51 \\
\hline UV & -.017 & -.02822 & -0.25 \\
\hline$u^{3}$ & -.127 & -.09025 & -0.35 \\
\hline$v^{3}$ & .134 & -.15033 & -0.86 \\
\hline$u_{3}^{2} v$ & .072 & -.13509 & -1.20 \\
\hline$v^{2} u$ & -.034 & .01857 & 0.16 \\
\hline $\begin{array}{l}\text { Origin } \\
.34145\end{array}$ & Multiple Correlation & "fel" Value & \\
\hline & .223 & 2.97008 & \\
\hline
\end{tabular}

Note: The critical values of " $t$ " and "f" are the same as in Table $x$. 


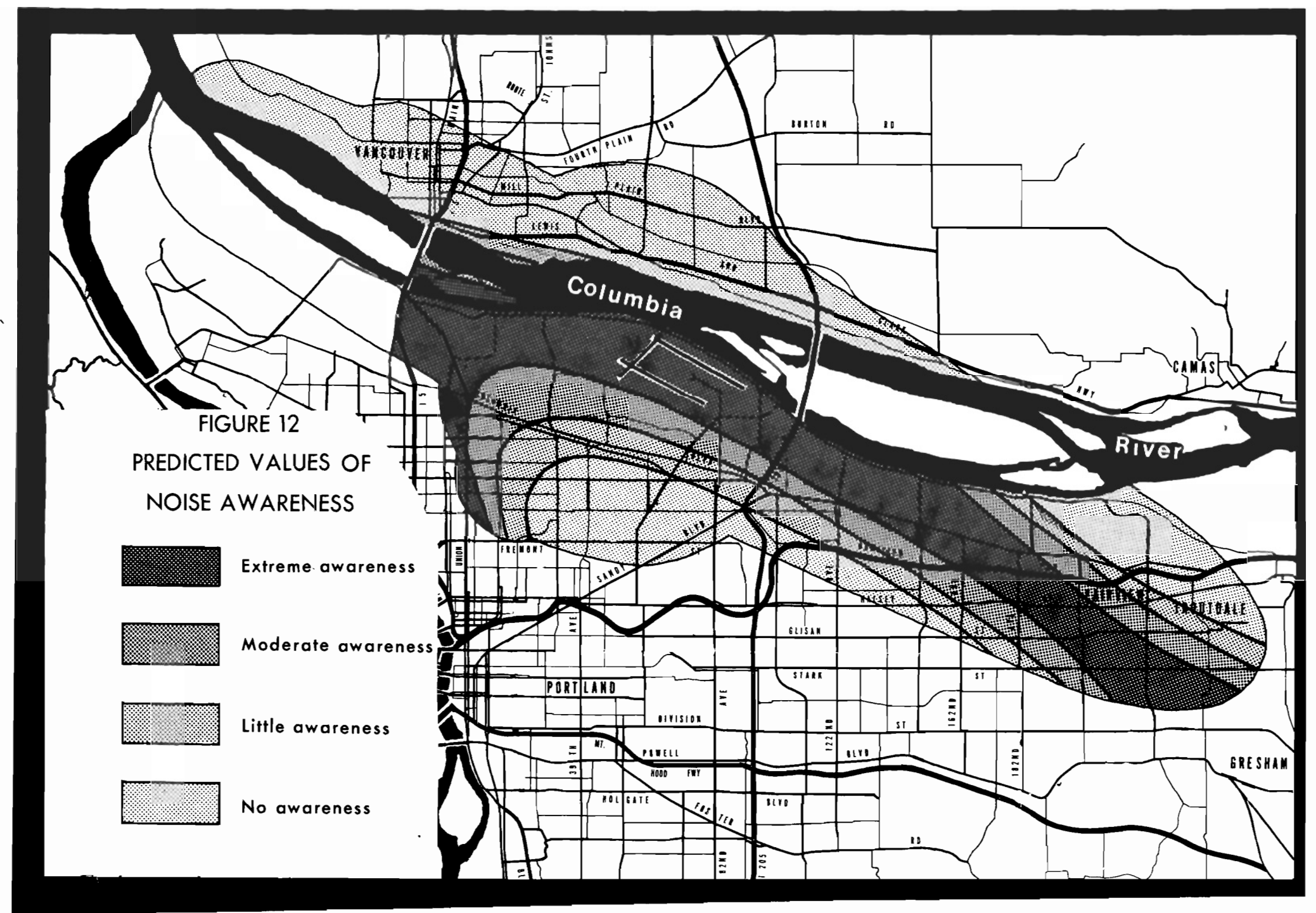


response hampered the analysis of the variables that structure noise - awareness. Hoise exposure and the ambient noise level at a given 10-cation were significant as expected. However, such variables as attitudes toward the airport, information about airport operations, and special interest were also significant. In all cases simple and multiple correlations were low, reflecting the limitations of this type of. survey data. Nevertheless, a map of noise awareness produced from noise exposure and attitudinal variables resembled the trend surface map of noise awareness. 
CHAPTER UI

\section{SUMMARY}

The basic objective of this paper has been methodological. In Chapter I the issue of the proper specification of community response to noise was raised. In previous research community response to noise has generally been measured in terms of annoyance. Sometimes complaint was given as an alternative response. Seldom had noise awareness been mentioned or investigated as a possible dimension of community noise response. Accordingly, the focus of the paper was on an in depth analysis of noise awareness as a dimension of community response to noise.

Three questions were asked with respect to noise awareness. They were:

(1) What is the relationship of noise awareness to noise annoyance and noise complaint?

(2) What are the factors that structure noise awareness?

(3) Does noise awareness form a spatially coherent pattern?

To answer these questions in Chapter II selected literature was reviewed from the standpoints of physical measurement of noise and of the psychological and sociological features of a communties' or individuai's response to noise

In the first instance noise measurement was traced from its basic physical characteristics to the sophisticated computer generated 
indices of aircraft noise exposure. Much past noise research has involved the establishment of a relationship between the measureable physical attributes of noise and human perceptions of these attributes. This research has resulted in a number of scales reputed to adequately measure human response to noise. These measures have been refined to measure specific noise sources. For aircraft noise, Perceived Noise Level (PML) and Effective Perceived Noise Level (EPNL) have been widely used. These in turn have been combined into fairly complex noise exposure indices which attempt to account for the spatial and temporal dimensions of a given sonic environment. The most elegant of these are Noise Exposure Forecasts (NEF) which attempt to approximate aircraft noise effects around airports.

Literature was cited, primarily from a TRACOR study, which shows that noise exposure indices correlate poorly with actual community annoyance over noise. This suggested that more factors structure community response to noise than indices of its physical presence.

In the second instance the psychological and sociological factors were discussed that create different responses between individuals, groups, and communities when exposed to equal noise levels. The literature was reviewed with respect to the three levels of response to noise. U. S. and British studies yere cited. The information derived from this review allowed a tentative specification of the factors that structure noise awareness and clarification of the relationship between

TraCoR Inc., Reaction to Airport Noise, p. 5.1. 
noise awareness, noise annoyance, and noise complaint. The relationship was conceived as pyramidal with awareness forming the-base, annoyance the middle, and complaint the top. The factors that structure each level are additive. Exposure to noise accounted for awareness. Exposure pius attitudes, susceptibility, and special interest accounted for annoyance, and all the preceding factors plus socioeconomic status accounted for complaint.

Once the factors assumed to structure noise awareness and the relationship of noise awareness to annoyance and complaint were hypothesized, they could be tested. Testing of these hypotheses was based on data derived from a survey conducted in conjunction with an environmental impact statement developed for a proposed expansion of Portland International airport.

The survey"was conducted in an area surrounding the airport. The extent of this area was roughly one nile beyond the thirty NEF contour. Population inside this boundary in 1970 was 134,000, of which only 3.3 percent lived within the thirty NEF contour. This figure is far lower than for other survey areas such as Heathrow Airport, London or Logan Airport, Boston, thus relatively little variation in airport noise exposure existed within the sanple.

The basic reason for comparatively low noise exposure was land use in the survey area. The predominant land use feature was the columbia River flood plain where the airport is located and where due to poor drainage and flooding no extensive residential development has taken place. A secondary land use feature was the wide range in age of housing stock encompassed by the survey area; varying from high 
density, pre-1900 in the western portions of the survey area to low density post-1960 in the eastern portions. In general socio-economic status varied accordingly from low to high on a west to east trend. From this analysis it was expected that people in the western sector of the survey area would be more exposed to competing human and mechanical noises, and that the highar socio-economic groups to the east would be more likely to complain.

The survey was conducted under the auspices of the Dortland State University Population Research and Census Center. It consisted of a sample of 523 households. The households were randomly selected. The number of selections in a given area was equal to the proportion of population that area contributed to the total population of the survey area.

The results from the survey were examined. They tended to support previous research on community response to noise. The best indicator of awareness of aircraft noise was distance from the NEF contours. As noise exposure increased, ablareness of aircraft noise increased. Most socio-economic indicators such as age, sex, income and education were weak or poor indicators of notice of aircraft noise. However, the fact that there were consistent differences between the Vancouver, South, Southivest and Southeast sectors of the survey area under conditions of equal noise exposure suggested that noise exposure was not the only systematic factor affecting communty noise response.

Chapter IV dealt with the problem of neasuring individual response to noise in a manner suitable for multiple regression analysis. Initially, the chapter addressed the conflict apparent in the literature 
over whether number of activities annoyed or type of activities annoyed constitutes the proper measure of noise response. This conflict is resolved by noting that activities observed to produce considerable annoyance when interrupted are difficult to interrupt. Activities with which little annoyance is associated are easily interrupted. The consequence is that a high probability exists that someone annoyed over sleep interruption will also mention interruption of TV watching or conversation though the latter two produce little annoyance.

This regularity allows scales of annoyance and of noise response in general to be developed. These scales are calibrated to the number of activities interrupted by noise. The greater the number of activities interrupted, the greater the individual noise response. Such a scale was used to measure individual response to noise in the PIA survay. However, in a departure from previous studies such as those perforned in Britain or the U.S. the questions were framed in terms of awareness rather than in terms of annoyance or complaint. Consequently, given that individual response to noise is multi-level, consisting of awareness, annoyance, and complaint, then a general response would contain all three levels. Since these levels are structured by different but additive sets of variables, then any measure of noise response which does not separate then will lead to poor correlations and perhaps nisleading conclusions.

Through the use of principle components: analysis which allows isolation and extraction of highly correlated trends from a data set, an attempt was made to disaggrejate the noise response questions in the PIA survey into the hypothesized levels of awareness, annoyance, 
and complaint. Four major factors were extracted. The first two relate primarily to awareness of noise, the third to complaint, and the fourth to annoyance. These factors were identified by noting their correlations with questions concerning the type of activities interrupted, attitude toward the airport, fear of crashes, etc. 'By comparing these correlations to the previous research on noise awareness, annoyance, and complaint tentative identification of the factors was made.

On an a priori basis it was known that the annoyance factor should be a larger factor than complaint. This was not the case. In addition a number of questions associated with annoyance correlated with the awareness factor. For these reasons it was assumed that the annoyance response was distributed within the awareness factor as well as the annoyance factor. Any subsequent measurement of awarenass based upon the awareness factor would include a component of annoyance as we11. This would detract from the accuracy of any multiple regression analysis.

Chapter $y$ addressed the questions raised in Chapter I regarding the spatial coherency of the noise awareness response, its relationship to annoyance and complaint and the factors that structure it. From the working hypothesis, established in Chapter I, that the factors which structure noise awareness are specific to location and the factors that structure annoyance and complaint are increasingly less so, the relationship of noise awareness to annoyance and comolaint was established. Factors specific to location have the property of spatial contiguity-values vary regulariy in space. Factors specific 
to individuals will not necessarily have that property; hence a measure of spatial association will be fairiy accurate for noise awareness but decreasing in accuracy for annoyance and complaint which are primarily structured by individual attitudes independent of location.

Using measures of noise awareness, annoyance and complaint derived by the methods discussed in Chapter IV the hierarchical, pyramidal relationship of noise awareness to noise annoyance and complaint was tested statistically. The results confirmed the predictions derived from the hypothesis. The degree of spatial contiguity declined from awareness to annoyance to complaint; the last of which was found to be random in space. This result established the general outline of the relationship between awareness, annoyance, and complaint.

The second part of Chapter $V$ investigated the specific factors which structure noise awareness. From chapters I and II these were hypothesized to be exposure variables, specific to location. The previous analysis confirmed that the variables which structured noise awareness varied by location. However, the nature of these variables was unknown.

Using the measure of noise awareness explained in Chapter IV as the dependent variable, a number of variables were correlated with it to evaluate their importance in explaining noise awareness. These variabies, numbering thirty in al1, were taken from the PIA survey data, census data, noise exposure maps and vehicle traffic volume data. These variables were broken into four categories. They were: (1) environmental attitudes, (2) airport attitudes, special interest, and information sources, (3) socio-economic indicators, and (4) noise 
exposure indices.

In category one, environmental attitudes were not significant in explaining noise awareness. In fact peopie who were more aware of noise tended to have positive attitudes toward their neighborhood's environment. Conversely, they tended to be critical of the city-wide enviromment. The only clearly significant variables in this category were neighborhood noise level and frequency of noise. With the effects of more explicit environmental attitudes held constant these are indicators of noise exposure and susceptibility to noise rather than environmenta 1 attitudes.

In category two, variables concerning level of information, attitude toward the airport, and special interest were all significant in explaining noise awareness. Hone of these variables directly measure noise exposure. Also their significance is contrary to the assumption that noise awareness is a function of noise exposure.

This anomaly is explained by the observation from Chapter IV that the noise awareness measure is imperfect, containing a certain degree of noise annoyance within $i t$. This assumption is substantiated somewhat by previous research which notes that attitudes toward the noise source, infornation sources and special interest effect the degree to which one is annoyed by a particular noise.

As suggested from the survey results reported in chapter III, sociomecononic variables were insignificant in explaining noise awareness. Neither age, number of people in household, education, political attitudes, ircome, sex or occupation were significant. This agrees with the hypothesis on the factors which structure noise 
awareness. It also agrees with the results of previous researchers.

Such variables as home ownership, length of residence, and place of previous residence were also insignificant in category three.

This would indicate that conditioning factors such as time or contrast with previous environment have no effect on noise awareness.

In the fourth category, noise exposure variables, two variables were significant. These were density of population and distance away from the thirty NEF contour. The greater the population density and the greater the distance away from high airport noise exposure areas, the less aware one is of airport noise. Other exposure variables such as dwelling type, time spent at home, and vehicle traffic noise were insignificant.

The significant variables in each category were continued into a final analysis. Again the results were much the same as in the earlier analyses. Three noise exposure variables: distance from thirty NEF, noisy neighborhood, and population density were significant. An attitudinal and an information variable were also significant, but their role in explaining noise awareness was not large. This is consistent with the assumption that the noise awareness measure contains a systematic disturbance associated with noise annoyance.

Difficulties in properly measuring noise awareness and the variables hypothesizad to structure it kept correlation coefficients low throughout the analysis. The correlation coefficient of .59 between noise dwareness and its locational coordinatos was the highest. In contrast in the final analysis the correlation coefficient between noise avareness and the five variables which structured it was but .39 . 
The correlation coefficient of .59 between noise awareness and its locational coordinates was taken as the systematic part of the noise awareness measure. This was the part that could be measured free of random and systematic errors. If the five variables isolated in the final analysis best explained noise awareness, then they should be able to approximate the systematic part of the noise awareness response surface. Maps were made of both the response surface predicted from the locational coordinates and from the five variables which best explained noise awareness. The two maps agreed well with the exception of the Vancouver area. This disagreenent is probably caused by noise exposure factors such as terrain and elevation that have been unaccounted for.

The spatial regularity of noise awareness values predicted by the five variables was also evaluated. A strong spatial trend was evident. The error vaiues, derived by subtracting the predicted values from the actual noise awareness values, had only a weak spatial trend. This indicates that much of the spatially coherent part of the noise awareness response surface was explained. Combined with the results of the first section of chapter $V$ this allows the conclusion that:

(1) Noise awareness is specific to location.

(2) Noise awareness is chiefly explained as a function of noise exposure.

Conclusion

The following figure represents the basic results of the paper. 


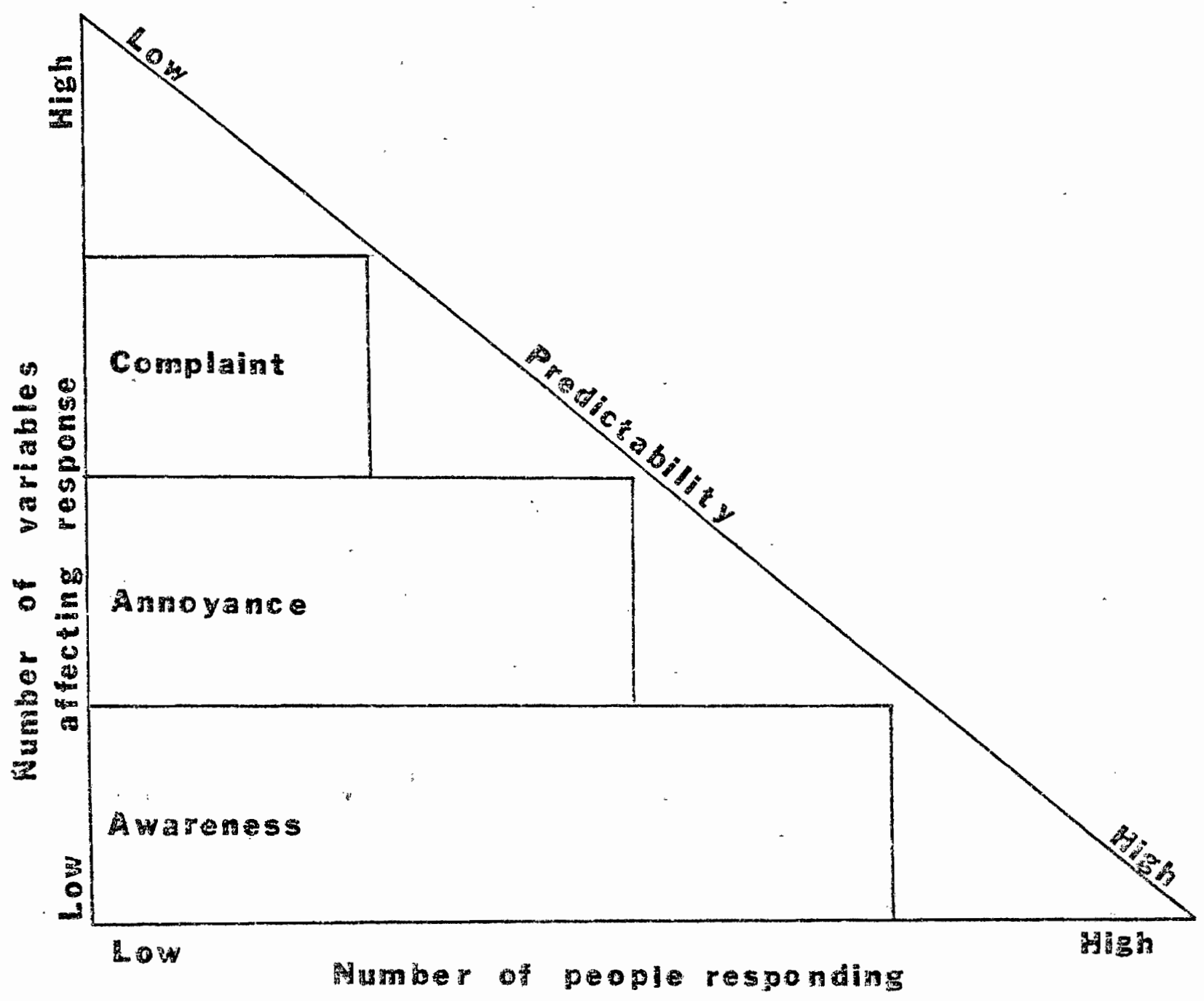

Figure 13: Salient features of the hierarchy of noise response. 
Response to a noise source can be specifiad as a hierarchy, pyramidal in shape, and with three stages: awareness, annoyance, and complaint. The factors which account for each stage are additive and increasingly specific to individuals. The result is that as the level of the hierarchy increases less people respond, the spatial regularity of the response decreases, and the response becomes less predictable. Noise awareness is explained by noise exposure variables. Noise exposure indices such as Noise Exposure Forecasts (NEF) with a correction for ambient noise levels adequately approximate the noise awareness response surface. There is no indication that such variables used alone are of much value in explaining noise annoyance and complaint. Their only value is in delimiting the area of noise awareness wherein a certain number of people may be annoyed or complain about noise. 
Beranek, L. "General Aircraft Noise." Noise as a Public Health Hazard. Edited by $D$. W. Ward and J. E Friche. Wastington D. C.: The American Speech and Hearing Association, 1969.

Berland, T. The Fight for ouiet. Englewood Cliffs, New Jersey: Prentice $\mathrm{Ha} \overline{11}$ 1970.

Berry, B. J. L.: Horton, F. E. Geographic Perspectives on Urban Systems. Englewood Cliffs, New Jersey: Prentice Hal1, 1970.

Blalock, H. M. Social Statistics. New York: MeGraw Hill Book Co. Inc., 1960.

Bishop, D., and Simpson, $M$. Noise Exposure Forecast Contours for 1967 , 1970 , and 1975 Operations at Selected Airports. Van Nuys,

California: Bolt, Beranek and Newman, Inc., 1970.

Bolt, Beranek and Newnan, Inc. Noise Environment of Urban and Suburban Areas.: Wasinington $D$ C.: Housing and Uraan Development, 1967.

Bolt, Beranek and Newman, Inc. Logan Airport Environmental Impact Study. Boston: Bolt, Beranek and Vewman, 1971.

Borsky, $P$. "Some of the Human Factors Underlying Community Reactions to Air Force Noise." Sth Annual Meeting of the Armed Forces. National Research Council Comittee of Hearing Acoustics. Washington, D. C.: U.S. Gcvernnent Printing office, 1950.

Borsky, P. "Effects of Noise on Commity Behavior." Noise as a Public Health Hazard. Edited by D. W. Ward and J. E. Friche. Washington, D. C.: The American Speech and Hearing Association, 1969.

Botton, C. 0.; Walters, D M. A Social Survey into Annoyance Caused by the Interaction of Aircraft Noise and Traffic Noise. London: Loughorough University of Technology, 1971.

Bureau of Municipai Research and Service. Portland-Vancouver Hetropolitan Transportation Study, interim Report I-205 Location, Social-Economic Study. Salem, Oregon: Oregon State Highway Coninission, 1964 .

Chorley, R J.; Haggett, P, Mrend Surface Mapping in Geographical Research." Transactions and Papers of the Institute of Britisin Geographers, 37, (1955), 47-67. 
Cohn, A. "Effects of Noise on Psychological State." Noise as a Fublic Health Hazard. Edited by D.W Ward and J. E Friche. Wasinington, D.: The American Speech and Hearing Association, 1969.

Columbia Region Association of Governments. 1970 Census: Population and Housing. Portland, Ore.: Columbia Region Association of Governments, 1971.

Cooley, H. W.; Lohnes, P. R. Multivariate Data Analysis. New York: John Wiley and Sons, $1 9 7 \longdiv { \text { . } }$

Coombs, C H.; Dawes, R. M.; Tversky, A. Mathenatical Psychology. Englewood Cliffs, New Jersey: Prentice Hall, 1970 .

Flanagan, J.; Levitt, $H$. "Speech Interference from Community $\mathrm{N}_{0}$ ise." Noise as a Public Heal th Hazard. Edited by $D W$ Ward and J. E. Friche. Wastington D.C.: The American Speech and Hearing Association, 1969.

Gebman, J. The Mechanics of Forecasting the Community Noise Impact of a Transportation Systern. Santa Monica, Calif.: Rand Corp., 1971.

Gierke, H. von. "lopening Remarks." Noise as a Public Health Hazard. Edited by D. W. Ward and J. E. Friche. Washington D. C.: The American Speech and Hearing Association, 1959.

Great Britain, Dépt. of Trade and Industry. Second Survey of Aircraft Noi se Annoyance Around London (Heathrow) Airport. London: Her Majesty's Stationery office, 1371.

Griffith, I. D.; Langdon, F J. HSubjective Response to Road Traffic Noise." Journal of Sound and Vibration, 8, (1959), 16-32.

Guilford, J. O. Psychometric Methods. New York: McGraw Hill Book Co. Inc., 1954.

Jennings, R. "Psychology Section." Socio-Economic Study, Exinibit III, Environmental Impacts, Portland International Airoort Expansion. Portland, Oregon: Port of Portland, 1972.

Jerome, A.; Nathanson, J. "Socio-Economic Implications of Airport Planning." Ekistics, 33, (1972), 30-35.

King, L. J. Statistical Analysis in Geography. Englewood Cliffs, New Jersey; Prentice HaT1, 1969.

Kryter, K. 0. The Effects of Noise on Man. New York: The Academic Press, $19 \overline{70 .}$ 
Lycan, R.; Durdan, S.; Dawson, R. "Land Use Section." Socio-Economic Study, Exhibit III, Environmental Impacts, Portland International Airport Expansion. Portland, Oregon: Port of Portland, 1972.

Mckennell, A.; Hunt, R. Noise Annoyance in Central London. London: Her Majesty's Stationery Office, 1960.

McGrath, D. C. Multidisciplinary Environmental Analysis: Janaica Bay and Kennedy Airport." Ekisties. 33, (1972), 20-26.

Massey, $W$ F. Mpinciple Components Regression in Exploratory Statistical Research." Journal of American Statistical Association, $60,(1965), 234-256$.

Metropolitan Planning Commission. Commercial Patterns. Portland, Ore.: Metro. Planning Commission, 1902.

Metropolitan Planning Comission. Population and Housing. Portland, ore.: Metro. Planning Connission, 1963.

Oregon State Highiway Commission. Portland Vancouver Metropolitan Transportation Study: Factual Data Report.

Portland City Planning Connission. Historic Annexation Map: Portland Ore. Portland, Ore.: Planning Commission, 1964.

Rodda, M. Noise and Society. London: 01 iver and Boyd, 1967.

Rudinose, W. "Primer on Methods and Scales of Noise Measurement." Noise as a Public Health Hazard. Edited by D. W. Ward and J. E. Friche. Washington D. C. The American Speech and Hearing Association, 1969.

Shepard, $R$ N. "The Analysis of Proximities: Multidimensional Scaling with an Unknown Distance Function," Psychometrika, 27, (1962), $125-140,219-246$.

Soroka, W. W. "Community Noise Surveys." Noise as a Public Health Hazard. Edited by D. W Ward and J. E. Friche. Washington D. C.: The American Speach and Hearing Association, 1969.

Stevens, S S. "On Quantitative Evaluation of Noise." Transportation Noises: A Symposium on Acceptibility Criteria. Edited by J. D. Chalupnik. Seattle, Wish.: University of Washington Press, $1970^{\circ}$

Tintner, G. Econometrics. New York: John Wiley and Sons, Inc., 1952.

Torgerson, $U s$. Theory and Mathods of Scaling. New York: John Wiley and Sons, Inc., 1953 . 
TRACOR, Inc. Community Reaction to Airoort Woise. Washington $D$ C.: National Aeronautics and Space Adininistration, CR $1761,1971$.

U. S. Federal Council for Science and Technology: Committee on Environmental Quality. Noise: Sound without Value. Washington D. C.: U. S. Government Printing office, 1968.

U. S. Panel on Noise Abatement. The Noise Around Us: Findings and Recommendations. Hashington $0 . \overline{C .:}$ Dept. of Commerce, 1970.

Washington State Highway Comission. Traffic Report, 1970. Olympia, Wash.: Washington State Highway Dept., 1971.

Weiss, J E.; Cressler, D.; Haggerty, I. "Sociology Section." SocioEconomic Study, Exhibit III, Environmental Impacts, Portland International Airport Expansion. Portland, Oregon: Port of Portland, 1972.

Wilson, A. Noise: Final Report. London: Her Majesty's Stationery office, 1963. 
APPENDIX A

The Survey Questionnaire 
PORTLAND STATE UNIVERSITY

Urban Studies

Field Interview Series

CPRC Study Number 42

Social Impact - Noise

Questionnaire No.

Interviewer 
1. Who is the head of this household?

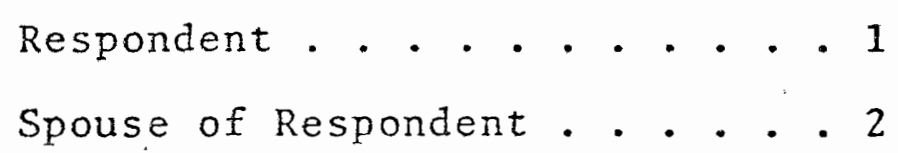

2. How would you rate the Portland area as a place to live?

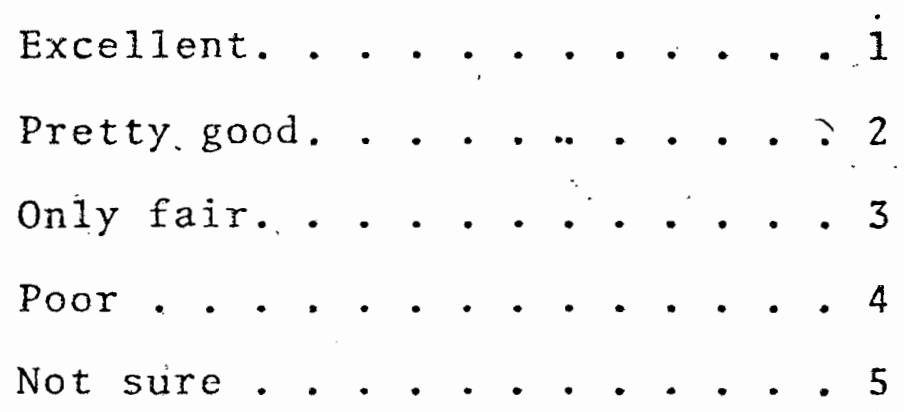

3. How would you rate the immediate area around your home as a place to live?

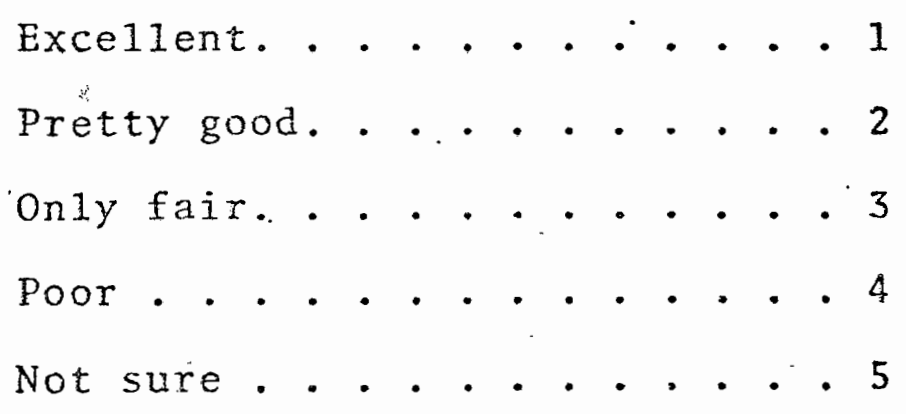

4. Since you have been living in this immediate area do you feel that it has become better, worse, or stayed about the same?

Become better. . . . . . . 1

Become worse........ 2

Stayed the same. . . . . . 3

Not sure......... 4 
5. Is the immediate area around your home:

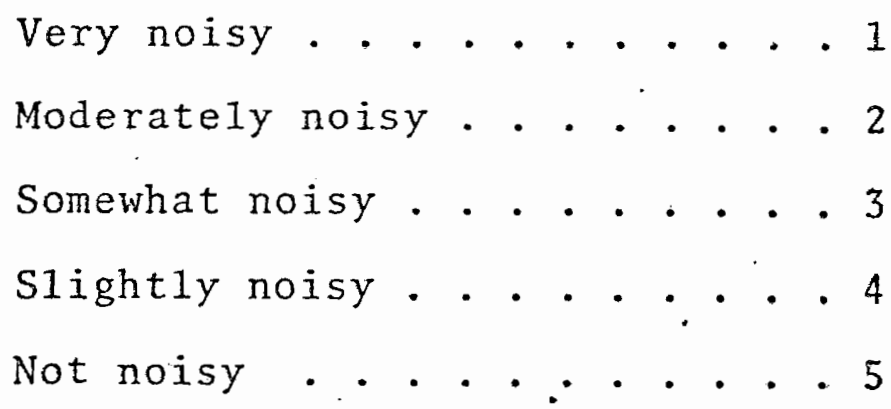

6. How does this compare with the noise level when you first moved to this address?

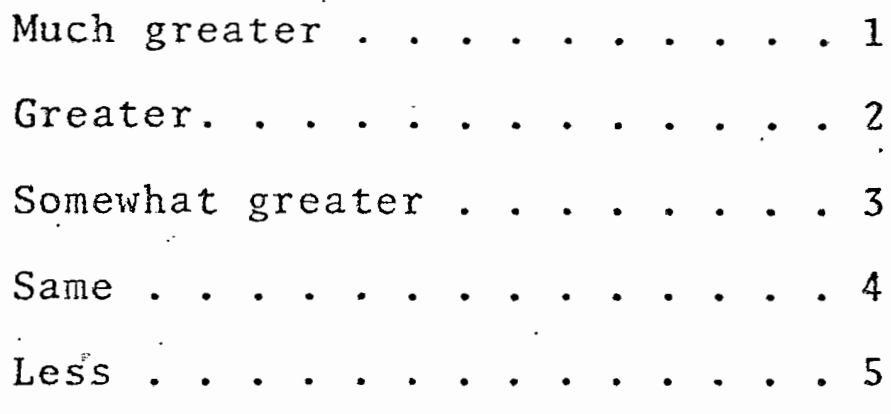

7. Is it noisier around here, or where you work?

Home . . . . . . . . . . 1

Work . . . . . . . . . . 2

No difference. . . . . . . 3

8. Which bothers you more--noise at home or noise at work?

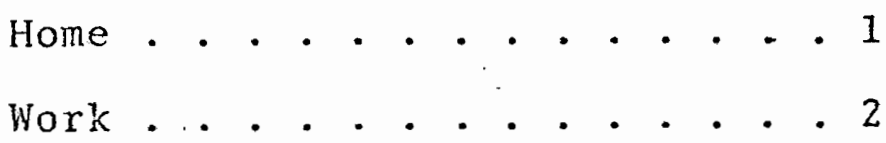

9. Which of the following noises do you notice most around your home?

(SHOW CARD "A". RECORD RESPONSE 
10. Is it the same as when you first moved here?

$$
\begin{aligned}
& \text { Yes. . . . . . . . } 1 \text { (IF YES, SKIP TO Q. 12) } \\
& \text { No . . . . . . . } 2
\end{aligned}
$$

11. If no, what was the most noticeable noise when you first moved here?

12. How often do you hear it?

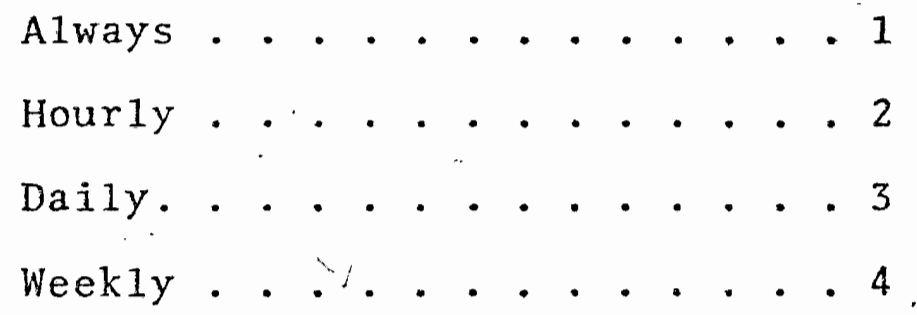

13. Have any noises ever interrupted or disturbed your:

a. Conversations

b. Phone conversations

c. Sleep

d. TV reception

e. Work

f. Entertaining

g. Hobbies

h. Walks

i. Other

[IF YES, ASK "WHICH NOISE?" (FROM CARD "A")] 
14. What are some of the features of the area around your home that you $1 \mathrm{ike}$ ?

(DO NOT READ LIST!)

Schools............ 1

Parks............ 2

Shopping . . . . . . . 3

Proximity to work. ..... 4

others

15. What are some of the features of the area around your home that you don't l'ike?

1 .

2 .

3 .

4 .

5 .

16. Do you want to move from this neighborhood?

(RECORD ANY ELABORATION BY RESPONDENT.)

Yes............. 1

No........... 2 (IF NO, SKIP TO Q. 18)

17. If yes, why? 
18. What hours of the day are you usualiy home?

1

Weekdays

A.M.

P.M.

Both
2

Weekends

A.M.

P.M.

Both

19. Have you heard about plans for expansion of Portland Airport?

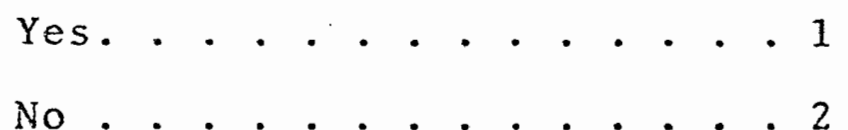

No........... 2 (IF NO, SKIP TO Q. 22.)

20. (IF YES TO ABOVE, ASK:) What have you heard?

21. Do you approve of these plans you have heard of?

Approve. . . . . . . . . . 1

Neither approve nor

disapprove... . . . . . 2

Disapprove . . . . . . . 3

Don't know........ 4

22. Do you think the Portland Airport should be expanded now?

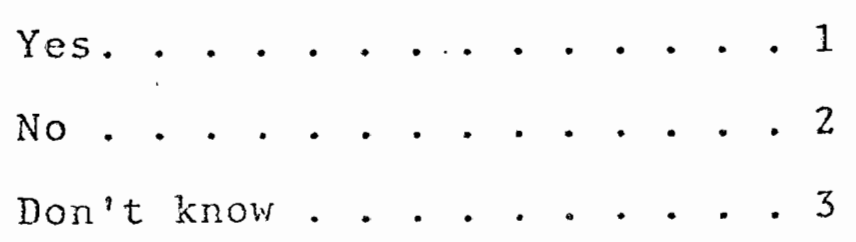

Several different plans have been proposed. I would now. like to briefly explain them to you. (READ CARD "B") (SHOW CARDS "C", "D", "E", AND "F" AND DESCRTBR..) 
23. Which of the following is the best overall plan for the Portland Airport?

(FROM CARD " $\mathrm{B}$ ")

$$
\begin{aligned}
& \text { Paragraph 1 . . . . . . . . } 1 \\
& \text { Paragraph 2......... } 2 \\
& \text { Paragraph } 3 \text {. . . . . . . } 3 \\
& \text { Paragraph } 4 \text {. . . . . . . } 4 \\
& \text { Paragraph } 5 \text {. . . . . . } 5 \\
& \text { Other (WHAT? - PROBE) . . . } 6
\end{aligned}
$$

24. Why do you favor this plan?

25. In any one-year period, how many times do you go to the airport for any reason whatsoever?

$$
\begin{aligned}
& 0 \text {. . . . . . . . } 1 \\
& 1-2 \text {. . . . . . } 2 \\
& 3-4 \text {. . . . . } 3 \\
& 5-6 \text {........ } 4 \\
& 7-8 \cdot . \cdot . \cdot . \cdot 5 \\
& 9+. . . \cdot . \cdot .6
\end{aligned}
$$

26. What is your usual reason for going to the airport?

F1y. . . . . . . . 1

Meet or deliver

passengers. . . . . 2

Other (Specify).... 3 
27. Do you use the Columbia River or islands opposite the airport
for recreation?

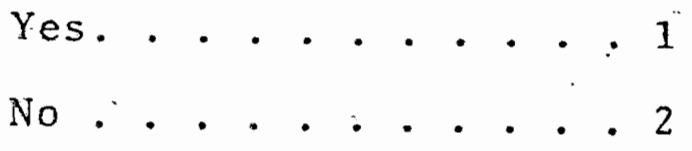

If yes, specify:

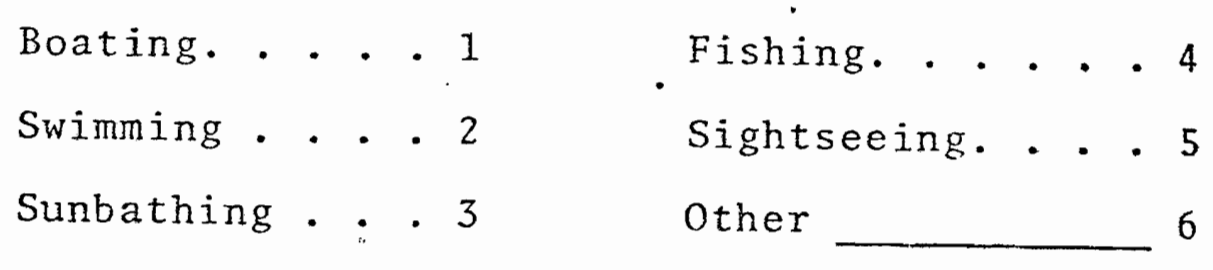
28. Who do you think should have the most to say about airport
plans?

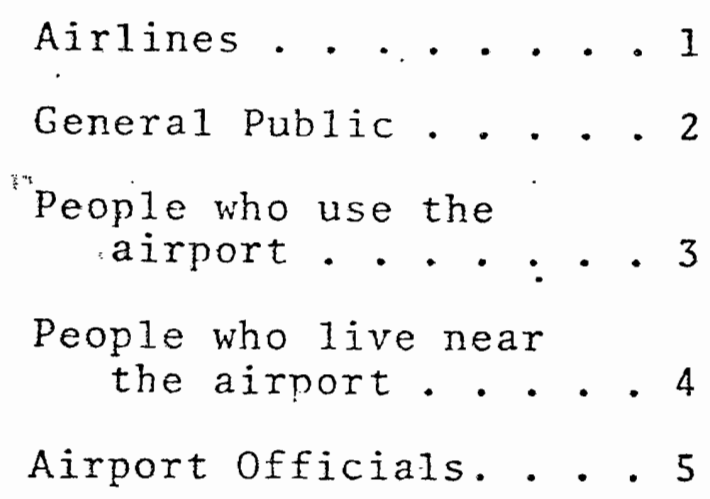

29. When at home, do you find vibrations from passing planes:

Very disturbing. . . . . 1

Disturbing . . . . . 2

Hardly disturbing. . . 3

Not at a11 disturbing. . 4 
30. Have you ever noticed oil films deposited by passing planes around here?

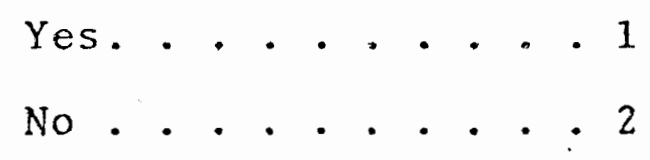

31. Have you ever smelled kerosene fuel from passing planes around here?

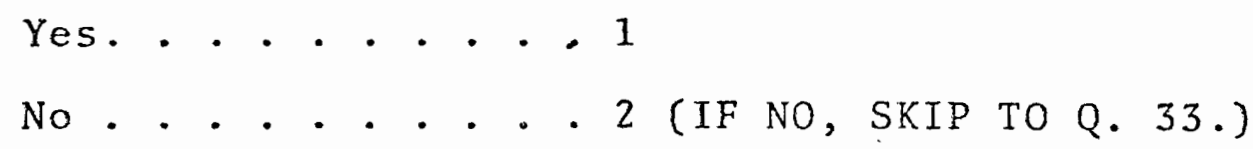

32. About how often?

33. Have passing planes ever caused damage to your home?"

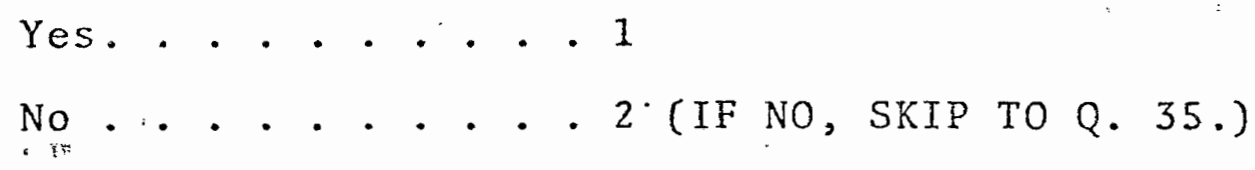

34. Approximately how much damage resulted?

$$
\begin{aligned}
& \$ 0-\$ 99 \text {. } \quad \text {. . . . } 1 \\
& \$ 100-\$ 299 \text {. . . . } 2 \\
& \$ 300-\$ 499 \text {. . . . } 3 \\
& \$ 500 \text { - over . . . . } 4
\end{aligned}
$$

35. Do you worry about planes crashing into your home?

$$
\begin{aligned}
& \text { Yes. } \cdot \text {. . . . . } 1 \\
& \text { No . . . . . } 2
\end{aligned}
$$

36. Did you worry about crashes when you first moved to this address?

$$
\begin{aligned}
& \text { Yes. . . . . } 1 \\
& \text { No... . . . } 2
\end{aligned}
$$


37. Have you talked to anybody about problems from airplanes taking off and landing at the airport?

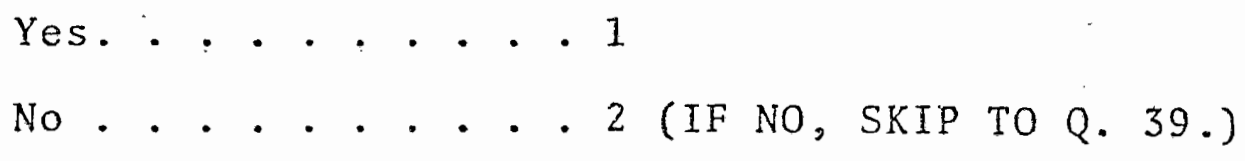

38. (IF YES TO ABOVE, ASK:) TO WhOm? (CIRCLE ALL MENTIONED)

Neighbors. . . . . 1

Friends. . . . : 2

Family...... 3

Airport officials. . 4

Politicians. . . . 5

Others...... 6

39. Would you complain about any of these problems?

Yes. . . . . . . 1

No....... 2 (IF NO, SKIP TO Q. 41.)

40. (IF YES TO ABOVE, ASK:) TO whom would you complain?

City officials . . . 1

Airport officials. . . 2

Environmental groups . 3

Airlines... . . 4

Other....... 5

41. Who is the main wage-earner of this household?

Respondent . . . . 1

Spouse of Respondent . 2

other ...... 3 
42. Are you (he/she) currently working:

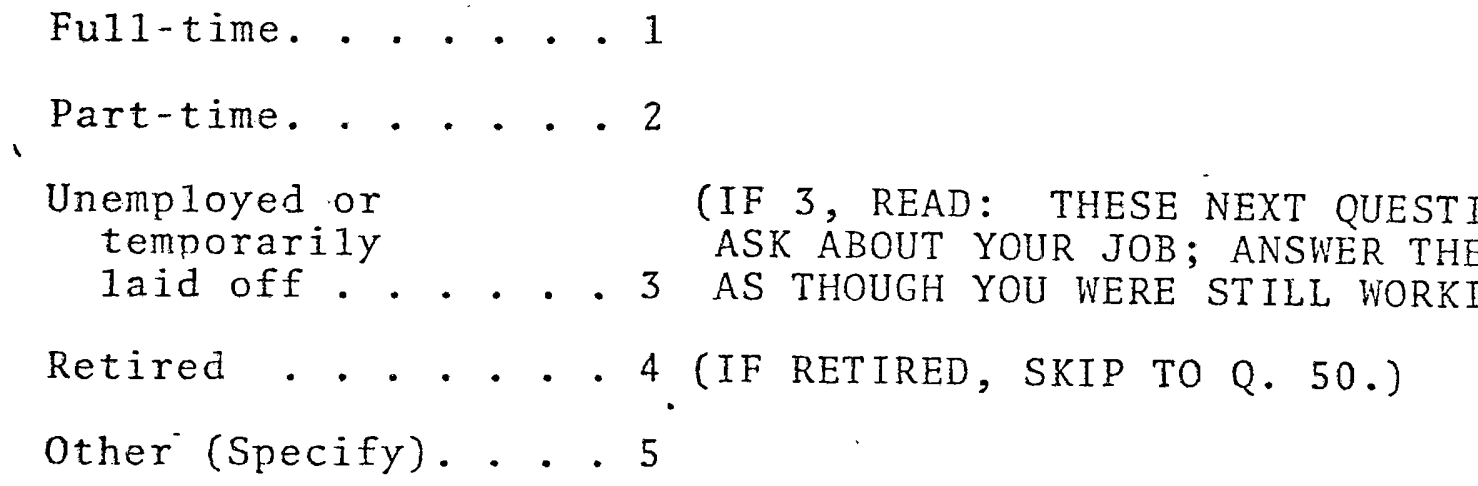

43. What type of business, company or organization do you work for (what do they do or make there?)?

$$
\begin{aligned}
& \text { Self-employed . . . } 1 \\
& \text { Other (Specify) . . } 2
\end{aligned}
$$

44. What is the address where you work?

45. (DO NOT ASK IF SELF-EMPLOYED) What is your specific job where you now work? (What is it you do there?)

46. How long have you been working there? weeks, OR, months, OR, years. 
47. How far do you live from your work? Would you say less than a mile, one to two miles, three to five miles, six to ten miles, or over ten miles?

(IF R. WORKS OUT OF HOME OR TRAVELS ON THE JOB, CIRCLE "g" AND SKIP TO Q. 50.)

Less than one mile... . 1 1 - 2 miles. . . . . . 2

$3=5$ miles .... . . . 3

6 - 10 miles...... 4

Over 10 miles..... 5

Not applicable......9 (SKIP TO Q. 50.)

48. How do you get to work?

Own car.......... 1

Drive in a car pool

or share ride with

another. . . . . . . 2

By bus . . . . . . . 3

Other (Specify)...... 4

49. About how long does it take you to get to work?

Under 10 minutes . . . . 1

10 - 30 minutes. . . . . 2

Over 30 minutes. . . . . 3 
50. What organizations do you belong to? (RECORD ANY BY NAME AND IF NOT OBVIOUS, ASK:) What kind of organization is that?

(IF MORE THAN 3 GIVEN, ASK:) Which 3 are most important to you? NAME NAME NAME

51. How many years have you been a member of (organization)?

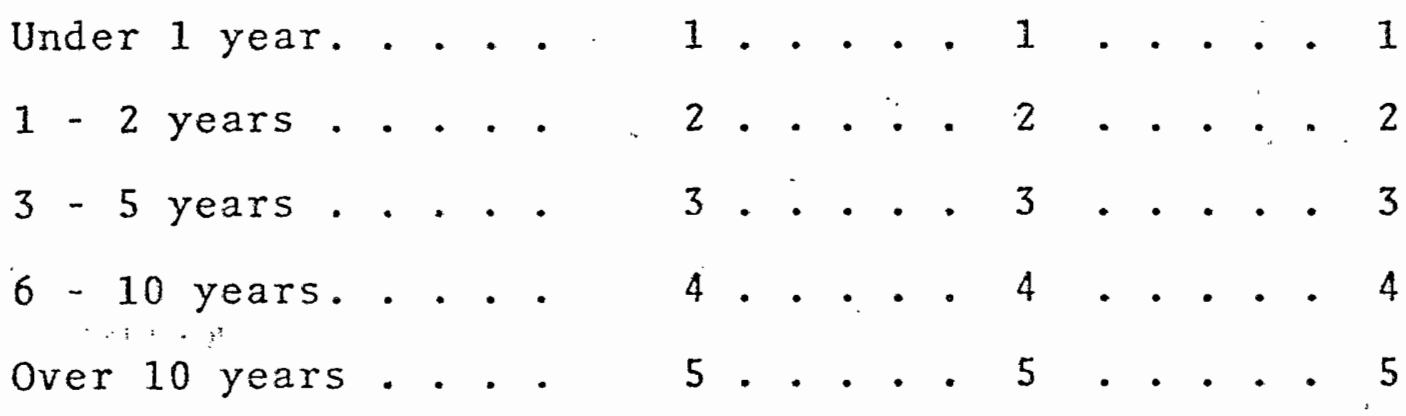

52. How often do you attend (organization) meetings-regularly, occasionally, seldom, or never?

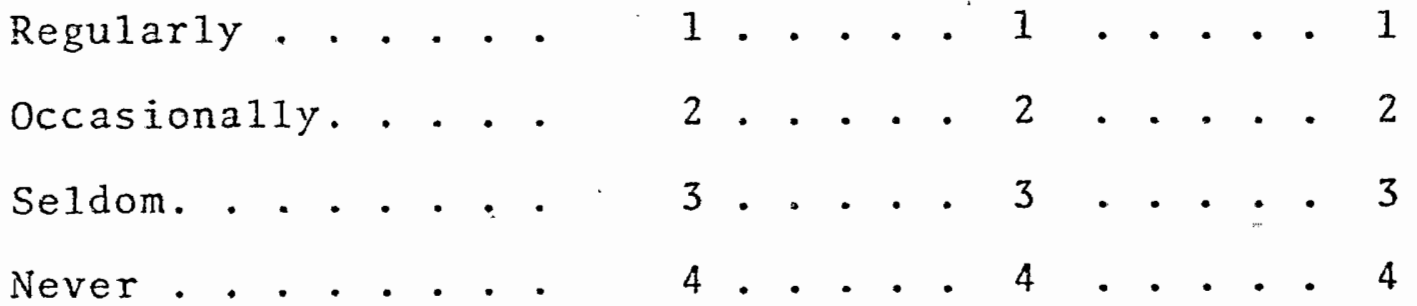

53. Have you ever been an officer in the (organization)?

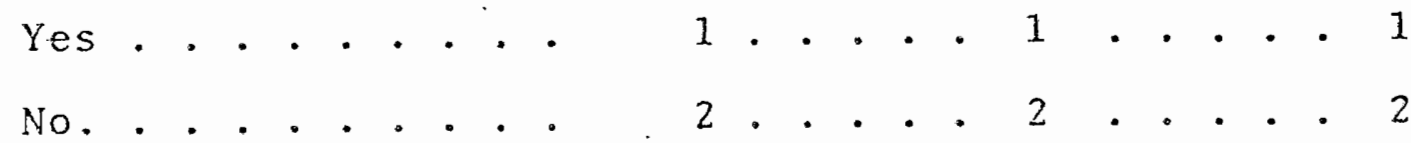


54. Compared to others, would you say you have more influence, less, or about average influence in this group?

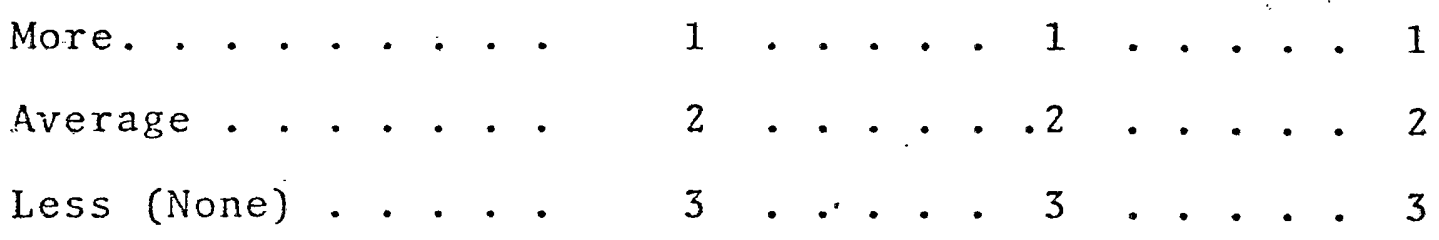

I would now like to get some background information.

55. What is your age? (IF NOT HEAD OF HOUSEHOLD, ASK:) What is the age of the Head of Household?

56, How many people, including yourself, live here?

57. (RECORD HOUSE OR APARTMENT OR DUPLEX)

House . . . . . 1 (Single Family Dwelling Unit)
Apartment . . . 2
Duplex. . . . . 3

58. Do you own or rent here?

Owns or buying. . . 1

Rents........ 2

59. How long have you been living. in this (house/apartment)?

$$
\begin{aligned}
& \text { Under } 1 \text { year. . . } 1 \\
& \text { 3. } 4 \text { years. . . } 2 \\
& 5 \text { - } 9 \text { years.... } 3 \\
& 10 \text { or more. . . . } 4 \text { (IF } 10 \text { OR MORE, SKIP TO Q. 61.) }
\end{aligned}
$$


60. (IF LESS THAN 10 YEARS IN ABOVE, ASK:) During the past ten years, in about how many different homes have you lived (including the present one)?

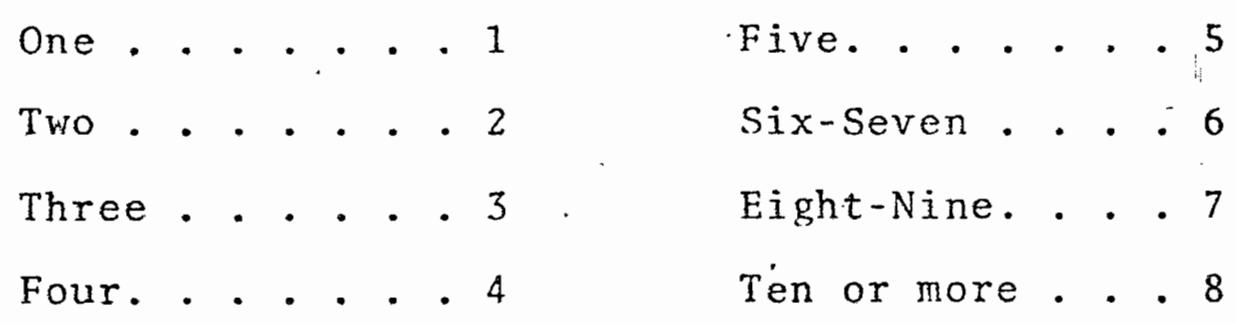

61. Where was your last residence prior to this one?

This city?

(ADDRESS)

Different place in Oregon?

(IF CITY, RECORD CITY ONLY: IF RURAL, RECORD NEAREST CITY.)

Different State?

(RECORD STATE ONLY)

(IF STATE OF WASHINGTON; ASK:) Where?

62. Education of Respondent

Altogether, how many years of school did you complete?

Less than 8 years $(0-7)$. . . . . 1

Completed 8 th grade. . . . . . . 2

9 - 11 years.......... 3

H. S. Grad. (12 Years) . . . . . . 4

Some college $(13$ - 15 years $)$. . . . 5

College Grad. (16 years) . . . . . 6

Post Grad. . . . . . . . . . . . 7 
63. Education of Head of Household. (SKIP IF SAME AS ABOVE)

Less than 8 years $(0-7) . . . . .1$

Completed 8 th grade. . . . . . . 2

9 - 11 years.......... . 3

H. S. Grad. (12 years) . . . . . . 4

Some college $(13-15$ years $) .. .55$

College Grad. (16 years) $)^{\circ}$. . . . 6

Post Grad............. . 7

64. Have you had any other type of schooling such as barber school or mechanical school or anything of that sort?

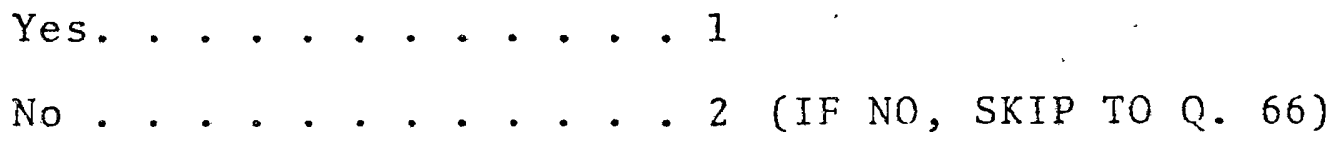

65. (IF YES TO"ABOVE, ASK:)

A. Kind of school:

B. How long did you go there?

weeks

months

years

stil1

attending

66. Regardless of how you may vote, how are you registered:

Republican, Democrat, Independent, or Other?

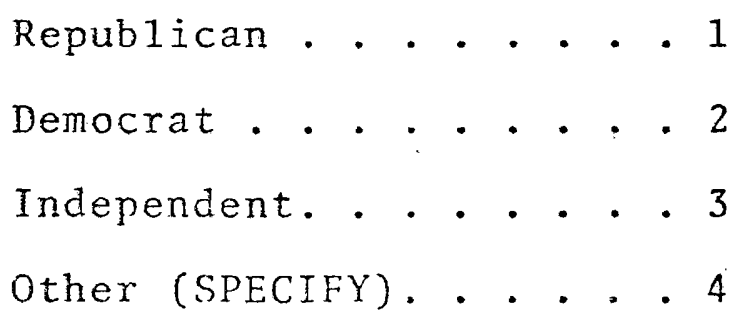


67. On most issues, would you describe yourself as conservative, middle-of-the-road, liberal, or other?

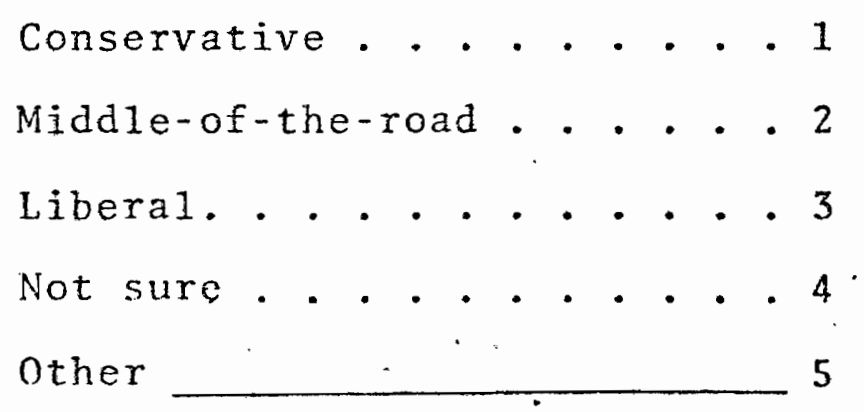

68. Could you tell me which yearly income group comes closest to the total amount that all members of this household, combined, received in the past year before taxes?

(SHOW CARD " $G "$ )

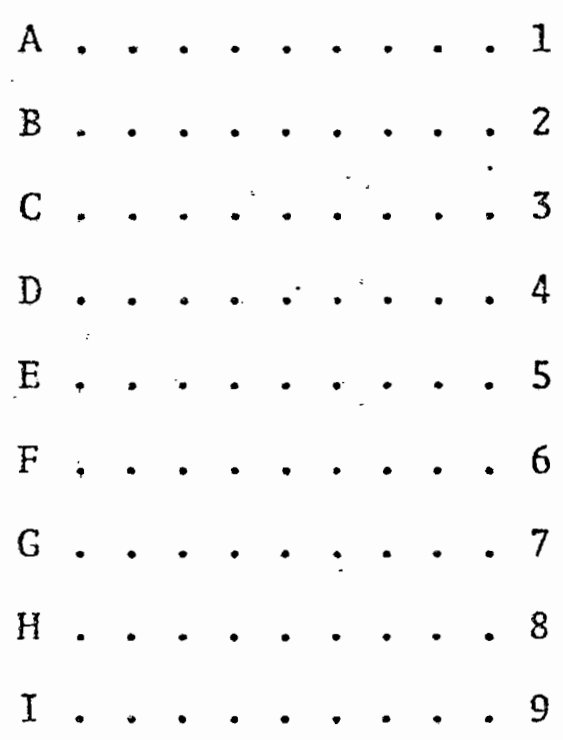

END INTERVIEW 


\section{(RECORD - DO NOT ASK)}

Address :

Sex of Respondent:

$$
\begin{aligned}
& \text { Male . . . . } 1 \\
& \text { Female . . . } 2
\end{aligned}
$$

Time interview began:

Time completed:

others present during interview?

$$
\begin{aligned}
& \text { Yes. . . . . } 1 \\
& \text { No..... . } 2
\end{aligned}
$$

Date of interview:

Reason for failure to complete interview:

Interviewer comments: 


\section{APPENDIX B}

\section{Measurement of Error in}

the Noise Awareness

Measure 


\section{Scaling and Error Measurement}

From the Matrix contained in Table $X X$ Torgerson outlinas a method through which the ordinal distance between the activities can be determined. 1 The technique involves calculating the proportion of times the activities were judged correct and incorrect. These proportions are converted to normal deviate scores, ${ }^{2}$ and the row totals added.

1W. S Torgerson, Theory and Methods of Sealing (New York: John Wiley and Sons, 1958), pp. 166-173.

${ }^{2}$ Let $x_{j k}$ be the number of times $j$ was judged ahead of $k$ and $x_{k j}$ be the number of times $k$ was judged ahead of $j . x_{j k} / x_{j k}+x_{k j}=$ $P_{j k}$ and $x_{k j} / X_{j k}+X_{k j}=P_{k j}$, which are the proportions two particular categories were judged ahead of one another. Notice that: $P_{j k}+P_{k j}$ $=1$. Normal deviate scores are computed by subtracting .5 from the proportions and calculating the value under the normal curve for the remainder with the condition that if: $P_{j k}$ or $P_{k j}-.5$ is less than 0 then the area under the normal curve is a negative number. Letting $Z$ be the normal deviate score and $Z_{j k}$ and $Z_{k j}$ be a pair of proportions transformed to normal deviate scores, then $Z_{j k}+Z_{k j}=0$ since $P_{j k}+$ $P_{k j}=1$. 
Table XX contains the normal deviate scores and the column totals as well as the column averages. The column averages indicate the approximate ordinal distance of any activity from another. It is apparent that T.V. and conversations have very little distance separating them. Phone calls and sleep also follow the same pattern. This indicates some ambiguity in the ordering of these particular pairs.

\section{TABLE XX}

MATRIX OF NORMAL DEVIATE SCORES

\begin{tabular}{|c|c|c|c|c|c|}
\hline e & T.V. & Conv. & Phone & Sleep & Entertainment \\
\hline T.V. & 0.0 & 0.46 & 0.83 & 0.93 & 1.48 \\
\hline conv. & -0.45 & 0.0 & 1.19 & 0.91 & 1.85 \\
\hline Phone & -0.83 & -1.19 & 0.0 & 0.04 & 0.53 \\
\hline sleep & -0.93 & -0.91 & -0.04 & 0.0 & 0.36 \\
\hline Enter. & -1.48 & -1.86 & -0.63 & -0.36 & 0.0 \\
\hline$\Sigma Z_{j k}$ & -3.70 & -3.50 & 1.35 & 1.52 & 4.33 \\
\hline$i_{\pi}^{1} \Sigma Z_{j k}$ & -0.74 & -0.70 & 0.27 & 0.30 & 0.87 \\
\hline
\end{tabular}

Source: Data from survey taken for Environmental Impacts, PIA Expansion.

Subtraction of the column averages each from the other reproduces the natrix of normal deviate scores. This matrix is not the same as the previous matrix. Torgerson and others have shown this matrix to be the least squares estimate of the original matrix of 
normal deviate scores. 3 From this matrix the original proportions matrix can be approximated. This matrix is contained in Table XXI. It represents the best estimate of the original response natrix. Also contained in Table XXI are the original proportions for comparison purposes.

\section{TASLE XXI}

ACTUAL AND ESTIMATED PROPORTIONS OF PAIRED COMPARISONS FOR FACTOR ONE

\begin{tabular}{|c|c|c|c|c|c|}
\hline & & & & & 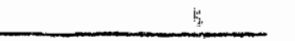 \\
\hline & T.V. & Conv. & Phone & S1 eep & Entertainment \\
\hline T.V. & 0.0 & $\begin{array}{l}.695^{a} . \\
.516\end{array}$ & $\begin{array}{l}.795 \\
.844\end{array}$ & $\begin{array}{l}.822 \\
.851\end{array}$ & $\begin{array}{l}.930 \\
.946\end{array}$ \\
\hline Conv. & $\begin{array}{l}.324 \\
.484\end{array}$ & 0.0 & $\begin{array}{l}.883 \\
.834\end{array}$ & $\begin{array}{l}.818 \\
.841\end{array}$ & $\begin{array}{l}.968 \\
.942\end{array}$ \\
\hline Phone & $\begin{array}{r}.205 \\
.156\end{array}$ & $\begin{array}{l}.117 \\
.156\end{array}$ & 0.0 & $\begin{array}{r}.517 \\
.512\end{array}$ & $\begin{array}{l}.736 \\
.726:\end{array}$ \\
\hline Sleep & $\begin{array}{l}.178 \\
.149\end{array}$ & $\begin{array}{l}.182 \\
.159\end{array}$ & $\begin{array}{l}.483 \\
.488\end{array}$ & 0.0 & $\begin{array}{l}.640 \\
.712\end{array}$ \\
\hline Enter. & $\begin{array}{l}.070 \\
.05 \frac{1}{4}\end{array}$ & $\begin{array}{l}.032 \\
.053\end{array}$ & $\begin{array}{l}.254 \\
.274\end{array}$ & $\begin{array}{l}.360 \\
.288\end{array}$ & 0.0 \\
\hline
\end{tabular}

Note: a. The actual proportion is given at the top; the estimated proportion is at the bottom.

Source: Same as Table $X X$.

Comparing the estimated values with the actual values produces a measure of discrepancy. This measure is called the average absolute deviation ${ }^{4}$

3 Torgerson, scaling, pp. 170-173.

4bid., p. 186. The average assolute deviation is given by the equation: $P_{j k}^{\prime \prime}-P_{j k} k^{\prime}=\frac{1}{N(n-1)} \sum p^{\prime \prime} k^{\prime \prime}-P_{j k} k^{\prime}$; where Pjk' is the original proportions matrix and $P_{j !} k^{\prime \prime}$ is the estimated proportions matrix. 
Computed for this matrix it is .0438 . In normal deviate terms it is -11. Considering the differences between T.V. and conversation and phone calls and sleep in normal deviates are .040 and .034 respectively, the value of the average absolute deviation would indicate they are insignificant. The inplication is that no ordering exists between these particular pairs.

Loevinger's honogeneity index is similar to Guttman's Rep. It improves on Guttman's technique in some instances by correcting inflated Reps. that result from one or two categories having a large majority of the responses. 5 In addition, it could be applied directly to the raw data matrix without any ordering of interrupted activities on an "a priori" susceptibility scale. On Loevinger's scale a homogeneity index of 1 is perfect. An index of 0 shows the itens to be completely independent," The homogeneity index computed for the PIA survey was 46. This seems quite low though no criteria are presented as to what constitutes a scale. in terms of a honogeneity index. Overall, the three methods chosen to analyze the awareness measure indicate considerable inconsistency and ambiguity in responses. 5Ibid., $P$. 325. The homogeneity index is given by the following
equation: $H_{t}=\Sigma P_{j} Q_{j} H_{j} / \Sigma P_{j} Q_{j}$; where $H_{t}$ is the homogeneity index for the complete test, $H_{i j}$ is the homogeneity index for a particular pair of $i$ tems, $P_{j}$ is the popularity of $i$ tem $i$ measured in numbers responding, $Q_{i}$ is $1-P_{j}$ and $H_{i j}$ is given by the equation $H_{i j}=\frac{P_{i} / j-P_{i}}{Q_{i}}$ where $P_{i} / j$ is the proportion of subjects endorsing item $j$ who also endorse itemi. $\left(P_{i j} / P_{j}\right)$. 
APPENDIX C

Calculation of Traffic

Noise Measure 
APPENDIX C

COMPUTATION OF AMBIENT NOISE LEVEL

Population density was calculated by census tract. Population figures were given by Columbia Regional Association of Governments, Population and Housing, 1970 (Portland, Ore.; CRAG, 1972). 1970 Census data were obtained from CRAG in unpublished reports. In the current anaiysis all observations in a census tract were given the same density figure. This is expected to impart some measurement error into the analysis.

Automobile noise was calculated for each observation from an equation adapted from Bolt, Beranek and Newnan Inc., Noise Environment of Urban and Suburban Areas (Washington, D C.: F.H.A.--H.U.0., 1967), pp. 5-25. The noise level and d8A from auto traffic for a particular point is given as:

(1) Noise in dBA $=37+\log _{10}$ (autos/sec.) $+20 \log _{10}$ (ave. speed). Attenuation of the noise in a residential area with respect to distance is given as:

(2) Noise in $d B A=-12 \log _{10}$ (distance in hundred of $f_{t .}$ ) Expressed in this fashion the equations are additive; so the auto tratfic noise exposure for a particular observation with respect to a single noise source is equation ( 1 ) nimis equation (2). Unfortunately, the method only allows for measurement of exposure from a single source, where in reality a number of sources should be 
recognized. Additionally, traffic noise attenuation varies widely even in residential areas depending on housing density, vegetation, street alignment, etc. These factors render the measure unsatisfactory. 
APPENDIX 0

Figure iL: Human Noise

Figure 15: Mechanical Noise 


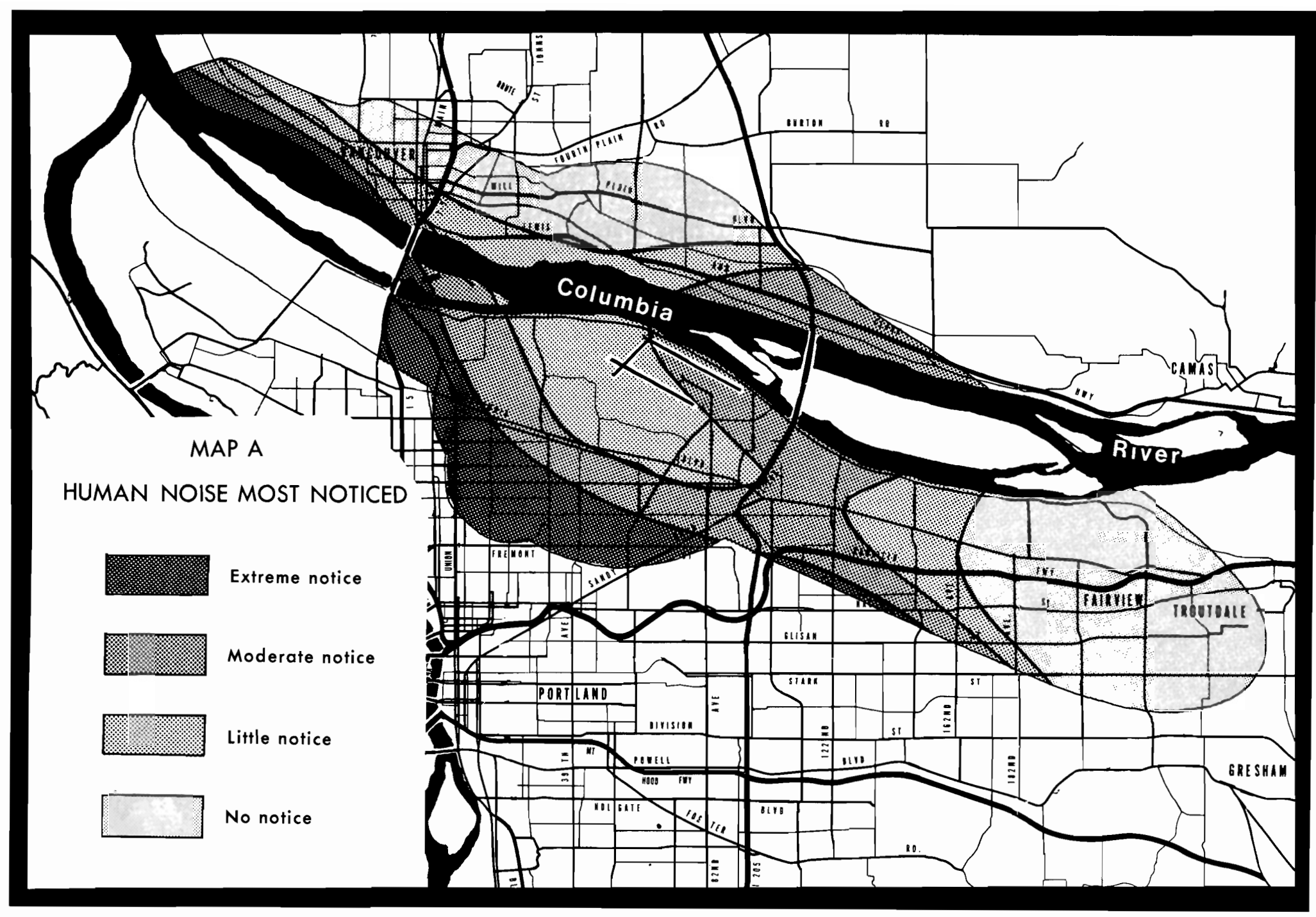

Figure 14 


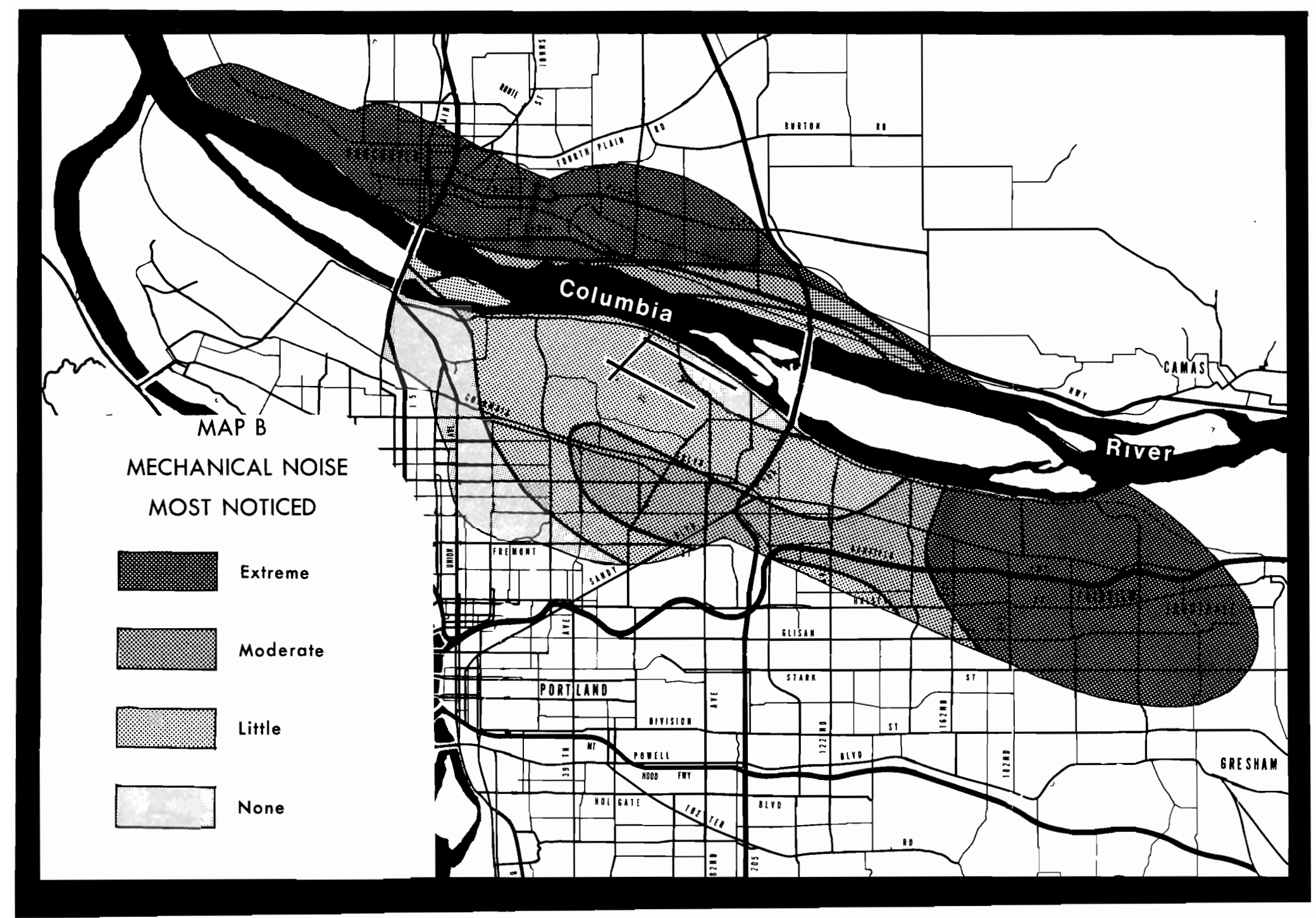

Figure 15 